\title{
ASSESSMENT OF SPENT-FUEL WASTE-FORM/STABILIZER ALTERNATIVES FOR GEOLOGIC DISPOSAL
}

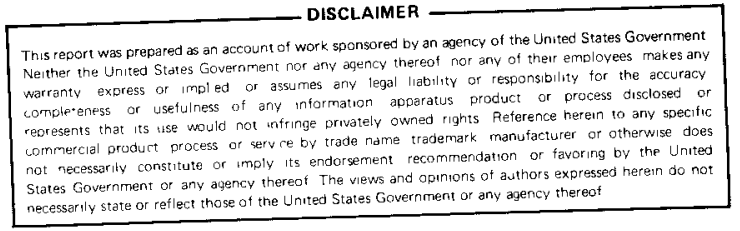

NOTICE

PORTIONS OF THIS REPORT ARE ILLEGIBLE. It

has been reproduced from ine best avallable

copy to permit the broadest possible avail-

ability.

\section{Hanford Engineering Development Laboratory}

R.E. Einziger D.A. Himes June 1982

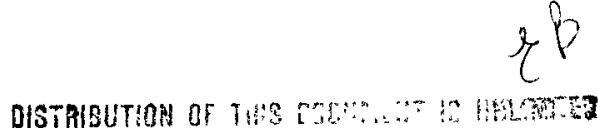

HANFORD ENGINEERING DEVELOPMENT LABORATORY

Operated by Westinghouse Hanford Company

P.O. Box 1970 Richland, WA 99352

A Subsidiary of Westinghouse Electric Corporation

Prepared for the U.S. Department of Energy under Contract No. DE-AC06-76FF02170 


\section{DISCLAIMER}

This report was prepared as an account of work sponsored by an agency of the United States Government. Neither the United States Government nor any agency Thereof, nor any of their employees, makes any warranty, express or implied, or assumes any legal liability or responsibility for the accuracy, completeness, or usefulness of any information, apparatus, product, or process disclosed, or represents that its use would not infringe privately owned rights. Reference herein to any specific commercial product, process, or service by trade name, trademark, manufacturer, or otherwise does not necessarily constitute or imply its endorsement, recommendation, or favoring by the United States Government or any agency thereof. The views and opinions of authors expressed herein do not necessarily state or reflect those of the United States Government or any agency thereof. 


\section{DISCLAIMER}

Portions of this document may be illegible in electronic image products. Images are produced from the best available original document. 
-

. 


\title{
ASSESSMENT OF SPENT FUEL WASTE FORM/ \\ STABILIZER ALTERNATIVES FOR GEOLOGIC DISPOSAL
}

\author{
R. E. Einziger \\ D. A. Himes
}

\begin{abstract}
The Office of Nuclear Waste Isolation (ONWI) is studying the possibility of burying canisterized unreprocessed spent fuel in a deep geologic repository. One aspect of this study is an assessment of the possible spent fuel waste forms. The fuel performance portion of the Waste Form Assessment was to evaluate five candidate spent fuel waste forms for postemplacement performance with emphasis on their ability to retard the release of radionuclides to the repository geology. Spent fuel waste forms under general consideration were: (1) unaltered fuel assembly, (2) fuel assembly with end fittings removed to shorten the length, (3) rods vented to remove gases and resealed, (4) disassembled fuel bundles to close-pack the rods, and (5) rods chopped and fragments immobilized in a matrix material. For this segment of the study, thirteen spent fuel waste forms, classified by generic stabilizer type (inert gas, particulate and solid), condition of the plenum, configuration of the rods and fuel form were evaluated. The 13 waste forms were analyzed for relative in-repository performance based on: (1) waste form/ stabilizer support against lithostatic pressure, (2) longterm stability for radionuclide retention, (3) minimization of cladding degradation, (4) prevention of canister/ repository breach due to pressurization, (5) stabilizer heat transfer, (6) the stabilizer as an independent barrier to radionuclide migration, and (7) prevention of criticality.
\end{abstract}

Based on their relative performance, the waste form candidates were ordered as follows: (1) the best waste form/stabilizer combination is the intact assembly, with or without end bells, vented (and resealed) or unvented, with a solid stabilizer, (2) a suitable altemative is the combination of bundled close-packed rods with a solid stabilizer around the outside of the bundle to resist lithostatic pressure, and (3) the other possible waste forms are of lower ranking with the worst waste form/stabilizer combination being the intact assembly with a gas stabilizer or the chopped fuel. 


\section{ACKNOWLEDGMENTS}

The authors wish to thank R. L. Fish, S. E. Girault, N. Wynhoff, and R. L. Knecht for helpful discussions. The contributions of G. Neely and F. Schmittroth on the criticality question and D. M. Bosi on thermal and mechanical fragmentation are also appreciated. This work was performed by the Hanford Engineering Development Laboratory for the Office of Nuclear Waste Isolation. 
Page

Abstract $\quad$ i i i

Acknowledgments iv

Figures vii

Tables ix

I. EXECUTIVE SUMMARY 1

II. INTRODUCTION 5

III. WASTE FORMS, ASSUMPTIONS, AND FUNCTIONS 9

A. WASTE FORMS 9

B. ASSUMPTIONS USED IN THE ASSESSMENT 12

C. POSSIBLE FUNCTIONS OF THE WASTE FORM/STABILIZER 14

IV. FUEL FORM ASSESSMENT FOR INTACT WASTE PACKAGES ASSESSMENT

A. STABILIZER SUPPORT FOR CANISTER AGAINST LITHOSTATIC PRESSURE

B. LONG-TERM STABILITY FOR RADIONUCLIDE RETENTION 22

C. AID IN PRESERVATION OF THE CLAUDING AS A BARRIER 30

D. BREACH OF CANISTER/REPOSITORY DUE TO PRESSURIZATION

E. MAXIMUM EXPECTED TEMPERATURES OF WASTE FORM/STABILIZER COMBINATIONS $\quad 45$

V. FUEL FORM ASSESSMENT FOR BREACHED WASTE PACKAGE 55
A. STABILIZER AND WASTE FORM GEOMETRY EFFECTS ON RADIONUCLIDE RELEASE RATES
B. CRITICALITY 


\section{CONTENTS}

Page

VI. RANKING OF THE WASTE FORMS 85

A. TEMPERATURE LIMITS

B. RANKING OF POSSIBLE FUNCTIONS 85

C. WEIGHTING OF FUNCTIONAL REQUIREMENTS 89

$\begin{array}{ll}\text { D. TRENDS IN THE RANKINGS } & 97\end{array}$

$\begin{array}{lll}\text { VII. CONCLUSIONS } & 101\end{array}$

$\begin{array}{ll}\text { REFERENCES } & 103\end{array}$

APPENDIX A - EVALUATION OF FUEL PELLET
DEGRADATION MECHANISMS

APPENDIX B - SUPPORT AGAINST LITHOSTATIC PRESSURE BY PARTICULATE STABILIZERS
OR "CLOSE-PACKED" WASTE FORMS

APPENDIX C - A SIMPLIFIED BARRIER BREAKDOWN AND FISSION PRODUCT RELEASE MODEL C

APPENDIX D - RANKING FOR THE WASTE FORM STABILIZER COMBINATIONS D-1

APPENDIX E - THERMAL STRESSES IN A SOLID CYLINDER WITH AXISYMMETRIC TEMPERATURE GRADIENT 


\section{FIGURES}

Figure

Page

1 Whole Rod Test Results, Indicating That Breach Time Predicted by Blackburn's Formulation is Very Conservative

21000 - Year Isochrons for Irradiated Zircaloy

Cladding with Various Internal Iodine Concentrations

3 Canister Pressurization vs Temperature for Inner Titanium Canister

4 Heat Drop Across Waste Package

5 Maximum Fuel Cladding Temperature vs Canister Temperature for Helium Stabilizer

6 Temperature Difference Between the Cladding of the Hottest Rod and the Canister vs Thermal Conductivity of the Stabilizer (5 - Year - 01d Spent PWR Fuel)

7 Individual Rod Fractional Release Rates for Unvented (Pressurized) Rods

8 Individual Rod Fractional Release Rates for Vented and Resealed Rods

9 Zone Placement for Analysis of Intact Subassembly with Solid Stabilizer

10 Fractional Release Rate for an Unvented PWR Assembly in a Solid Metallic Stabilizer

11 Release Rates for Chopped Fuel in Uncracked Stabilizer

12 Release Rate for Chopped Fuel in Cracked Stabilizer

13 Total Radioactive Decay of PWR Spent Fuel

14 Keff as a Function of the $\mathrm{H}_{2} \mathrm{O}$ Volume to $\mathrm{UO}_{2}$ Volume Ratio and for Different Cylinder Diameters

15 Spent Fuel Containment Configuration 


\section{FIGURES (Cont'd)}

Figure

17 Temperature Scale for In-Repository Effects on Spent Fuel Degradation

18 Schematic Approach to Ordering the waste Fuel/Stabilizer Combinations

19 Waste Form Ranking Order
95

Page

86

98 


\section{$\underline{\text { TABLES }}$}

$\underline{\text { Table }}$

$\underline{\text { Page }}$

1 Candidate Waste Forms 6

2 Method of Approach 6

3 Relationship Between DOE Waste Forms and the Assessment Waste Forms

$4 \quad$ Candidate Stabilizers

$5 \quad$ General Assumptions

$6 \quad$ Stabilizer Assumptions

$7 \quad$ Effective Multiplication Factors $\left(K_{\text {eff }}\right)$ for Potential Stabilizer Materials

8 Possible Functions of the Waste Form/Stabilizer Combination Which Influence the Assessment

9 Ranking of Waste Forms For Their Ability to Withstand Lithostatic Pressure

10 Functional Dependence of Degradation Mechanisms on Waste Form Configuration

11 Possible Concerns About Fuel Pellet Degradation

12 Ranking of Waste Forms Based on Fuel Degradation

13 Particulate Stabilizer Support for the Cladding

14 Ability of Stabilizer to Aid in Protecting the Cladding as a Barrier

15 Individual Assembly Characteristics

16 P/T -- Canister Pressure (ATM) per Degree Kelvin

17 Ranking of Waste Forms For Their Ability Not to Compromise the Package by Pressurization

18 Temperature Gradients Across Waste Package 47

19 Maximum Inside Canister Temperature for PWR Fuel 48

20 Thermal Conductivity Established by Potential Stabilizer Materials 


\section{TABLES (Cont'd)}

$\underline{\text { Table }}$

Page

21 Maximum Cladding Temperatures for Different Configurations of PWR Assemblies in Various Candidate Geologies

22 Ranking of Waste Forms for Heat Transfer

23 Pertinent Physical Characteristics of Reference Case LWR Fuel Assemblies

24 Source Characteristics for the Close-Packed Rod Case

$25 \quad$ Cladding Transport Resistance Characteristics

60

26 Examples of Individual Source Contributions (PWR, Pressurized Rods)

27 Source Concentrations for the Chopped Fuel Case

28 Rankings of Waste Forms Based on Release Characteristics

29 Waste Form Rankings Based on Possibility of Criticality

30 Use of Table 17 for Ranking of the Waste Form's Ability Not to Compromise the Canister 88

31 Waste Form Ranking by Concern -- $<425^{\circ} \mathrm{C} \quad 90$

32 Waste Form Ranking by Concern -- $425-600^{\circ} \mathrm{C} \quad 91$

33 Waste Form Ranking by Concern -- $600-660^{\circ} \mathrm{C} 92$

34 Waste From Ranking by Concern $--660^{\circ} \mathrm{C} 93$

35 Recommended Waste Forms/Stabilizer Combinations $\quad 100$ 


\section{EXECUTIVE SUMMARY}

A three-part study was undertaken under the auspices of the office of Nuclear Waste Isolation (ONWI) to determine a recommended spent fuel waste form. E. R. Johnson Associates evaluated the effect of the waste form on the repository Westinghouse Advanced Energy Systems Division (WAESD) evaluated the effect of the waste form on the canister, and Westinghouse Hanford Company (WHC) evaluated the relative in-repository performance of the candidate waste forms. The in-repository performance evaluation is the subject of this report.

The ultimate goal of the performance study was to pick the waste form which has the best relative ability to reduce the rate of radionuclide migration after the waste package breaches. It became evident early in the study that the waste form and the generic stabilizer form were not independent entities, but had to be considered as a combination. The important variations among the candidate waste forms which affect performance are: 1) in-grid or close packed rods, 2) vented or unvented rods, 3) intact or chopped fuel, and 4) gas, particulate, or solid stabilizer. Major functions addressed include the following:

1. Ability of the waste form/stabilizer combination to resist lithostatic pressure

2. Prevention of canister breach due to pressurization

3. Long-term stability of the fuel due to pressurization

4. Criticality

5. Release of radionuclides after waste package breach

If the canister is designed to withstand the lithostatic pressure loading, then the waste form is not affected by the pressure. If the waste form/stabilizer combination must support the lithostatic pressure, then a solid stabilizer is the best choice. Due to possible compaction of the particulates to a higher density or rearrangement of rods, neither a 
particulate stabilizer or a randomly loaded agglomerate of "close-packed" rods will provide support to the canister under lithostatic pressure. Gas stabilizers are only useful if combined with "close-packed" rods which have been banded to prevent rearrangement.

No fuel pellet degradation mechanisms could be identified which would be operative below $1000^{\circ} \mathrm{C}$ if the cladding remains intact. Above $1000^{\circ} \mathrm{C}$ one could get volatile fission product migration within the pellets which would change the condition of the grain boundaries. If the cladding breaches in repository, then the thermodynamic system changes because of the contact of the fuel with the stabilizer and canister. This may not be detrimental to the fuel pellet but insufficient evidence is available to allow degradation of the pellet in the new thermodynamic system to be evaluated. For this reason, efforts should be made to keep the cladding intact. Below $425^{\circ} \mathrm{C}$, no cladding breach mechanisms should be operative during the 1000-year thermal period; above $425^{\circ} \mathrm{C}$, stress rupture may be life-limiting.

Unless vented prior to disposal, the rod plenums will contain 300-500 psi of pressure for PWR rods and 150-200 psi for BWR rods. Should an unlikely off-normal event occur which causes these rods to breach, then one must be concerned about premature canister failure due to pressurization. Below $600^{\circ} \mathrm{C}$ fuel temperature, none of the waste forms will generate sufficient hoop stress in the canister due to pressurization to cause premature canister breach. If the fuel temperature is raised above $600^{\circ} \mathrm{C}$, then appreciable fission gas release from the fuel pellet occurs during the 1000-year thermal period, and the integrity of the canister may be jeopardized.

Based on host rock temperatures of $150-200^{\circ} \mathrm{C}$, the waste form fuel temperature should not exceed $380^{\circ} \mathrm{C}$. This is below any of the critical temperatures identified. Of course, those waste forms with a solid stabilizer operate considerably cooler than waste forms using a particulate or gas stabilizer. 
Once the canister breaches, it can be inundated with a $\mathrm{H}_{2} \mathrm{O}$ moderator. As long as the waste form shape remains intact, then none of the waste forms have propensity for criticality. If an unlikely event should occur which rearranges the waste form into an optimal critical shape, then only the intact assemblies in a canister with a gas stabilizer have even the remotest chance of criticality.

Once the canister breaches, the solid stabilizer provides only a small time delay ( $~ 200$ years based on lead) before the cladding would be exposed to ground water. The cladding could then provide a time delay from 4500 to 8000 years before the fuel pellet is exposed (4500 for an unvented PWR rod, 8000 for a vented BWR rod). The vented rods have a higher initial release than the unvented rods because of different expected modes of cladding breach. The only role the solid stabilizer plays is to reduce the in $i-$ tial pulse of activity and spread out the release for a longer period because of the built-in time delay for rod breaches. The chopped fue 1 releases activity as soon as the canister breaches, but it has a much lower initial pulse and longer release times than the intact rods. Unless premature canister breach occurs, the reduction in radionuclide release rate due to nuclide decay during the time span gained by the resistance of the stabilizer or cladding is relatively minor (factor $\sim 2$ ).

The best waste form/stabilizer combination is the intact assembly, with or without end bells, vented or unvented, with a solid stabilizer. It has the lowest operating temperature, withstands lithostatic pressure, has the lowest initial radionuclide release rate upon canister breach, has no propensity for criticality, and offers support to keep the cladding intact during the thermal period. If lithostatic pressure does not need to be supported by the waste form/stabilizer combination and fuel temperatures are kept below $425^{\circ} \mathrm{C}$, then a gas or particulate stabilizer may be used. No performance disadvantages could be identified for this waste form.

A suitable alternative is close-packed rods, either vented or unvented. Only a gas stabilizer should be used with this waste form, since a solid 
could not be satisfactorily poured between the close-packed rods, and a particulate offers no significant advantages over the gas. This waste form will operate at higher temperatures than the intact assemblv with a solid stabilizer because of a higher heat loading and poorer stabilizer thermal conductivity. Criticality will not be a problem. As long as the fuel temperature is kept below $425^{\circ} \mathrm{C}$, there should be little fuel degradation, since the cladding will remain intact. Above $425^{\circ} \mathrm{C}$, little support is offered by the cladding, and chemical interactions of the fuel and canister may be a problem. If it is required that lithostatic pressure be supported by the waste form, then the close-packed rods should be banded before being emplaced to take advantage of the bundle rigidity. Once radionuclide release begins, there will be a higher initial pulse from this waste form, but will be over a shorter duration than the intact assembly with a solid stabilizer.

The chopped fuel in a monolith will support lithostatic pressure and also remains subcritical. The initial radionuclide release after canister breach will be lower than the other waste forms, but it will occur over a much longer period. An overriding disadvantage of this waste form is that there will be fuel/stabilizer/canister chemical interactions in a thermodyamic system that has not been previously studied. This interaction may not cause significant fuel pellet degradation, but this cannot be confirmed without significant additional study.

It is WHC's recommendation that if the waste form must support 1ithostatic pressure, then intact assemblies with a solid stabilizer or banded "close-packed" rods with a gas stabilizer should be used at fuel temperatures below $425^{\circ} \mathrm{C}$. If the canister will support the lithostatic pressure, then randomly "closed-packed" rods also constitute a suitable waste form. Venting the rods or removing the end bells has little, if any, effect on the fuel rod performance. Waste form/stabilizer combinations such as chopped and immobilized fuel which destroy the integrity of the cladding should be avoided because of the unknown effect of fuel pellet/stabilizer/canister interactions. 


\section{INTRODUCTION}

The Office of Nuclear Waste Isolation (ONWI) has initiated an assessment of five spent light water reactor (LWR) fuel configurations under consideration by the Department of Energy $(D O E)^{(1)}$ in order to choose a reference waste form. The fuel configurations are listed in Table 1. This assessment covers waste form and canister performance, repository and packaging operations, safety, and economics. While these configurations were selected for their ability to use a standard package design, conserve repository space, or reduce packaging costs (among other reasons), these factors can only be considered if satisfactory waste form performance can be established. In addition to the waste form, the multi-barrier concept for spent fuel disposal includes a stabilizer with in the waste package. The ability of the waste form to perform adequately will be influenced by the stabilizer form i.e., solid, gas, or particulate. Therefore, waste forms cannot be assessed alone but rather as waste form/stabilizer combinations. This report will assess the expected relative in-repository performance of each waste form in combination with its associated generic stabilizer type.

Two fundamental questions form the bas is for the assessment:

1. Can the waste form/stabilizer and canister "interact" to cause premature waste package breach or waste form degradation so that after canister breach higher radionuclide release rates occur? ("Interact" is to be interpreted in a positive and negative sense since some physical interactions, such as support for the canister against lithostatic pressure, may be beneficial.)

2. What is the relative ability of each of the proposed waste forms to resist radionuclide migration after water enters a breached waste package?

The method of approach chosen to answer these questions is given in Table 2.

The waste forms as given in Table 1 were not directly amenable to performance analysis, so they have been related to a second and larger set of waste forms that can be analyzed. The two fundamental questions have been translated into a set of working criteria to be applied to each waste form 


\section{TABLE 1}

\section{CANDIDATE WASTE FORMS}

1. Unaltered Assembly.

2. Assembly with End Fittings Removed to Shorten Length.

3. Rods Vented to Remove Gases and Resealed.

4. Disassembled Fuel Bundles to Close-Pack Rods.

5. Rods Chopped and Fragments Immobilized in Matrix Material.

\section{TABLE 2}

METHOD OF APPROACH

1. Determine differences in waste forms which affect performance.

2. Determine tentative functions for waste forms.

3. Determine areas and questions of concern as a function of time.

4. Assess waste form performance before waste packaqe breach.

5. Assess waste form performance after packaqe breach.

6. Weight criteria and rank waste forms. 
and stabilizer combination. The performance of the waste forms was assessed with respect to these functions for the intact waste package period and breached waste package period, and a relative ranking was given to each waste form for each criteria. Finally, an overall waste form ranking based on relative performance was established.

Ideally, one would like to carry the analysis one step farther to separate the satisfactory performers from the unsatisfactory performers. The current state of knowledge precludes this type of separation. While this assessment will give a relative waste form/stabilizer ranking, the absolute performance of any waste form/stabilizer combination will depend on the actual stabilizer material and will have to be experimentally tested. 
- 


\section{WASTE FORMS, ASSUMPTIONS, AND FUNCTIONS}

\section{A. WASTE FORMS}

The classification of spent fuel into the five forms given in Table 1 is not broad enough for an adequate performance assessment. Because the stabilizer may affect the relative performance of each waste form and because vented rods may be either close packed or left in a grid-type configuration, there are additional options to consider. For the purpose of this assessment, thirteen spent fuel waste forms will be used. These waste forms are classified by generic stabilizer type, condition of the plenum, configuration of the rods, and fuel form. The relationship between these thirteen waste forms and the original five waste forms given in Table 1 is shown in Table 3.

\section{Stabilizer}

Three types of stabilizers are considered: inert gas, particulate, and solid. Examples of these stabilizers are given in Table 4. In general, only generic classes of stabilizers are considered, since it is not the purpose of this study to evaluate the merits of individual stabilizer candidates. The only time the relative merit of individual stabilizers will be considered is when a range of a physical parameter for a generic class of stabilizer must be determined.

\section{Plenum Condition}

The rods will be either unvented or vented. Unvented rods will contain all the pre-pressurization and fission gas present in the rod at the end of irradiation. Vented rods will have the pre-pressurization and fission gas present in the plenum region and fuel-cladding gap after removal from irradiation. No effort will be made to remove the 80 to $99 \%$ of the fission gas which is contained in the fuel matrix at the end of the irradiation. Vented rods will be resealed after the venting process, prior to repository disposal. 
TARLE 3

RELATIONSHIP BETWEEN DOE WASTE FORMS AND THE ASSESSMENT WASTE FORMS

DOE Waste Forms

Unaltered Assembly

End Bells Removed From Assembly

$\vec{\circ}$

Rods Vented to Remove Gas and Resealed

Close-Packed Fuel Rods

Rods Chopped and Immobilized in Matrix Material
Assessment Waste Forms

\begin{tabular}{cccc}
\multicolumn{4}{c}{ Assessment Waste Forms } \\
\hline & $\begin{array}{l}\text { Plenum } \\
\text { Stabilizer }\end{array}$ & State & Config- \\
uration & Form
\end{tabular}

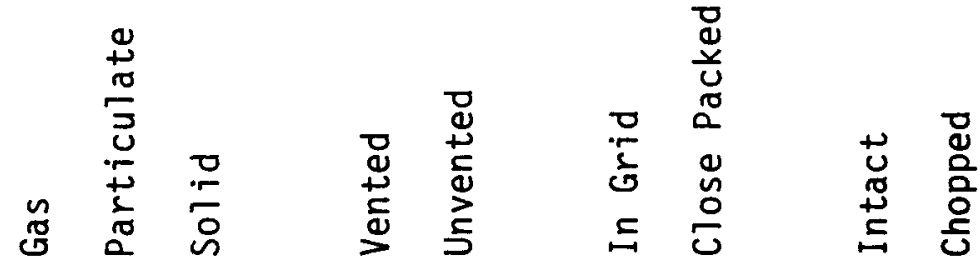

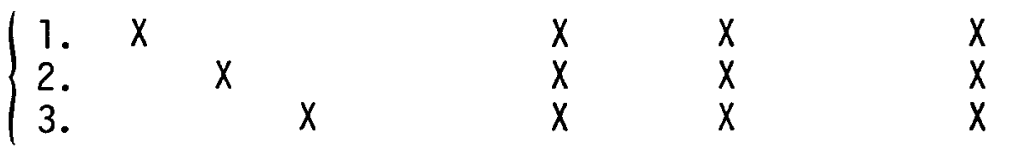

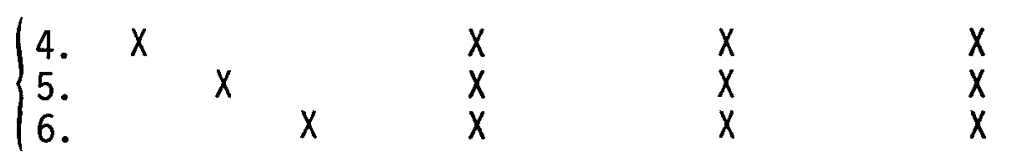

$\left\{\begin{array}{cccccccc}7 . & x & & & & x & x & x \\ 8 . & & x & & & x & x & x \\ 9 . & & & x & & x & x & x \\ 10 . & x & & & x & & x & x \\ 11 . & & x & & x & & x & x \\ 12 . & & & x & x & & x & x\end{array}\right.$

13.

$x$

$x$

$x$ 
TABLE 4

CANDIDATE STABILIZERS

\begin{tabular}{|c|c|c|}
\hline Solids & Particulates & Gases \\
\hline silica - quartz/Bondate* & silica-amorphour & $\mathrm{He}$ \\
\hline mullite/Bondate & silica-quartz & $\mathrm{N}_{2}$ \\
\hline zirconia/Bondate & $\begin{array}{l}85 \% \text { silica-quartz/ } \\
15 \% \text { bentonite }\end{array}$ & \\
\hline basalt/Bondate & mullite & \\
\hline graphite/Bondate & $85 \%$ mul1ite $/ 15 \%$ bentonite & \\
\hline $1 \%$ antimonial lead & zircon & \\
\hline calcium lead & zirconia & \\
\hline commercial lead & $85 \%$ zirconia/ $15 \%$ bentonite & \\
\hline Zn alloy $A G 40 A$ & basalt & \\
\hline Zn alloy AC41A & $85 \%$ basalt $/ 15 \%$ bentonite & \\
\hline zinc-copper-titanium & & \\
\hline alloy & granite & \\
\hline commercial zinc & shale & \\
\hline $\begin{array}{l}\text { copper casting alloy } \\
3 \mathrm{~A}\end{array}$ & tuff & \\
\hline $\begin{array}{l}\text { copper casting alloy } \\
8 \mathrm{~A}\end{array}$ & s and & \\
\hline $\begin{array}{l}\text { copper casting alloy } \\
13 \mathrm{~B}\end{array}$ & graphite & \\
\hline
\end{tabular}

*Bondate is the registered trademark of Bondate Industries, Inc. 


\section{Fuel Rod Configuration}

The in-grid configuration refers to rods that remain in the grid formed by the irradiation vehicle. In this case, there is physical separation and support for the rods. The close-packed configuration refers to rods that are removed from the irradiation vehicle and packed in the canister. Two close-packed configurations will be considered. The first is a pre-bundling of the rods prior to insertion into the canister with a solid stabilizer surrounding the bundle. This configuration is designated as close-packed with a solid stabilizer. The second configuration does not use bundling and considers only a particulate or gas stabilizer. Bundle rods are close packed. Due to rod bow from irradiation, the non-bundled rods may be less than close-packed but still be significantly closer than the in-grid case.

\section{Fuel Form Condition}

Two fuel forms are considered: intact rods and chopped rods. Intact rods are defined as whole rods in which the fuel column has not been altered by post-irradiation processing. As specified by E. R. Johnson Associates, chopped rods will consist of fuel sections approximately $36 \mathrm{~mm}$ long. About $25 \%$ of the fuel will be reduced to fines. These fines will be placed in the canister along with the chopped rods.

\section{B. ASSUMPTIONS USED IN THE ASSESSMENT}

To facilitate the performance analyses and ensure integration with other aspects of the total assessment, a number of assumptions were made. These assumptions are broken into two groups. The first are general assumptions which were reached by concensus agreement of the assessment task group with Office of Nuclear Waste Isolation concurrence. These are given in Table 5. Clearly, if assumptions 1,2, or 3 are varied, the absolute fuel performance may change. The relative performance rankings of the waste forms may change if any of these assumptions are violated, but no attempt was made to study the validity of the assessment as a result of such a violation. 
TABLE 5

\section{GENERAL ASSUMPTIONS}

1. No off-normal repository events.

2. Waste form can be fabricated satisfactorily.

3. The waste package is emplaced without damage.

4. The fuel will be out-of-reactor for $10+$ years.

5. The number of assemblies, heat loads and inside canister radius (R) are:

\begin{tabular}{|c|c|c|c|c|c|c|}
\hline & In & rid & Clos & acked & $\mathrm{Ch}$ & ped \\
\hline & PWR & BWR & PWR & BWR & PWR & BWR \\
\hline Number of Assemblies & 1 & 2 & 3 & 8 & 2.3 & 5.6 \\
\hline $\mathrm{kW}$ & .53 & .38 & 1.59 & 1.52 & 1.2 & 1.1 \\
\hline$R($ in) & 6.75 & 6.75 & 6.25 & 6.25 & 8.50 & 8.50 \\
\hline
\end{tabular}

TABLE 6

STABILIZER ASSUMPTIONS

1. Minimal interaction with cladding or canister.

2. Minimal gas generation from outgassing under heat, decomposition by radiation, or other active mechanisms.

3. Resistant to radiation damage.

4. The matrix for the chopped fuel can be considered a solid stabilizer.

5. Particulate stabilizer will consist of two fractions and will be sequentially packed to $84 \%$ density. (See Appendix B) 
The second set of assumptions concerns the stabilizer material and is given in Table 6 . The first three assumptions are actually criteria used for screening candidate stabilizer materials. If a material does not meet these criteria, then it should not be considered as a stabilizer. The fourth assumption allows the matrix material used in the chopped fuel form to be treated like a stabilizer in order to conduct a comparative assessment. The last assumption is the optimum practical packing condition for a particulate stabilizer. $(2,3)$ In most cases, if this assumption is not met, waste form/particulate stabilizer combinations will perform at a lower standard than the assessment indicates.

\section{POSSIBLE FUNCTIONS OF THE WASTE FORM/STABILIZER}

There are two time periods of concern: the post-emplacement period prior to package breach, lasting approximately 1000 years, when there will be no water in intimate contact with the fuel rods, ${ }^{(4)}$ and the period after waste package breach (approximately 1000 to 10,000 years after emplacement) during which water may be in contact with the fuel form. For the first 1000 years, we are interested in any interactions which will possibly compromise the waste package integrity and any degradation of the fuel form which would eventually lead to an increased radioactivity release after waste package breach. After the packace is compromised, the prime areas of concern are the prevention of radionuclide transport and an assurance that the package will not go critical.

\section{Possible Causes of Premature Canister Breach}

As stated in the assumptions, a stabilizer would be chosen to have minimal chemical interaction with the canister. Depending on the final design of the waste package, it may be necessary for the stabilizer to support the canister against deformation caused by applied lithostatic pressure. Another force which might compromise the canister is a sudden release of gases from the fuel rods. For some proposed waste form/stabilizer combinations, the canister may be sufficiently pressurized because of 
the gas release from the rods to result in deformation and/or fracture of the canister.

\section{Long-Term Fuel Stability for Radionuclide Retention}

The leachability of the fuel after intrusion of water into the waste package will depend on:
a) Effective exposed fuel surface area
b) Grain boundary conditions
c) Fission product residence distributions
d) Phases in the fuel
e) Distribution of free radionuclides in the system

It is important that a repository temperature be established which minimizes any adverse changes of these spent fuel characteristics. This temperature will largely be dependent on repository heat load which has not yet been established, the heat load in the package, and the thermal conductivity of the stabilizer. To determine an upper acceptable temperature limit, the following degradation mechanisms, which could affect spent fuel characteristics, have been assessed:
a) Chemical changes
b) Volatile fission product migration
c) Gas diffusion
d) Radiation damage to the fue 1
e) Thermal fragmentation
f) Mechanical fragmentation

Over $99.5 \%^{(5)}$ of the fuel that enters the repository will have its cladding intact. This cladding serves as a barrier to radionuclide release but also serves to define a closed thermodynamic system. As long as the system remains closed and the internal condition of the rod is preserved, characterization data generated from examination of as-irradiated fuel 
pellets are valid representation of the condition of the fuel in a repository (See Appendix A). Once the cladding is compromised, fuel interactions with the stabilizer and canister may occur. This further complicates the chemical system, and a new thermodynamic state for which no analyses or measurements have been made is created. Thus any waste form/stabilizer system should strive to minimize cladding degradation to delay breach and to minimize the complexities of radionuclide transport predictions.

\section{Prevention of Radionuclide Transport}

Radionuclide transport rates are determined by the waste form and stabilizer in the following ways:

a) The stabilizer and cladding may act as physical barriers which prevent the leachant from reaching the waste form.

b) The condition of the waste form will determine the leaching/dissolution rates by limiting surface area exposed to the leachant and establishing the condition of the grain boundaries and residence positions of both the fission products and actinides.

c) Radionuclides are absorbed in the stabilizer.

The various waste form/stabilizer combinations have been modeled and assessed to determine whether there are configurations which significantly delay the initial time of release or decrease the maqnitude of radionuclide releases.

\section{Criticality}

Criticality can occur if a critical mass is concentrated and there is sufficient moderation. This will happen only if water inundates the canister and a highly unlikely event occurs which can rearrange the fuel into a critical mass. None of the proposed waste form configurations represents a critical situation in the dry state, since the multiplication factor (K ${ }$ ) of the proposed stabilizer materials is less than 1.0 (see Table 7). 

EFFECTIVE MULTIPLICATION FACTORS ( $\left.K_{\text {eff }}\right)$ FOR
POTENTIAL STABILIZER MATERIALS

\begin{tabular}{ll}
\multicolumn{1}{c}{ Stabilizer } & Keff \\
\cline { 2 - 2 } commercial copper & 0.085 \\
copper casting alloy 13B & 0.092 \\
copper casting alloy 8A & 0.093 \\
zinc-copper-titanium alloy & 0.093 \\
zinc alloy AC4lA & 0.12 \\
commercial zinc & 0.12 \\
zinc alloy AG40A & 0.12 \\
rutile & 0.13 \\
calcium lead & 0.14 \\
commercial lead & 0.14 \\
aluminum casting alloy 336 & 0.14 \\
nitrogen & 0.14 \\
Portland cement, Type IV & 0.14 \\
air & 0.14 \\
commercial aluminum & 0.15 \\
aluminum casting alloy A413 & 0.15 \\
silica-amorphous & 0.15 \\
concrete cement Type I & 0.15 \\
Portland Coling glass 0l20 * & 0.15 \\
Corning & 0.15 \\
basalt & 0.15 \\
sand & 0.16 \\
silica-quartz & 0.16 \\
zirconia & 0.16 \\
alumina & 0.16 \\
shale & 0.17 \\
graphite & 0.19 \\
bentonite & 0.28
\end{tabular}

*Corning Glass is the registered trademark of the Corning Glass Company 
There may be enough fissile material present, especially at low burnups, for a waste package to go critical in the "worst case" situation of redistribution of material and water intrusion. (7) The possible advantages of a stabilizer type which prevents redistribution of material or reduces the availability of water were analyzed.

These possible stabilizer and waste form functions are summarized in Table 8. 


\section{TABLE 8}

POSSIBLE FUNCTIONS OF THE WASTE FORM/STABILIZER

COMBINATION WHICH INFLUENCE THE ASSESSMENT

- Stabilizer

- Support canister against lithostatic pressure

- Prevent criticality

- Provide path for heat transfer

- Provide independent barrier against radionuclide transport

Waste Form

- Provide long-term stability of radionuclide retention

- Resist fracturing into respirable particles

- Immobilize gases produced in waste form

Stabilizer \& Waste Form

- Minimize all stress-related claddina degradation mechanisms 
•

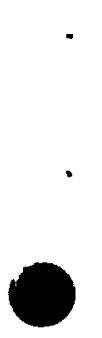




\section{A. STABILIZER SUPPORT FOR CANISTER AGAINST LITHOSTATIC PRESSURE}

While in repository, the canister will have to resist crushing or deformation to an oval or other shape under any applied hydrostatic and lithostatic pressures. Since lithostatic pressures will always be greater than hydrostatic pressures (host rock density is greater than the density of water), only resistance to lithostatic pressure will be considered. Lithostatic pressure is given by the equation: ${ }^{(8)}$

$$
P_{h}=\rho g h
$$

where $\rho=$ density of the rock, $g=9.8 \mathrm{~m} / \mathrm{sec}^{2}$, and $\mathrm{h}$ is the depth of the repository, which will be taken as 1000 meters for this analyses. The density of rock varies from a low of $2.2 \times 10^{3}$ for salt ${ }^{(9)}$ to a high of $3.0 \times 10^{3} \mathrm{Kg} / \mathrm{m}^{3}$ for basalt. ${ }^{(9)}$ The maximum 1 ithostatic pressure expected on a canister would be $29.4 \mathrm{MPa}(4.4 \mathrm{Ksi})$.

One method of resisting deformation from lithostatic pressure is to fill the voids in the canister with a stabilizer material. Three classes of stabilizers were previously identified. The gases are useless for resisting lithostatic pressures unless the canisters are pressurized to extremely high pressures, an undesirable choice. Solids represent the optimum case for resistance to 1 ithostatic pressure, since they essentially fill 100\% of the void spaces and have compressive strengths which in most cases exceed the lithostatic pressures. Note that for the case of chopped fuel, the matrix itself acts as a solid stabilizer.

The particulate stabilizers may or may not resist 1 ithostatic pressure because of rearrangement or fracturing of the particulate. In addition, for the "close-packed waste form," there is the possibility of rearrangement of the rods to a higher density. These concerns about the viability of the particulate stabilizer or close-packed rods to support lithostatic pressure are analyzed in Appendix B. 
The relative rankings of the 13 waste forms with respect to resisting lithostatic pressures according to the maximum possible eccentricity is given in Table 9. The usefulness of these rankings to establish the necessity of a particular stabilizer type to resist lithostatic pressure can only be judged if the critical eccentricity of the canister is established.

\section{B. LONG-TERM STABILITY FOR RADIONUCLIDE RETENTION}

The ability of the waste form to resist leaching after the waste package breaches will be dependent on the characteristics of the spent fuel pellet. These characteristics include surface area, arain boundary conditions, fission product residence positions, phases, and surface structure. During the thermal period, prior to intrusion of water into the waste package, these characteristics may change with time. In order to reduce the leaching propensity, it would be desirable to choose a waste form and specify an upper repository temperature so that the fuel pellet does not deteriorate from its initial condition during the thermal period.

Five mechanisms have been identified which might alter the fuel pellet condition:
1. Chemical changes
2. Volatile fission product migration
3. Diffusion of gas to grain boundaries
4. Radiation damage due to decay of fission products
5. Fragmentation due to thermal and mechanical effects

These mechanisms are analyzed in detail in Appendix A for an isolated intact rod. Based on that analysis, each of the mechanisms has been evaluated for its sensitivity to temperature, cladding intactness, stabilizer type, venting of the fuel rod, and fuel rod configurations. The functional dependence is shown in Table 10. Possible concerns about degradation are listed in Table 11 and discussed below: 
TABLE 9

RANKING OF THE WASTE FORMS FOR THEIR ABILITY TO WITHSTAND LITHOSTATIC PRESSURE

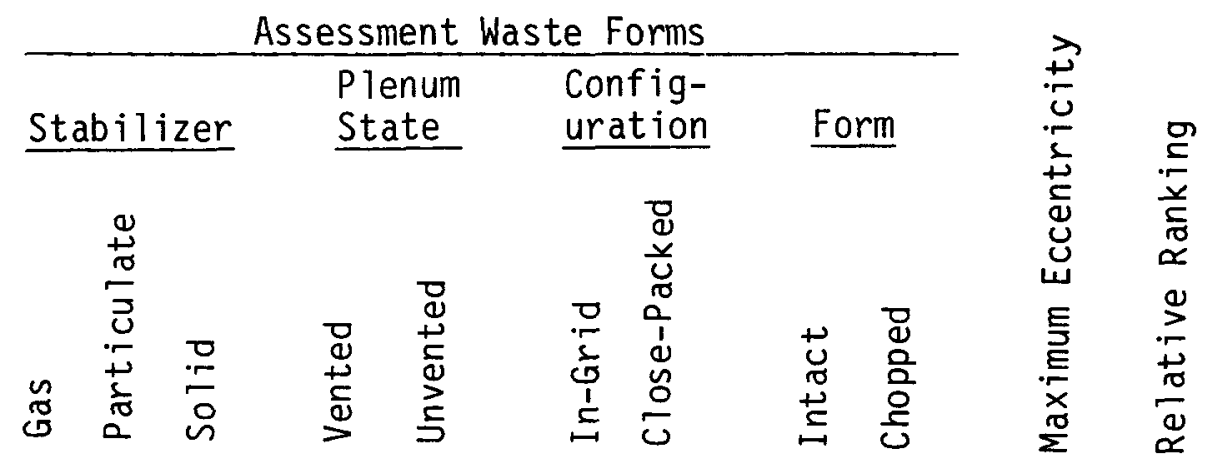

$\tilde{\omega}$

\section{DOE Waste Forms}

Unaltered Assembly

$\left\{\begin{array}{l}\text { 1. } x \\ 2 . \\ 3 .\end{array} x x\right.$

$\begin{array}{ll}X & X \\ X & X \\ X & X\end{array}$

$\begin{array}{ccc}X & H i g h & 4 \\ X & .67 & 2 \\ X & 0 & 1\end{array}$

Rods Vented to Remove Gas and

Resealed

$\left\{\begin{array}{lll}4 . & x & \\ 5 . & x & x \\ 6 . & & x\end{array}\right.$

Close-Packed Fuel Rods

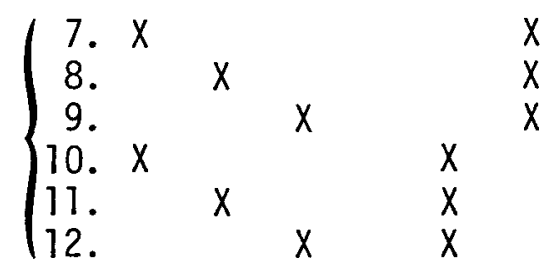

$x$
$x$
$x$

$x$
$X$
$x$

$\begin{array}{ll}\text { High } & 4 \\ .67 & 2 \\ 0 & 1\end{array}$

Rods Chopped and Immobilized

13.

$x \quad x$

in Matrix Material 
TABLE 10

FUNCTIONAL DEPENDENCE OF DEGRADATION MECHANISMS ON WASTE FORM CONFIGURATION

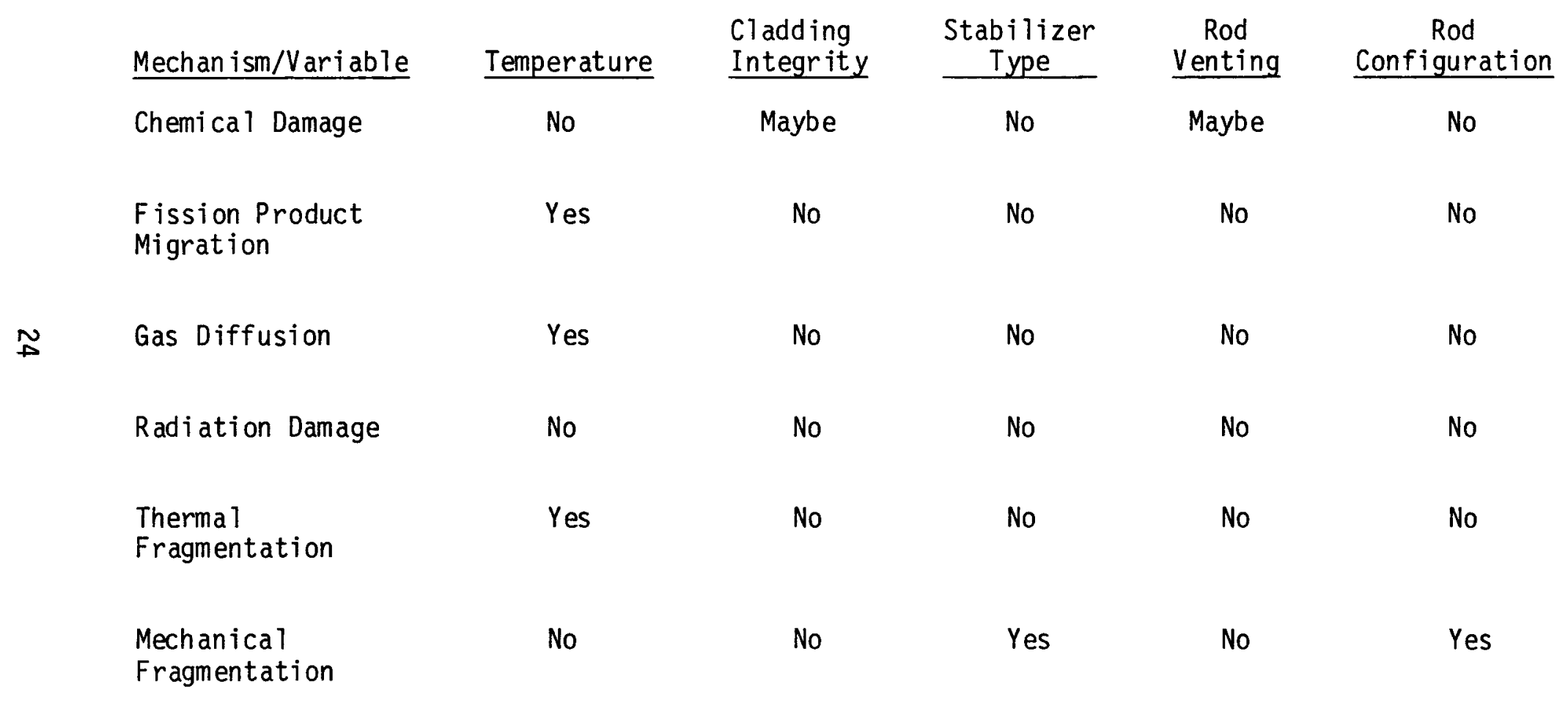


TABLE 11

POSSIBLE CONCERNS ABOUT FUEL PELLET DEGRADATION

Mechanism

Chemical Change

Fission Product Migration

N

Gas Diffusion

Thermal Fragmentation

Mechanical Fragmentation
Variable

Cladding Integrity

Rod Venting

Temperature

Temperature

Temper ature

Stabilizer Type Rod Configuration

\section{Concern}

1. Will the chopped or breached fuel interact with stabilizer or monolith?

2. Will the venting process change the internal rod environment and cause a new thermodynamic equilibrium to be established?

3. At what temperature will the volatiles start to migrate?

4. What is the maximum temperature before significant gas diffusion starts?

5. At what temperature does the gradient across the fuel become great enough to cause fragmentation?

$6 / 7$ How will the stabilizer type or rod configuration affect the coupling between the rods and canister? 
1. Will the Chopped or Breached Fuel Interact With the Stabilizer or Monolith?

As long as the fuel rod stays intact, the phases in the fuel along with the stoichiometry will be governed by the thermodynamics of the chemical system internal to the rod. While the condition inside the rod is not experimentally well known, it is known that there is little, if any, driving force for change, as pointed out in Appendix $A$.

Once the rod is cut or breached, the thermodynamics of the system changes, and the possibility exists for interaction of the fuel with the stabilizer, canister, moisture in the canister, or oxygen in the canister. Without better knowledge of the internal phase composition of the rod prior to breach, thermodynamic potentials, and reaction rates in the open system, it is impossible to predict what the thermodynamic equilibrium will be after breach. If the cladding can be kept intact as long as possible, then the concerns about the interaction of the fuel with the stabilizer and canister will be minimized. Because of the long period of time involved with the thermal period, very low reaction rates may be troublesome.

If the preferred waste form is chopped fuel or if the repository temperature is chosen such that the cladding may be compromised, the situation described above will hold.

2. Will the Venting Process Change the Internal Rod Environment and Cause a New Thermodynamic Equilibrium to be Established?

The answer to this question relates to two processing variables. The first is the composition of the atmosphere in which the rods are vented, and the second is the integrity of the reseal after venting. In all probability, the internal rod atmospheric composition will not change much because of venting, since initially there is high internal rod pressure and the flow of gas will be outward from the rod. This may not be true for the low pressure BWR rods or if the vent hole is not promptly resealed. The quality of the reseal 
is a concern, since every reseal that eventually fails brings the rod back to a situation similar to the case for Question 1.

\section{At What Temperatures will the Volatiles Start to Migrate?}

According to Figure $A .2$ in Appendix A, fission product redistribution from the grain bulk to the grain boundary with possible weakening of the grain boundaries is not expected below $1000^{\circ} \mathrm{C}$. If the fuel temperature in the repository is kept below $1000^{\circ} \mathrm{C}$, which is at least twice the presently projected temperature (see Section IV.E), volatile fission product migration is a benign mechanism.

\section{What is the Maximum Temperature Before Significant Gas Diffusion Starts?}

Figure A.5 of Appendix A gives the fractional gas release as a function of temperature for various grain sizes based on a 1000-year time period. The grain size distribution in spent LWR fuel deduced from the EPRI Fuel Performed Data Base ranges from $5 \mu \mathrm{m}$ to $30 \mu \mathrm{m}$; exact distributions are dependent on reactor operating conditions and manufacturing variables of the fuel. The quantity of interest is the surface density of gas on the grains, which is proportional ${ }^{(10)}$ to $f R_{g}$, where $f$ is the fractional release and $R_{g}$ is the radius of the grain. As can be seen from Figure A.5, the highest surface gas density at any temperature occurs for the smallest grain size, so the $5 \mu \mathrm{m}$ radius case will be used as a conservative case for analyzing gas release.

Once the gas is released from the grain, one of two events will take place. Either the gas will form a bubble which remains at the grain boundary, or the gas will diffuse along the grain boundary out of the fragment into the rod plenum. If the bubble remains at the grain boundary, eventually the internal bubble pressure will build until the vapor-to-solid interface energy and solid-solid interface energy are such that it is favorable to propagating a grain boundary crack. The pressure in the bubble 
can be relieved if diffusion from the bulk to the grain boundary is slower than from the grain boundary to the fragment surface. This will occur if:

$$
D_{g b} R_{g}^{2}>D x^{2}
$$

where $D$ and $D_{g b}$ are the grain and grain boundary diffusion coefficients and $R_{g}$ and $X$ are the grain and fragment radii. In this case, the gas diffuses from the grain boundary to the plenum faster than it diffuses from the grain to the grain boundary. This is is highly likely, because, as mentioned in Appendix A, the bubbles interlink prior to 10 GWD/MTU, and thus $D_{g b}$ becomes a vapor transport diffusion coefficient which is much greater than solid state diffusion coefficients. Therefore, the fuel would not be degraded, because buildup of gas at the grain boundaries should not occur. This conclusion is supported by the fact that fuel in reactor has never been observed to be torn apart by gas bubble formation under normal operating conditions.

A possible problem occurs in gas release to the plenum. If excessive gas is released to the plenum, the integrity of the canister may be jeopardized as discussed in Section IV.D. If it is decided that the cladding can be jeopardized over a long time span to obtain higher waste form temperatures, then one is only limited by the temperature at which the gas release becomes excessive. An excessive gas release may lead to pressurization of the canister, since the cladding has been sacrificed.

It is seen from Figure $4(p .44)$ that $20 \%$ gas release for BWR rods can be tolerated without canister breach if a gas stabilizer near $600^{\circ} \mathrm{C}$ is used. (Note that only the gas stabilizer has been considered here, since other considerations indicate that the particulate stabilizer should not be used.) Based on known diffusion coefficients (see Appendix A), 20\% gas release will not occur over a 1000-year period for temperatures less than $600^{\circ} \mathrm{C}$. Therefore, based on possible pressurization of the canister, fuel temperatures should be held below $600^{\circ} \mathrm{C}$ for all of the intact work forms. In chopped fuel, gas will also be generated. The amount of gas release before the 
monolith cracks will depend on the strength of the particular monolith material, the post-fabrication geometry, and the equilibrium pressure which develops in the bubbles in the monolith. This question has not been addressed, since the nature of the monolith may strongly affect the limits.

5. At What Temperature Does the Gradient Across the Fuel Pellet Become Great Enough to Cause Fragmentation?

Bosi (11) calculated that a minimum temperature differential of $66^{\circ} \mathrm{C}$ is necessary before a worst case intact pellet could undergo thermal fragmentation. Figure A.6 (Appendix A) shows that even for 1-year fuel operating up to $1000^{\circ} \mathrm{C}$, the radial temperature drop across the pellet will not exceed $0.5^{\circ} \mathrm{C}$; therefore, thermal fragmentation is not a concern.

\section{How Will the Stabilizer Type or Rod Configuration Affect the Coupling Between the Rods and the Canister?}

The calculations summarized in Appendix $A$ were made for an in-qrid assembly with a qas stabilizer. While no detailed analysis has been done with other rod configurations or stabilizer types, Bosi (11) has indicated the expected qualitative differences.

For the case of a transportation or emplacement shock, the main source of pellet fracture is due to rattling of the assembly in the canister. As the freedom of movement of the rods in the canister is reduced, the propensity for fracture by transportation shock loading events is reduced. Hence a solid stabilizer would be better than a particulate stabilizer, which in turn is better than a gas stabilizer. For ease of calculation, Bosi (11) dissipated the loads only at the grid spacers. For the case of close-packed rods, the load would be dissipated over the full length of the rod; therefore, close-packed rods would be less susceptible to fracture than in-grid rods. Since calculations show that there is no problem for the worst case situation with in-grid rods and a gas stabilizer, it is concluded that this question is not a concern. 
A problem arises, however, if there is a seismic event with an accompanying shear wave. In this case, the better the coupling between the canister and the waste form, the higher the propensity for fuel pellet damage. In this case, gas is the best stabilizer and a solid is the worst. Since care will probably be taken to isolate the repository from known seismic faults, this case should not be weighted as heavily as the case considering transportation and emplacement shock.

Rankings of the waste form with respect to fuel degradation are done in two classes. The first ranking is for repository conditions where the cladding remains intact, and the second ranking is for repository conditions conducive to cladding breach. The ranking of rods that have breached cladding or chopped fuel is lower than rods with intact cladding because of the uncertainty of low-temperature, long-term chemical interactions of the fuel with the canister or stabilizer (Table 12). If repository conditions are chosen such that there is a propensity for cladding breach, then a detailed experimental program to study fuel-stabilizer-canister interactions should be instituted.

\section{AID IN PRESERVATION OF THE CLADDING AS A BARRIER}

Cladding is a barrier to radionuclide migration, and care should be taken to preserve its integrity when possible. A possible function for the stabilizer/waste form combination is to minimize all stress-related cladding degradation mechanisms. This can be done in either of two ways: the stress can be relieved from the cladding, or the stabilizer can offer additional support to the cladding. In either case, two questions must be answered.

1) Is support for the cladding or relief of the stress offered?

2) Is support for the cladding or relief of the stress necessary?

For many of the thirteen possible waste forms, the answers to one or both of these questions aresimple and will only be summarized. For the chopped rods, the cladding will be destroyed so that support or stress 
TABLE 12

RATINGS OF WASTE FORMS BASED ON FUEL DEGRADATION

Assessment Waste Forms

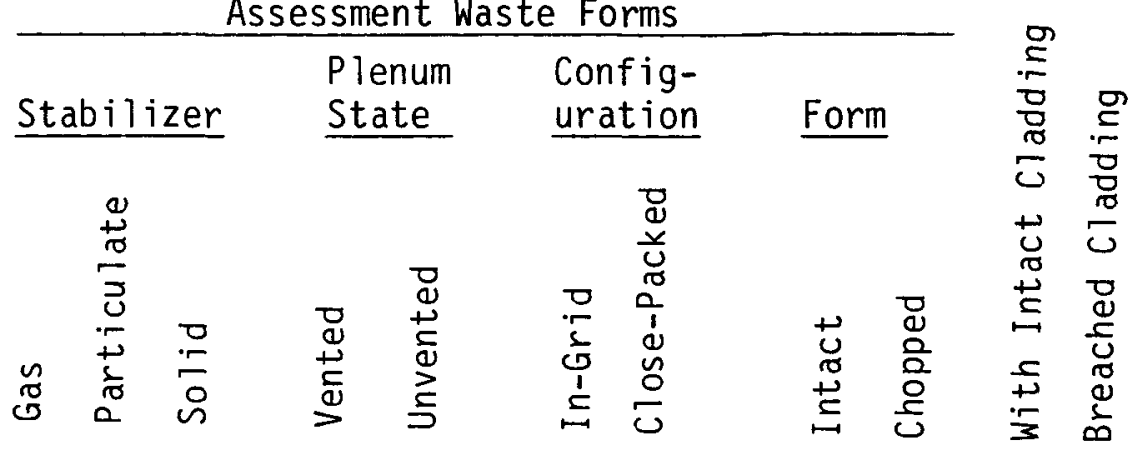

$\omega$

\section{DOE Waste Forms}

Unaltered Assembly $\left\{\begin{array}{l}1 . x \\ 2 . \\ 3 .\end{array} \quad x \quad x\right.$

Rods Vented to Remove Gas and Resealed

$\left\{\begin{array}{lll}4 . x & x \\ 5 . & x & x \\ 6 . & x\end{array}\right.$

Close Packed Fuel Rods

$\left\{\begin{array}{lllll}7 . & & & & x \\ 8 . & x & & & x \\ 9 . & & x & & x \\ 10 . \times & & & \times & \\ 11 . & x & & x & \\ 12 . & & x & x & \end{array}\right.$

Rods Chopped and Immobilized

13. in Matrix Material

13.

$x$

$x$

$\begin{array}{ll}x & x \\ x & x \\ x & x\end{array}$

$X$
$X$
$X$

$\begin{array}{ll}1 & 2 \\ 1 & 2 \\ 1 & 2 \\ 1 & 2 \\ 1 & 2 \\ 1 & 2\end{array}$

$\begin{array}{lll}x & 1 & 2 \\ X & 1 & 2 \\ x & 1 & 2 \\ x & 1 & 2 \\ x & 1 & 2 \\ x & 1 & 2\end{array}$

$x$

$X$


relief is not necessary, but this also destroys the cladding as any barrier. For all waste forms that are vented, the stress is relieved from the cladding, and the stabilizer need provide no support function. Since canisters with gas stabilizers would probably only be pressurized to a few atmospheres or less, no support will be offered to a PWR pre-pressurized rod with 350 to 500 psi internal pressure.

Because of differences in thermal expansion coefficients, there is a possibility that a solid stabilizer could have a gap around a fuel rod after solidification. During the 1000-year period, the cladding can be expected to creep approximately $0.5 \%$ or less. Therefore, for the stabilizer to support the cladding, any gap would have to be smaller than .001 inches. However, there are metallic stabilizers with thermal expansion coefficients sufficiently close to that of Zircaloy which allow this criterion to be met.

Physical support of the cladding available from particulate stabilizers is somewhat more difficult to assess. The pertinent question is: how much does the cladding have to creep before compaction of the stabilizer ceases and support for the cladding is available?

Since particulates are usually compacted under 10 - $30 \mathrm{ksi}$ pressure $(2,3)$ and the stress on the cladding of the fuel rods will be approximately $10 \mathrm{Ksi}$, as shown in Appendix $B$ there is a possibility of approximately an $8 \%$ volume compaction of the stabilizer. In the case of intact assemblies, this would only be the stabilizer material between rods. For the close-packed situation, all the stabilizer is available for compaction. If $A_{S}$ is the stabilizer area available for compaction, then the final radius $\left(R_{f}\right)$ at compaction of $N$ rods with an initial radius $\left(R_{0}\right)$ is given by:

$$
R_{f}=\left[\left(\frac{.08 A_{S}}{\pi N}\right)+R_{0}^{2}\right]^{1 / 2}
$$

The cladding creep necessary to accomplish this compaction in 1000 years $\left(\varepsilon_{N}\right)$ is given in Table 13. In none of the cases is the expected creep 
TABLE 13

PARTICULATE STABILIZER SUPPORT FOR THE CLADDING

\begin{tabular}{|c|c|c|c|c|}
\hline & & & Disasse & \\
\hline & PWR & BWR & PWR & BWR \\
\hline (a) Stabilizer Area, $A_{S}\left(i^{2}\right)$ & 41.92 & 24.25 & 35 & 54.3 \\
\hline Area Available/Rod for Expansion (in $\left.{ }^{2}\right)$ & 0.016 & 0.18 & $3.5 \times 10^{-3}$ & 0.014 \\
\hline$R_{0}($ in $)$ & .211 & .242 & .211 & .242 \\
\hline$R_{f}$ (in) & .223 & .254 & .214 & .251 \\
\hline${ }^{(b)} \varepsilon_{n}(\%)$ & 5.59 & 4.96 & 1.42 & 3.7 \\
\hline${ }^{(c)} \varepsilon_{c}(\%)$ & 0.63 & 0 & 0.63 & 0 \\
\hline
\end{tabular}

(a) Stabilizer area for the in-grid case based only on inter-rod area being available for compression by cladding creep.

(b) Necessary cladding creep for stabilizer to act as a support for the cladding.

(c) Maximum expected cladding creep at $600^{\circ} \mathrm{F}$ for 1000 hours. 
$\left(\varepsilon_{c}\right)$ large enough to cause stabilizer compaction. Thus a particulate stabilizer may not give support to the cladding if support is required.

It must still be determined if in fact support for the cladding is necessary. This will only be relevant if the rod remains pressurized during disposal. Blackburn (13) identified stress-rupture and stress-corrosion cracking $(S C C)$ as the two most likely stress-related cladding degradation mechanisms. A conservative estimate of $377^{\circ} \mathrm{C}$ for a maximum disposal temperature based on stress rupture was established. (13) Whole rod anneals have demonstrated that this temperature limit for stress-rupture is probably conservative by at least $50^{\circ} \mathrm{C}^{(14)}$ (see Figure 1). This new temperature 1 imit $\left(425^{\circ} \mathrm{C}\right.$ ) may still be conservatively low and could possible be increased with further analysis of presently available data.

The Stress Corrosion Cracking Initiation and Growth (SCCIG) Model (15) developed for EPRI was used by Miller to evaluate the propensity of fuel fuel rods for SCC. The model was used to determine the maximum radial crack that could be present in an unfailed spent fuel rod after normal LWR exposure and to develop a 1000-year fuel rod fail/no-fail boundary based on crack size, temperature, iodine concentration, and internal rod stress.

As long as the probability of in-reactor failure is less than $1 \%$, (the case for the vast majority of LWR fuel rods,) then $99 \%$ of the remaining unfailed rods will enter the repository with incipient SCC cracks, if present, of less than $20 \%$ of the wall thickness. When the model is applied for repository/storage conditions, the 1000-year fail/no-fail lines in Figure 2 are obtained. With realistic iodine concentrations representative of the majority of the rods $\left(5 \times 10^{-5} \rightarrow 5 \times 10^{-4} \mathrm{Kg} / \mathrm{m}^{2}\right)$ and a $20 \%$ radial wall crack, Zircaloy cladding temperatures up to at least $600^{\circ} \mathrm{C}$ can be tolerated without SCC causing cladding breach.

Below $425^{\circ} \mathrm{C}$, the cladding should survive the 1000 -year thermal period without breach. As the temperature is increased above $425^{\circ} \mathrm{C}$, the lifetime will become progressively shorter (no significant gas release from the rods). 


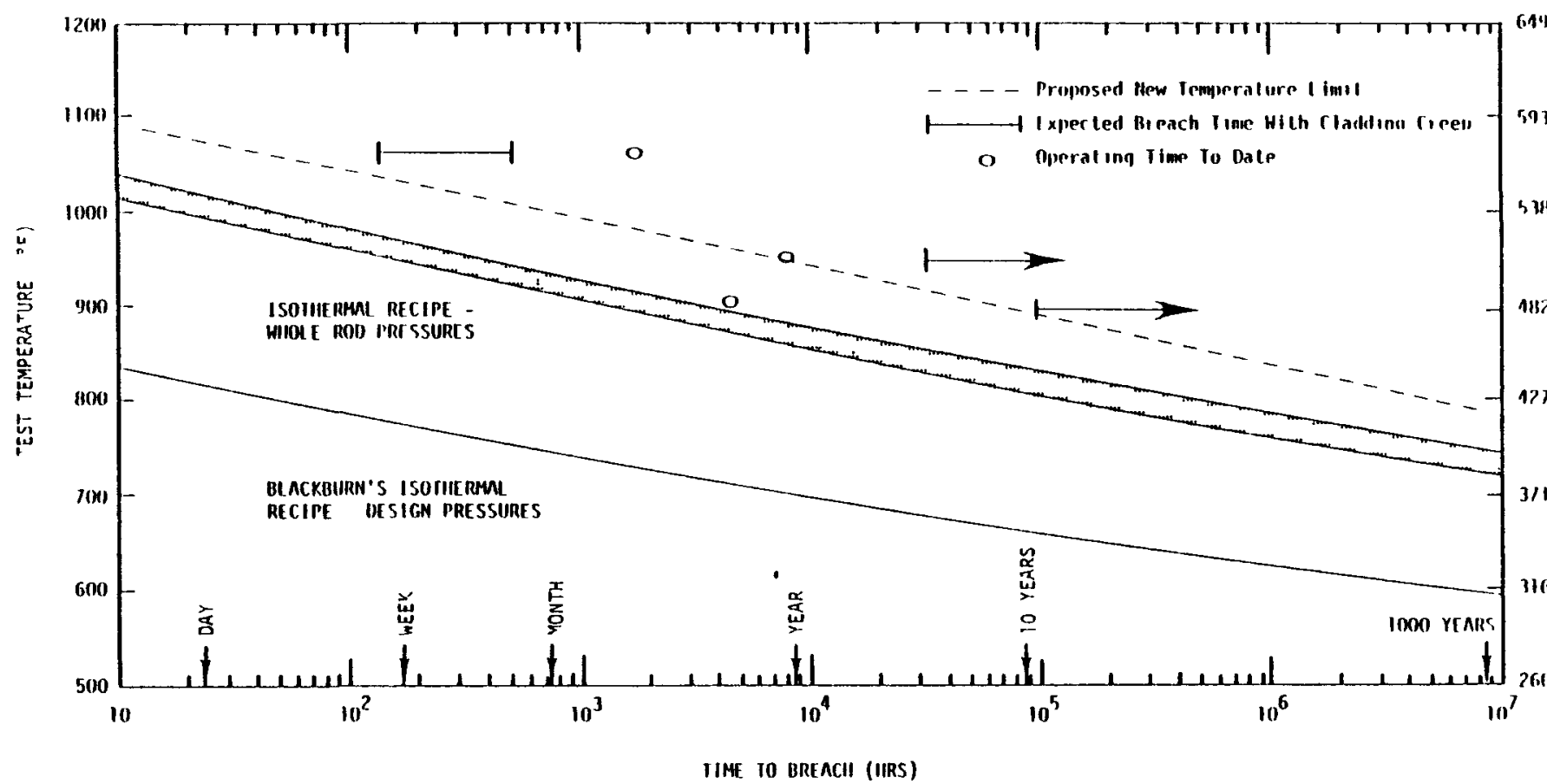

FIGURE 1. Whole Rod Test Results, Indicating that Breach Time Predicted by Blackburn's Formulation (16) is Very Conservative 


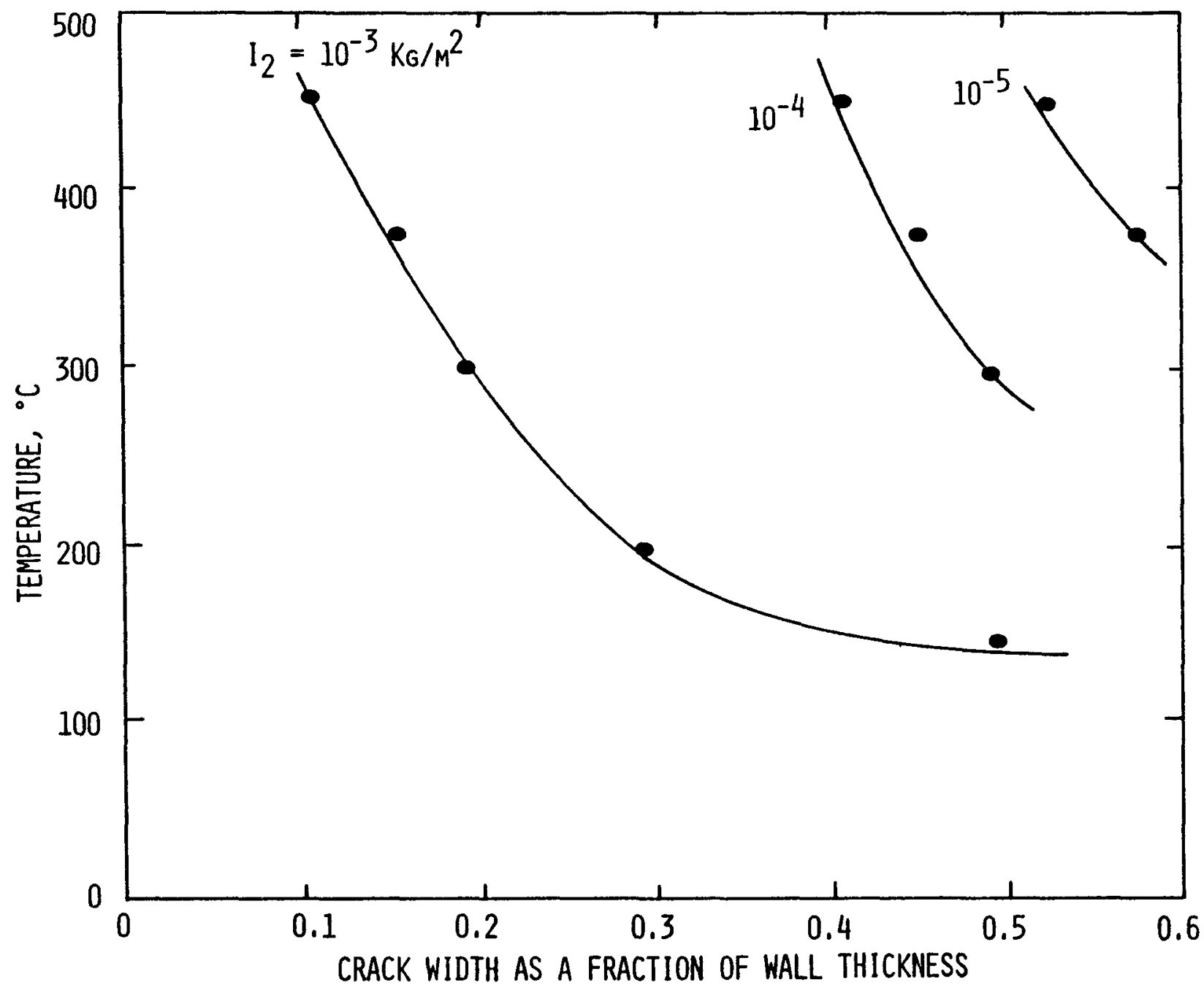

FIGURE 2. 1000 Year Isochrons for Irradiated Zircalov Cladding for Varying Internal Iociine Concentrations. $\sigma_{H}(\mathrm{MPa})=0.11 \mathrm{~T}\left({ }^{\circ} \mathrm{K}\right)$ was Used for the Rod lloop Stress: 
During this time period, physical support for the cladding should be offered to all unvented rods to resist rupture. Above $600^{\circ} \mathrm{C}$, as shown in previous sections, gas release will occur from the fuel column, and support is needed even for the vented rods if failure is to be averted.

The rankings (see Table 14) are made on the ability to resist cladding degradation in the three temperature ranges given above, i.e., below $425^{\circ} \mathrm{C}$, 425 to $600^{\circ} \mathrm{C}$, and above $600^{\circ} \mathrm{C}$. The chopped fuel is rated low since all protection of the cladding is lost, compared to only a pinhole type breach occurring in the other situations.

\section{BREACH OF CANISTER/REPOSITORY DUE TO PRESSIJRIZATION}

The chosen waste form should not be able to cause premature package breach. In particular, will the stress induced in the package by release of the plenum gases exceed the ultimate strength of the canister? As long as intact rods which enter the repository are not subject to conditions or events which cause them to breach prior to the loss of canister integrity, there is no gas load to pressurize the canister and hence there is no reason for concern. In the same respect, the chopped fuel will not cause any pressurization problems. It should be noted however, that with chopped rods there is the possibility of chemical interaction between the canister/ stabilizer/fission product system which might produce gas. Since this interaction is dependent on the exact composition of the stabilizer, it is not being addressed at this time. If this waste form is chosen, this problem will have to be addressed.

Pressurization becomes a concern if repository conditions are set such that the cladding breaches prematurely or if there is an abnormal repository event which causes premature cladding breach. The integrity of the waste package is analyzed for two cases:

1) Rods are vented prior to repository disposal. 
TABLE 14

ABILITY OF STABILIZER TO AID IN PROTECTING THE CLADDING AS A BARRIER

Key to Ability

TNeeded \& Provided

1. $\{$ Not Needed, Not Provided

Not Needed, Provided

2. Needed, Not Provided

DOE Waste Forms

$\underset{\infty}{\omega}$
Assessment Waste Forms

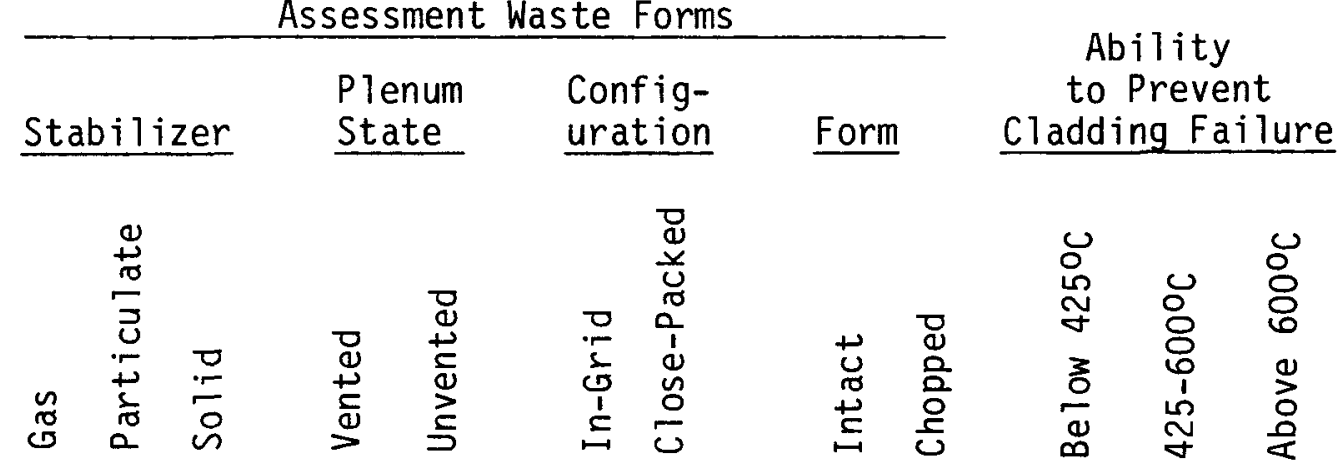

Unaltered Assembly $\left\{\begin{array}{l}1 \cdot x \\ 2 \cdot x \\ 3 .\end{array} \quad x \quad x\right.$

Rods Vented to Remove Gas and Resealed

Close Packed Fuel Rods

Rods Chopped and Immobilized in Matrix Material

$\left\{\begin{array}{lll}4 . x & x \\ 5 . & x & x \\ 6 . & x\end{array}\right.$

$\begin{array}{ll}x & x \\ x & x \\ x & x\end{array}$

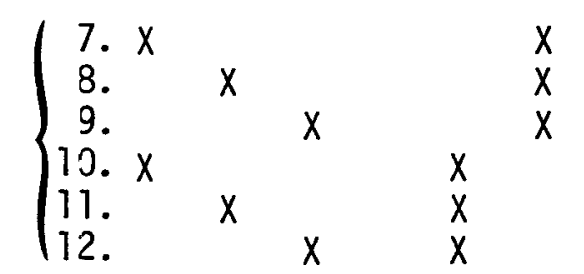

13.

$x \quad x$

$x$
$x$
$x$
$x$
$x$
$x$

$x$

$x$
$x$
$x$
$x$
$x$
$x$

$x$

$\begin{array}{llll}X & 1 & 2 & 2 \\ X & 1 & 2 & 2 \\ X & 1 & 1 & 1 \\ X & 1 & 1 & 2 \\ X & 1 & 1 & 2 \\ X & 1 & 1 & 1\end{array}$

$x$

$x$
$x$

$X$
$X$

$$
\begin{aligned}
& x \\
& x
\end{aligned}
$$$$
\begin{aligned}
& x \\
& x \\
& x
\end{aligned}
$$

$\begin{array}{lll}1 & 2 & 2 \\ 1 & 2 & 2 \\ 1 & 1 & 2 \\ 1 & 1 & 2 \\ 1 & 1 & 2 \\ 1 & 1 & 2 \\ 4 & 4 & 4\end{array}$


TABLE 15

\section{INDIVIDUAL ASSEMBLY CHARACTERISTICS}

Assembly Void Volume(a)

Prepressurized Pressure

Burnup

Initial He Inventory (STP)

Fission Gas and He From Actinide Decay at 1000 Years

Total Gas in Plenum

(\% Release)

$1 \%$

$20 \%$

$100 \%$

\begin{tabular}{clc} 
PWR & Units & BWR \\
\cline { 3 - 3 } 369 & GWD/MTU & $260(\mathrm{~b})$ \\
500 & psi & $250(\mathrm{~b})$ \\
50 & GWD/MTU & 35 \\
189 & liters/ & 39 \\
35.7 & assy & \\
& moles & 24.6 \\
& liters/ & \\
8.1 & ass.y & \\
988 & & 110
\end{tabular}

(a) Babcock and Wilcox $17 \times 17$ and G.E. $7 \times 7$ BWR which have the largest void volumes.

(b) Usually if there is as much as $20 \%$ gas release, then the BWR rods were unpressurized; if the rod was pressurized, the release is less than $1 \%$, so that this represents the worst possible BWR normal case. 
2) The rods enter the repository with a maximum normal gas release to the plenum in reactor. For PWR rods, this is a $1 \%$ gas release; for BWR rods, a $20 \%$ gas release. (16)

The particular characteristics of the assemblies are given in Table 15. Waste package dimensions were given previously in Table 5. Two stabilizer types were considered: $84 \%$ dense particulates and a gas. Solid stabilizers were not considered, since they provide extra support for the cladding and would further prevent cladding rupture. The results for intact rods in whole assemblies and in shortened assemblies are reported together, since the analysis indicated that the difference in the canister dimensions will have only minor effects and will not influence the conclusions drawn. As described in Section III, two cases of the close-packed configuration are considered. The first, labeled "random," is the case where the rods are slid into the canister without prebundling. The case referred to as "bundled" has the rods bundled into a close-packed configuration prior to insertion into the canister; a solid stabilizer is then poured to fill the top and bottom head spacing as well as the bundle-canister gap.

The analys is follows the method used in Refs 6 and 17; only the results are presented here. In order to establish temperature limitations, the results (Table 16) are presented as canister pressure (atm) per degree Kelvin $\mathrm{P} / \mathrm{T}\left(\mathrm{atm} /{ }^{\circ} \mathrm{K}\right)$. This is related to the induced canister hoop stress by the equation:

$$
\sigma_{H}(p s i)=14.7 \times(P / T) \times(R / t)
$$

where $(R / t)$ stress factor is dependent on the geometry of the waste package. $R$ is the canister radius and $t$ is the canister wall thickness. Results are shown in Figure 3 for unvented rods (which would be representative of the majority of the population of the rods which enter the repository) and for these same rods vented. Induced stresses below 2/3 of the canister material yield stress $(13,18)\left(s_{y}\right)$ are used as the criteria for acceptable performance. 
TABLE 16

P/T - CANISTER PRESSURE (ATM) PER DEGREE KELVIN

Canister Load (a)

GAS RELEASE AND STABILIZEP.

\begin{tabular}{|c|c|c|}
\hline $1 \%$ PWR & $-20 \%$ BWR & VENTED \\
\hline PARTI CULATE & GAS & PARTICULATE \\
\hline
\end{tabular}

1. PWR - Intact Assembly .0063 (9) 0067 (10) 00069

2. BWR - Intact Assembly .0205 (11) .0088 (12) 00062

$\pm$

3. PWR - Close Packed

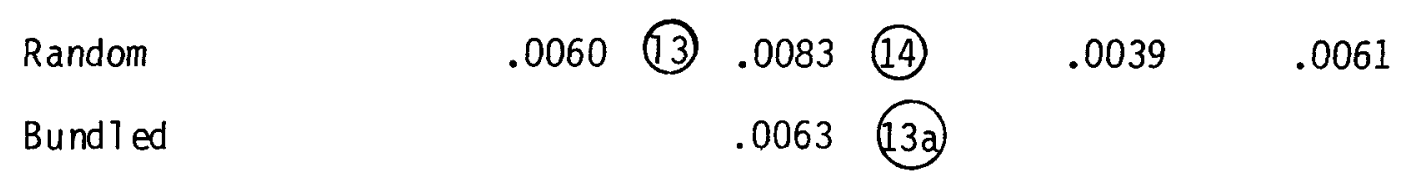

8. BWR - Close Packed

\begin{tabular}{|c|c|c|c|c|}
\hline Random & .0863 & .0267 & .0033 & .0059 \\
\hline Bund 1 ed & & .0493 & (15V) & .0067 \\
\hline
\end{tabular}

(a)Canister load refers to the number of assemblies in the canister and the configuration of the rods. (b) Refers to case number. 


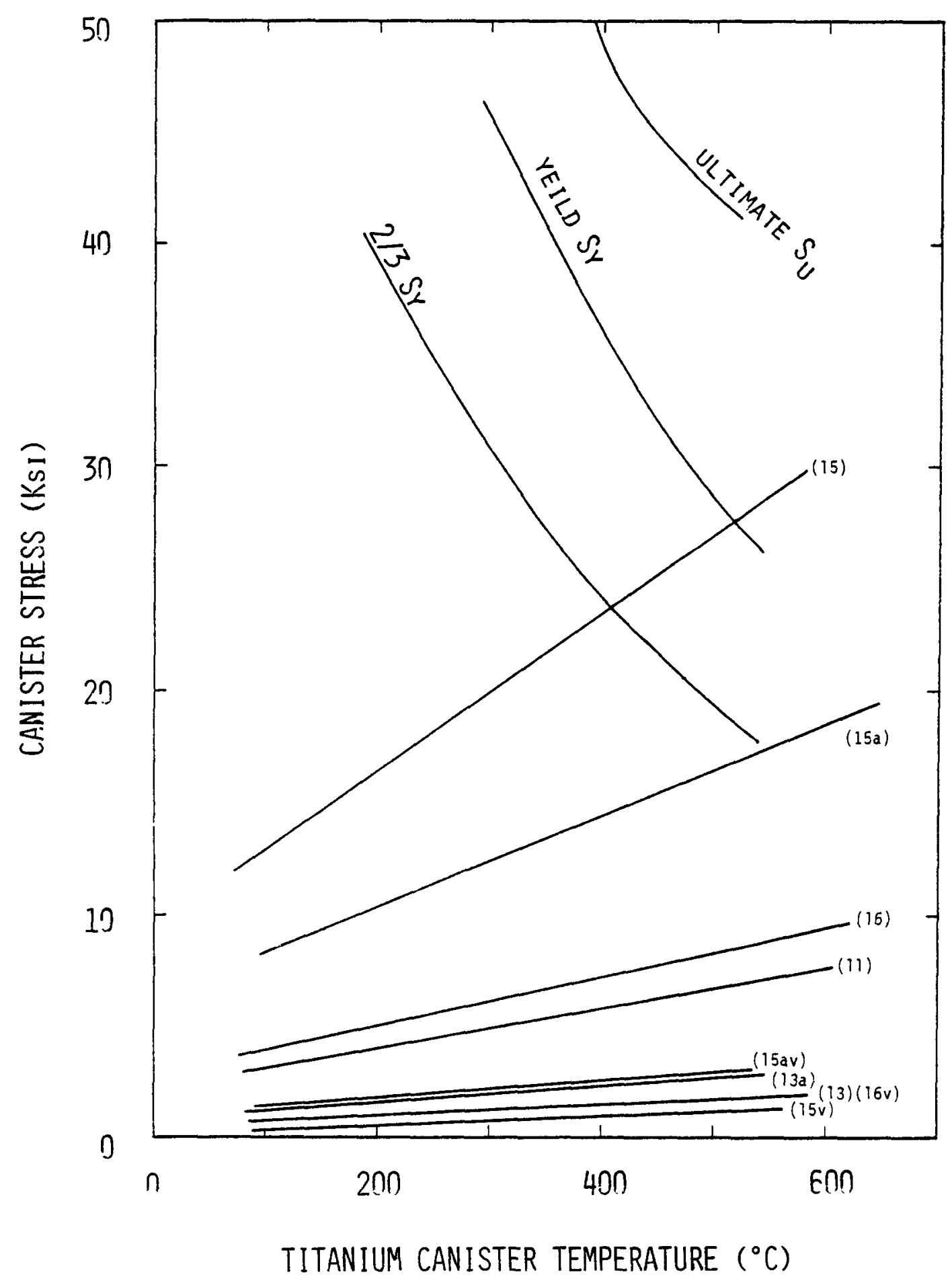

FIGURE 3. Canister Pressurization vs. Temperature for Inner Titanium Canister. Vented Rods, 1\% PWR and 20\% RWR Release (Numbers on Curve Refer to Cases in Table 15). 
To keep the cladding intact for 1000 years, the cladding temperature should be kept below $425^{\circ} \mathrm{C}$ (see Section IV.C). For a gas or particulate stabilizer (see Section IV.E) the best gradient across the waste form is approximately $10^{\circ} \mathrm{C}$; the canister should therefore be no hotter than $415^{\circ} \mathrm{C}$. At this temperature, even the worst case "normal" waste form (BWR - $20 \%$ gas release) will not compromise the canister if all the rods breach. If the temperature is raised so that the cladding may be compromised, then the case of the close-packed rods in either configuration does not fulfill the $\sigma_{H}>2 / 3 \mathrm{~S}_{y}$ criterion and will have to be reexamined. If the rods are vented prior to repository disposal, then the internal canister pressure drops when the rods rupture. The bundled close-packed BWR rods represent the worst case for vented rods and present no problem for canister integrity. If the rods are close-packed and a canister temperature of $415^{\circ} \mathrm{C}$ is exceeded, then venting the rods, at least the BWR rods, should be considered. Only cases 15 and 15 a represent a problem due to canister pressurization. This can probably be alleviated by canister design changes, but the relative cost of these changes must be factored into the total assessment of the waste form.

To this point only the inner titanium canister has been considered. If the inner canister fractures, then the outer Inconel barrier must be considered. The yield strength ${ }^{(18)}$ of Inconel is approximately $30 \mathrm{Ksi}$ and is independent of temperature from 0 to $1000^{\circ} \mathrm{F}$. Although the stress is 3 times lower than for the inner titanium canister, some of the close-packed waste forms may cause pressurization problems for the Inconel canister.

Based on the preceding analyses, the thirteen waste forms were rated for three different cases, as shown in Table 17. They are:

1) The canister response if the rods had normal in-reactor gas release and the cladding remained intact during repository disposal.

2) The canister response if the rods had normal in-reactor gas release and the cladding breached during repository disposal.

3) The rods entered the repository having had normal in-reactor gas release, then released a high amount of gas from the fuel to the plenum in the repository. The cladding is assumed to breach in repository. 
TABLE 17

RATING OF WASTE FORMS FOR THEIR ABILITY NOT TO COMPROMISE THE PACKAGE BY PRESSURIZATION

\begin{tabular}{|c|c|c|c|c|}
\hline \multicolumn{4}{|c|}{ Assessment Waste Forms } & \multirow{2}{*}{$\begin{array}{c}\text { Ability } \\
\text { to Prevent } \\
\text { Cladding Failure }\end{array}$} \\
\hline Stabilizer & $\begin{array}{l}\text { Plenum } \\
\text { State }\end{array}$ & $\begin{array}{l}\text { Config- } \\
\text { uration }\end{array}$ & Form & \\
\hline
\end{tabular}

DOE Waste Forms

$\stackrel{+}{\rightarrow}$ Unaltered Assembly $\left\{\begin{array}{l}1 . x \\ 2 . \\ 3 .\end{array} \quad x \quad x\right.$

Rods Vented to Remove Gas and Resealed

Close-Packed Fuel Rods

Chopped and Immobilized in Matrix Material

$\left\{\begin{array}{lll}4 . & x & x \\ 5 . & x & x \\ 6 . & x\end{array}\right.$

$\left\{\begin{array}{lllll}7 . & x & & & x \\ 8 . & x & & & x \\ 9 . & & x & & x \\ 10 . \times & & & x & \\ 11 . & x & & x & \\ 12 . & & x & x & \end{array}\right.$

13.

$x$

$x$

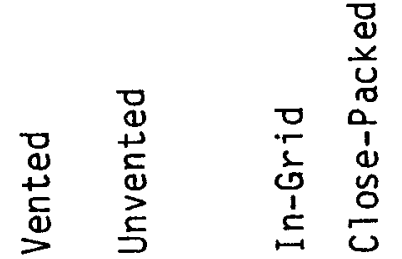

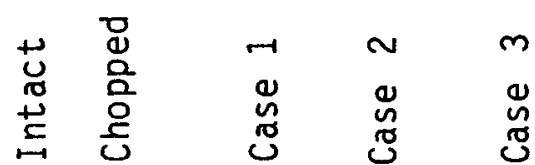

$\begin{array}{ll}x & x \\ X & x \\ X & X\end{array}$

$$
\begin{aligned}
& x \\
& X \\
& X
\end{aligned}
$$$$
\begin{array}{lll}
1 & 1 & 1 \\
1 & 1 & 1 \\
1 & 1 & 1
\end{array}
$$$$
\begin{array}{lll}
1 & 1 & 1 \\
1 & 1 & 1 \\
1 & 1 & 1
\end{array}
$$

$\begin{array}{lll}1 & 3 & 3 \\ 1 & 3 & 3 \\ 1 & 1 & 3 \\ 1 & 1 & 1 \\ 1 & 1 & 1 \\ 1 & 1 & 1\end{array}$

$x$ 
As one increases the repository temperature, the likelihood of Case 2 occurring becomes greater. The overall ratina of a waste form with respect to compromising a package or repository will depend on the repository temperature. This is addressed later in Section VI, which deals with rankings of the waste forms.

The chopped fuel case is rated lower than fuel with intact cladding because of the possibility of fuel-stabilizer-canister chemical interaction, which is unknown at this time. The degree to which this is a problem can only be answered by further study. Of course, in cases where the cladding has breached, all the waste forms have this uncertainty and chemical interaction no longer becomes a relative problem, although it may still remain as an uncertainty.

\section{E. MAXIMUM EXPECTED TEMPERATURES OF WASTE FORM/STABILIZER COMBINATIONS}

Tentative maximum temperatures have been set for the various possible host repository geologies $\left(140^{\circ} \mathrm{C}\right.$ - salt, $165^{\circ} \mathrm{C}$ - basalt, $185^{\circ} \mathrm{C}$ - tuff, $150^{\circ} \mathrm{C} \mathrm{--} \mathrm{granite} \mathrm{and} 130^{\circ} \mathrm{C}$ - shale). (19) The waste form which generates heat will be hotter than the rock. In order to evaluate relative performance of the waste forms from a temperature standpoint, the maximum cladding temperature corresponding to maximum rock temperatures were determined.

For the purpose of this evaluation, only the configuration of rods and the type of stabilizer utilized are pertinent differentiating characteristics among the waste forms. The heat loads and canister internal radius are those given in Table 5. Based on a $12 \mathrm{ft}$ fuel column, Figure 4 was used to calculate the temperature drops across the waste package as listed in Table 18. The inside canister temperatures are given in Table 19.

The calculation of maximum rod temperatures was based on the work of R. A. McCann. (20) Since in all cases (in-grid, chopped, close-packed) BWR canister packages have a slightly lower linear power generation than the 


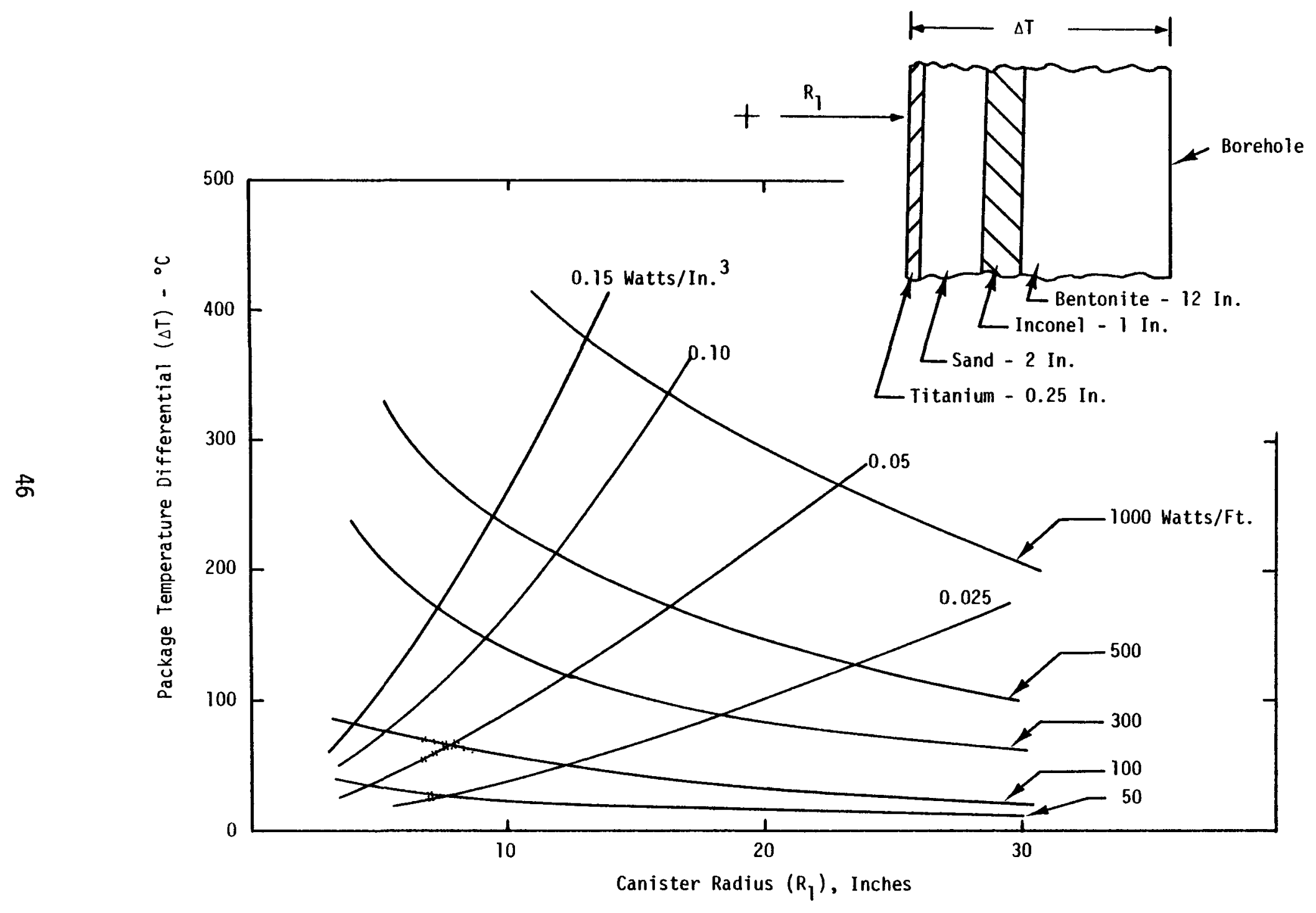

FIGURE 4. Heat Drop Across Waste Package. Cross Hatching Represents Region of Expected Repository Operation. 
TABLE 18

TEMPERATURE GRADIENTS ACROSS WASTE PACKAGE

\begin{tabular}{|c|c|c|c|c|c|c|}
\hline & \multicolumn{2}{|c|}{ In-Grid } & \multicolumn{2}{|c|}{ Close-Packed } & \multicolumn{2}{|c|}{ Chopped } \\
\hline & PWR & BWR & PWR & BWR & PWR & BWR \\
\hline Canister I.D. (in) & 6.75 & 6.75 & 6.25 & 6.25 & 8.50 & 8.50 \\
\hline $\begin{array}{l}\text { Linear Power } \\
\text { (watts/ft) }\end{array}$ & 44.2 & 31.7 & 132.5 & 111 & 100 & 91.7 \\
\hline$\Delta \mathrm{T}\left({ }^{\circ} \mathrm{C}\right)$ & 30 & 20 & 85 & 75 & 60 & 50 \\
\hline
\end{tabular}


TABLE 19

MAXIMUM INSIDE CANISTER TEMPERATURES FOR PWR FUEL(a)

\begin{tabular}{|c|c|c|c|c|c|c|c|c|c|}
\hline & Stabilizer & & Con & iguration & Shale & Salt & Granite & Basalt & Tuff \\
\hline$\underline{\text { Gas }}$ & Particulate & Solid & In-Grid & Close-Packed & $130^{\circ} \mathrm{C}$ & $140^{\circ} \mathrm{C}$ & $150^{\circ} \mathrm{C}$ & $165^{\circ} \mathrm{C}$ & $185^{\circ} \mathrm{C}$ \\
\hline$x$ & & & $x$ & & 160 & 170 & 180 & 195 & 215 \\
\hline & $x$ & & $x$ & & 160 & 170 & 180 & 195 & 215 \\
\hline$P$ & & $x$ & $x$ & & 160 & 170 & 180 & 195 & 215 \\
\hline$x$ & & & & $x$ & 215 & 225 & 235 & 250 & 270 \\
\hline & $x$ & & & $x$ & 215 & 225 & 235 & 250 & 270 \\
\hline & & $x$ & & $x$ & 215 & 225 & 235 & 250 & 270 \\
\hline & & $x$ & & Chopped & 190 & 200 & 210 & 225 & 245 \\
\hline
\end{tabular}

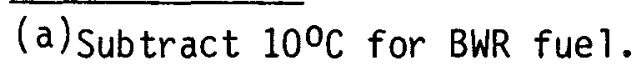


PWR packages, temperatures were only calculated for PWR packages. The cases using a gas stabilizer were analyzed by means of Figure 5 . Curve $C$ was used to represent the in-grid situation, and Curve $A$ was used to represent the close packed situation. Chopped fuel was analyzed with a linear interpolation of the power generated in the canister.

Maximum temperatures for the particulate and solid stabilizer were determined from Figure 6 , using the effective thermal conductivities determined by Wynhoff, et al., (6) as given in Table 20. Once again, a 1inear thermal conductivity to temperature differential was used. Using these approximations, the maximum calculated temperatures reached in the closepacked case are probably overestimated, since McCann's calculations were for an in-grid case of the same heat load as the close packed rods considered in this asssessment. McCann would have had far more particulate stabilizer to impede the heat flow. For solid stabilizers, the thermal conductivities are so high that the error using McCann's values should be small.

The maximum expected cladding temperatures as a function of the repository rock and waste form configuration are given in Table 21 . Little reduction in maximum temperature is achieved by switching from a gas to a particulate stabilizer. A significant gain is achieved, however, by switching to a solid stabilizer for the case of close-packed fuel, but the necessity for lower temperatures can only be determined after the behavior of fuel at the higher temperatures is analyzed. The waste forms are rated in Table 22 according to their calculated maximum temperatures. 


$\begin{array}{ccc}\text { Curve } & \begin{array}{c}\text { Thermal } \\ \text { Power, kW }\end{array} & \text { Fuel Age, Yrs. } \\ \text { A } & 1.786 & 3 \\ \text { B } & 0.964 & 5 \\ \text { C } & 0.554 & 10 \\ \text { D } & 0.0 & \end{array}$

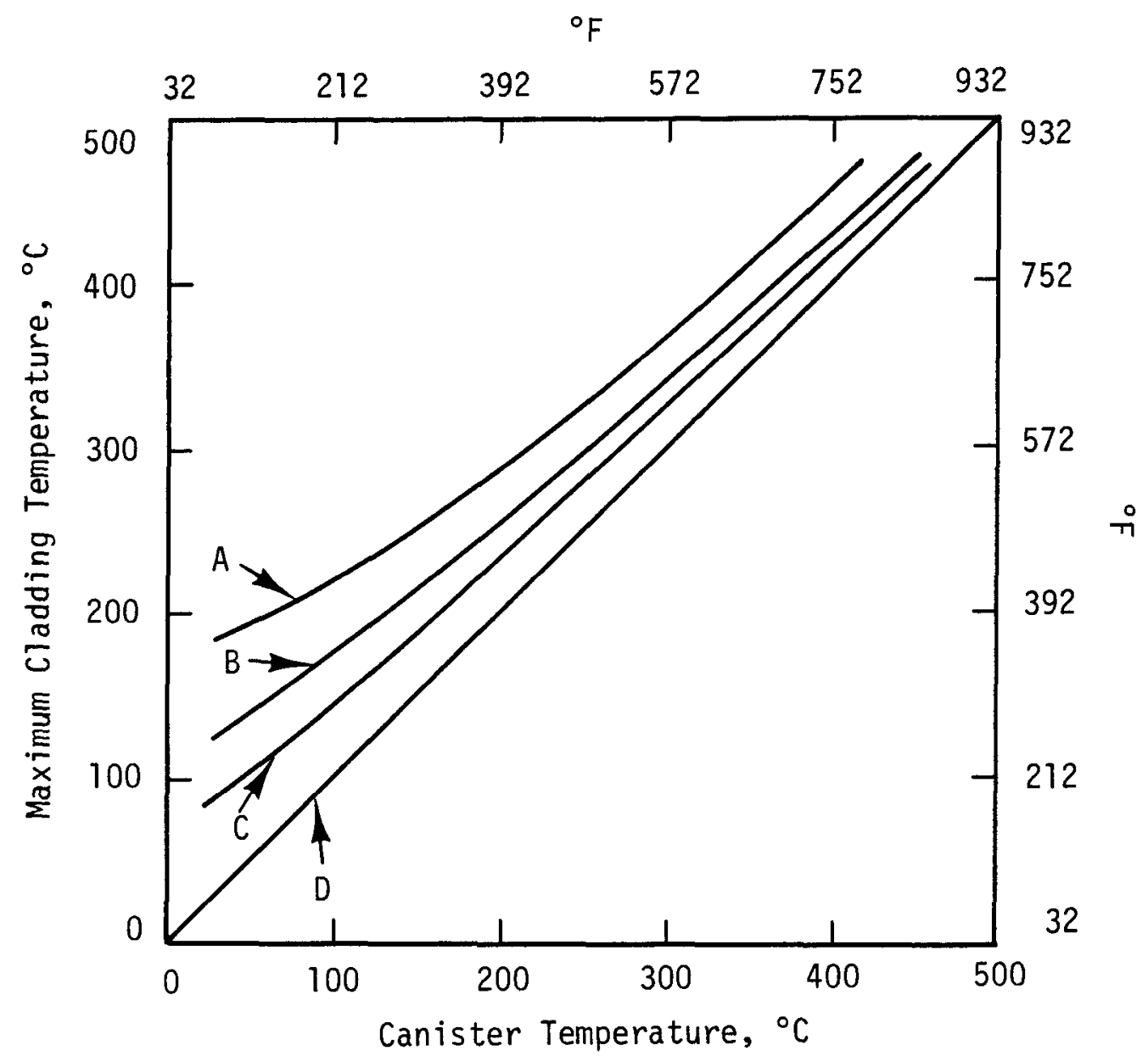

FIGURE 5. Maximum Fuel Cladding Temperature vs Canister Temperature for Heli um Stabilizer. (22) 


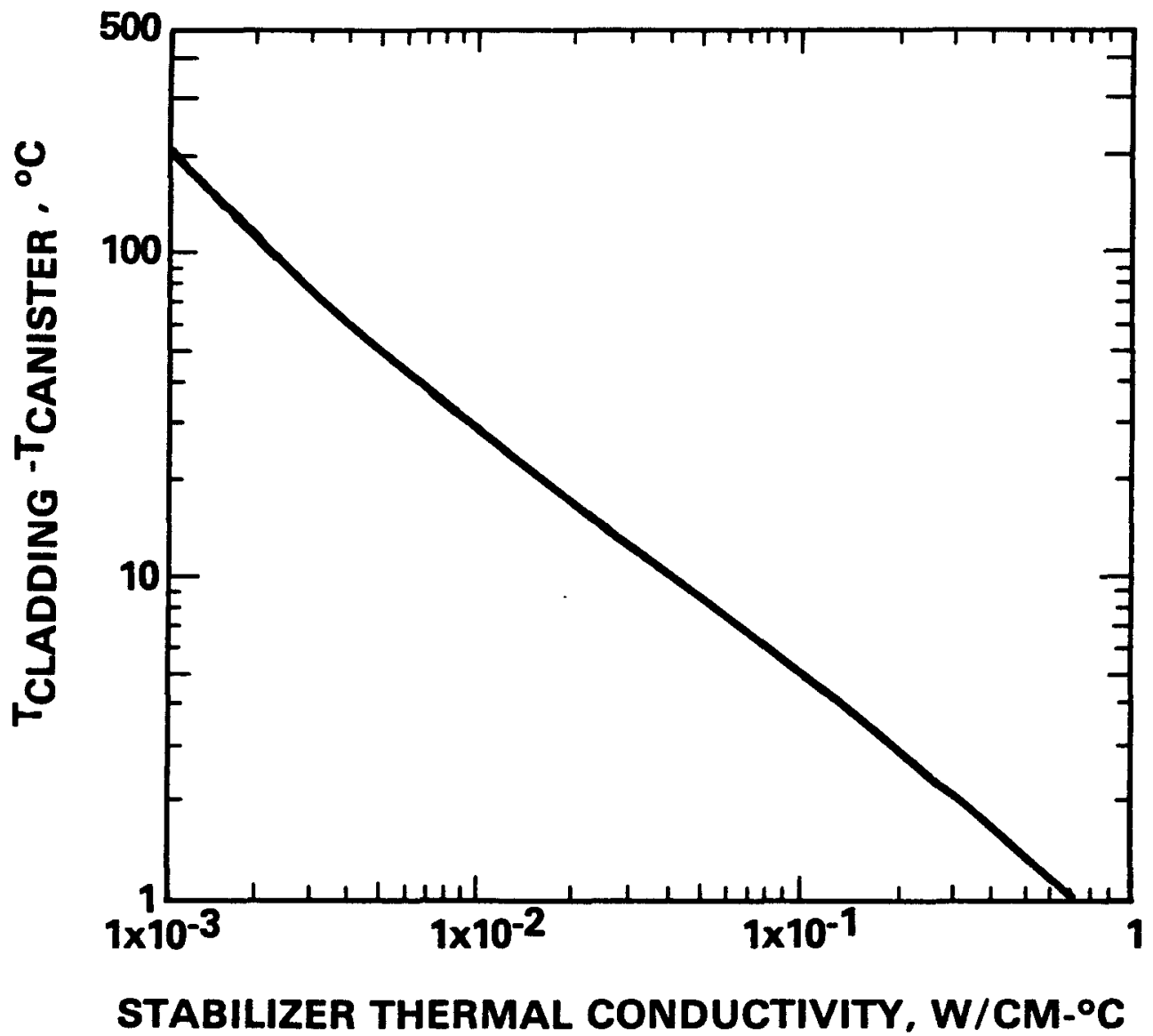

FIGURE 6. Temperature Difference Between the Cladding of the Hottest Rod and the Canister vs Thermal Conductivity of Stabilizer (5-Year 01d Spent PWR Fue 1). (22) 
THERMAL CONDUCTIVITIES ESTABLISHED BY POTENT IAL STAB ILIZER MATERIALS $(6)$

Stabilizer

commercial copper

commercial aluminum

aluminum casting alloy $\mathrm{A} 413$

aluminum casting alloy 336

commercial zinc

zinc alloy $A G 40 A$

zinc alloy AC4 1A

zinc-copper-titanium alloy

copper casting alloy $3 \mathrm{~A}$

commercial lead

$1 \%$ antimonial lead

graphite
Thermal Conductivity $\left(\mathrm{W} / \mathrm{cm}{ }^{\circ} \mathrm{C}\right)$

\section{9}

2.2

1.2

1.2

1.1

1.1

1.1

1.0

0.5

0.3

0.3

0.1

\begin{tabular}{ll}
\hline 0.03 \\
0.02 \\
0.1 \\
0.009 \\
0.008 \\
0.007 \\
0.005 \\
0.005 \\
0.005 \\
\hline
\end{tabular}

silica-amorphous*

basalt*

tuff*

zirconia*

mullite*

silica-quartz*

helium $\star \star$

nitrogen**
0.004

0.003

0.003

0.003

0.003

0.003

0.002
0.004

*Effective thermal conductivities are given for these particulate stabilizers with helium fill:

**Effective thermal conductivities for gases include convection effects.

*** Registered trademark of the Corning Glass Company. 
TABLE 217

MAXIMUM CLADDING TEMPERATURES(a) FOR DIFFERENT CONFIGURATIONS OF PWR ASSEMBLIES IN VARIOUS CANDIDATE GEOLOGIES

\begin{tabular}{|c|c|c|c|c|c|c|c|c|c|}
\hline \multicolumn{3}{|c|}{ Stabilizer } & \multicolumn{2}{|c|}{ Configuration } & \multicolumn{5}{|c|}{ Cladding Temperatures (b) } \\
\hline Gas & Particulate & Solid & In-Grid & Close-Packed & Shale & Salt & Granite & Basalt & Tuff \\
\hline$x$ & & & $x$ & & 205 & 215 & 225 & 240 & 260 \\
\hline & $x$ & & $x$ & & 205 & 215 & 225 & 240 & 260 \\
\hline & & $x$ & $x$ & & 170 & 180 & 190 & 205 & 225 \\
\hline$x$ & & & & $x$ & $<323$ & $<333$ & $<343$ & $<358$ & $<378$ \\
\hline & $x$ & & & $x$ & $<323$ & $<333$ & $<343$ & $<358$ & $<378$ \\
\hline & & $x$ & & $x(c)$ & $<323$ & $<333$ & $<343$ & $<358$ & $<378$ \\
\hline & & $x$ & & Chopped (d) & 253 & 263 & 273 & 288 & 308 \\
\hline
\end{tabular}

\footnotetext{
(a)BWR temperatures are slightly lower.

(b) Actual temperatures may be lower if a suitable stabilizer with a greater thermal conductivity than used on the calculations is found. Thermal conductivities used were the lowest in Table 19 for any generic stabilizer type.

(c) Solid Stabilizer, close-packed refers to bundled rods with gas between the rods and a solid poured stabilizer between the bundle and the canister.

(d) Based on glass monolith; cladding temperatures would be lower for concrete.
} 
TABLE 22

RATING OF WASTE FORMS FOR HEAT TRANSFER

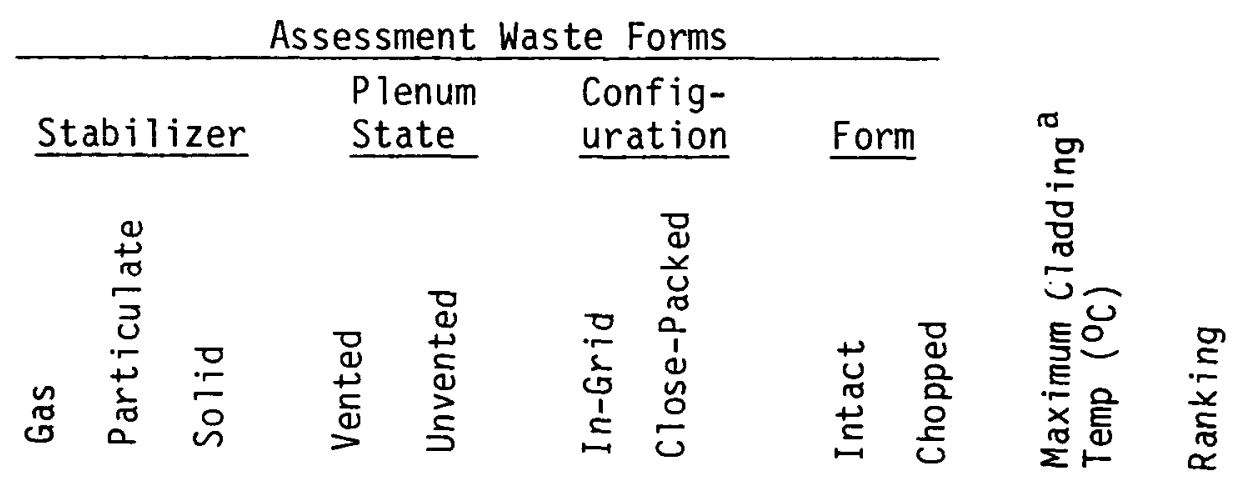

DOE Waste Forms

Unaltered Assembly

End Bells Removed From Assembly $\left\{\begin{array}{l}1 . x \\ 2 . x \\ 3 .\end{array} x x\right.$

Rods Vented to Remove Gas and

Resealed

$\begin{cases}4 . x & x \\ 5 . & x \\ 6 . & x\end{cases}$

Close Packed Fuel Rods

$\left\{\begin{array}{lllll}7 . & x & & & x \\ 8 . & x & & & x \\ 9 . & & x & & x \\ 10 . x & & & x & \\ 11 . & x & & x & \\ 12 . & & x & x & \end{array}\right.$

Rods Chopped and Immobilized in Matrix Material

13.

$x$

$X$

$\begin{array}{ll}x & x \\ x & x \\ x & x\end{array}$

$\begin{array}{lll}X & 260 & 2 \\ X & 260 & 2 \\ X & 225 & 1 \\ X & 260 & 2 \\ X & 260 & 2 \\ X & 225 & 1\end{array}$

\footnotetext{
a Actual temperature may be lower if a suitable stabilizer with a greater thermal conductivity than used in the calculations is found. Thermal conductivities used were the lowest in Table 19 for any generic stabilizer type. solid poured stabilizer between the bundle and the canister.
} 


\section{FUEL FORM ASSESSMENT FOR BREACHED WASTE PACKAGE}

\section{A. STABILIZER AND WASTE FORM GEOMETRY EFFECTS ON RADIONUCLIDE RELEASE RATES}

A simplified model of barrier breakdown and radionuclide transport out of the waste form has been developed in order to quantitatively compare the release characteristics of various geometric arrangements of the waste form/ stabilizer combinations. This model, summarized in Appendix $C$, is not sufficiently mechanistically detailed to predict absolute release rates, and it is useful only in comparing different waste form geometries made up of physically similar components. A radionuclide is defined to be released at the time it starts to traverse the remains of the canister wall.

\section{General Assumptions}

Since the purpose is to compare various alternative geometries rather than to calculate absolute release rates, assumptions regarding geology and physical properties of materials have been made on the basis of what is reasonable or expected rather than limiting cases. The characteristics of LWR fuel assemblies pertinent to this analysis are shown in Table 23.

The long-term leach rate of radionuclides from the spent fuel material was assumed to be controlled by the dissolution rate of $\mathrm{UO}_{2}$ and taken to be $10^{-5} \mathrm{~g} / \mathrm{cm}^{2}$ day $(21,22$ ) (a volumetric release rate of approximately $10^{-11} \mathrm{~cm}^{3} / \mathrm{cm}^{2} \mathrm{~s}$ ). This is based on the exposed geometric surface area of cracked irradiated fuel in cladding. The source formulation for the fission products in the gap was assumed to include zero internal resistance to transport. The fraction of solid fission products residing in the gap would be highly variable; however, for purposes of this analys is, $10 \%$ of the solid fission products was assumed to be in the gap.

Zircaloy-2 cladding corrosion in brine at $250^{\circ} \mathrm{C}$ has been measured at approximately $10^{-3} \mathrm{~mm} / \mathrm{y}^{(24)}$ based on a maximum credible temperature in a salt repository. This temperature is much higher than temperatures expected 
PERTINENT PHYSICAL CHARACTERISTICS OF

REFERENCE CASE LWR FUEL ASSEMBLIES (23)

REACTOR TYPE

Fuel Rod Array

Rod Pitch $(\mathrm{cm})$

Number of Fueled Rods

Active Fuel Length $(\mathrm{cm})$

Rod Diameter $(\mathrm{cm})$

Cladding Thickness (mm)

Pellet Diameter $(\mathrm{cm})$

Radial Gap (mm)
PWR

$17 \times 17$

1.26

264

365.8

0.95

0.57

0.819

0.084
BWR

$8 \times 8$

1.63

62

375.9

1.23

0.81

1.041

0.12 
when the canister has breached, however. Data for corrosion of Zircaloy-2 in water as a function of temperature ${ }^{(25)}$ indicate that the corrosion rate would probably be one to two orders of magnitude less for temperatures $\left(\sim 150^{\circ} \mathrm{C}\right)$ expected at the time of claddina attack. Therefore, the cladring corrosion rate in the model was assumed to be $10^{-4} \mathrm{~mm} / \mathrm{y}$.

The internal pressure in unvented PWR fuel pins is assumed to be approximately $600 \mathrm{psi}^{(13)}$ and would he expected to cause claddina failure before the tube wall is completelv corroded. Although a wall thickness of about $7 \%$ of the initial value would be sufficient to contain the oressure, based on an ultimate strength of $70 \mathrm{ksi}$, (13) it is assumed here that the wall fails at $20 \%$ of its oriqinal thickness to allow for non-uniform corrosion and possible cladding flaws. Unvented BWR rods are assumed to fail at $10 \%$ of original cladding wall thickness because of the lower pressure. (13) The geometric area available for transport through the failed cladding for the pressurized rod case is based on the assumption that the initial breach size is approximately $0.1 \mathrm{~mm}$ in diameter.

A reasonable value for radionuclide transoort speed was assumed to be $4 \times 10^{-6} \mathrm{~cm} / \mathrm{s}$ based on thermally driven ground water motion through typical repository basalt in the volume immediately surroundina the canister. $(26)$ The barrier resistance of the cladding was assumed to decrease linearly from the initial value at the time of claddina breach to the minimum value corresponding to the above transport speed at the time when the cladding is completely consumed by uniform corrosion. Vented and resealed fuel rod cladding is assumed to fail when uniform corrosion completely penetrates the cladding wall thickness.

The radionuclide retardation effect of the corroded barriers do not, anpear to be significant over the short distances inside the canister and the time scales involved. The transport retardation effects of the harrier remains have, therefore, not been included in this model. 
For the intact fuel case, the stabilizer (if present) was assumed to be a solid metallic material with properties similar to those of lead. The uniform corrosion rate of this material in water was assumed to be $5 x$ $10^{-2} \mathrm{~mm} / \mathrm{y}$ based on $2.5 \times 10^{-3} \mathrm{~mm} / \mathrm{v}$ in water at room temperature ${ }^{(27)}$ and $5 \times 10^{-1} \mathrm{~mm} / \mathrm{y}$ in brine at $250^{\circ} \mathrm{C}(24)$ for lead.

\section{Case 1: Close-Packed Rods}

The fuel rods are assumed to be removed from the subassemblv and packed into the canister. If the rod bundle is compacted with straps prior to insertion into the canister, a small space next to the canister wall could be filled with stabilizer. Such a laver of stabilizer would have the effect of delaying entry of water into the fuel rod volume by about 200 years per $\mathrm{cm}$ of thickness. It is assumed that all the fuel rods in the close-packed bundle are exposed to water simultaneously when the canister (or the thin stabilizer laver) breaches at time $t=0$, and that all rods behave the same with time.

As soon as the fuel is exposed, it begins to transport out of the fuel rods through the failed claddina accordina to the model qiven in Appendix $B$. The source characteristics of the fission products in the fuel matrix and in the fuel-cladding qap are given in Table 24. Notice that the source concentrations have been normalized to be fractions of the total solid fission product inventory in the rod. The resulting release rates are, therefore, fractional release rates of the total inventory.

The cladding transport resistance characteristics are given in Table 25. Since the water must penetrate and exit the cladding, the barrier areas for transport are one half the circumferential area of the cladding tubes. The cladding transport resistance is assumed to vary linearly between time $t_{1}$ and $t$ ime $t_{2}$ (the unvented rod case).

The resulting individual source responses for the PWR are qiven as an examole in Table 26. The total fractional release rates as functions of 


\section{TABLE 24}

\section{SOURCE CHARACTERISTICS FOR THE}

CLOSE-PACKED ROD CASE

\begin{tabular}{|c|c|c|c|}
\hline SOURCE & ITEM & $\underline{\text { PWR }}$ & BWR \\
\hline \multirow[t]{4}{*}{ fuel matrix } & $\begin{array}{l}\text { exposed fuel area } \\
\text { per rod }\end{array}$ & $942 \mathrm{~cm}^{2}$ & $1230 \mathrm{~cm}^{2}$ \\
\hline & $\begin{array}{l}\text { source internal } \\
\text { resistance }\end{array}$ & $1.06 \times 10^{8} \mathrm{~s} / \mathrm{cm}^{3}$ & $8.13 \times 10^{7} \mathrm{~s} / \mathrm{cm}^{3}$ \\
\hline & source capacity & $193 \mathrm{~cm}^{3}$ & $321 \mathrm{~cm}^{3}$ \\
\hline & $\begin{array}{l}\text { initial source } \\
\text { concentration }\end{array}$ & $4.66 \times 10^{-3} / \mathrm{cm}^{3}$ & $2.80 \times 10^{-3} / \mathrm{cm}^{3}$ \\
\hline \multirow[t]{3}{*}{ gap material } & $\begin{array}{l}\text { source internal } \\
\text { resistance }\end{array}$ & 0 & 0 \\
\hline & source capacity & $7.9 \mathrm{~cm}^{3}$ & $14.8 \mathrm{~cm}^{3}$ \\
\hline & $\begin{array}{l}\text { initial source } \\
\text { concentration }\end{array}$ & $1.27 \times 10^{-2} / \mathrm{cm}^{3}$ & $6.76 \times 10^{-3} / \mathrm{cm}^{3}$ \\
\hline
\end{tabular}


TABLE 25

\section{CLADDING TRANSPORT RESISTANCE CHARACTERISTICS}

\begin{tabular}{|c|c|c|}
\hline$\underline{\text { ITEM }}$ & $\underline{\mathrm{PWR}}$ & BWR \\
\hline transport speed & $4 \times 10^{-6} \mathrm{~cm} / \mathrm{s}$ & $4 \times 10^{-6} \mathrm{~cm} / \mathrm{s}$ \\
\hline transport area & $546 \mathrm{~cm}^{2}$ & $725 \mathrm{~cm}^{2}$ \\
\hline $\begin{array}{l}\text { time to initiala } \\
\text { breach }\left(t_{1}\right)\end{array}$ & $\frac{1.44 \times 10^{11} \mathrm{~s}}{(4560 \mathrm{y})}$ & $\begin{array}{l}2.30 \times 10^{11} \mathrm{~s} \\
(7290 \mathrm{y})\end{array}$ \\
\hline $\begin{array}{l}\text { initial geometric } \\
\text { parameter }(x) \text { at } t=t_{0}\end{array}$ & $10^{6}$ & $10^{6}$ \\
\hline $\begin{array}{l}\text { time to } c l \text { add ing } b \\
\text { destruction }\left(t_{2}\right)\end{array}$ & $\begin{array}{l}1.80 \times 10^{11} \mathrm{~s} \\
(5700 \mathrm{y})\end{array}$ & $\begin{array}{l}2.56 \times 10^{11} \mathrm{~s} \\
(8110 \mathrm{y})\end{array}$ \\
\hline $\begin{array}{l}\text { transport resistance } \\
\text { at } t=t_{1}\end{array}$ & $4.58 \times 10^{8} \mathrm{~s} / \mathrm{cm}^{3}$ & $3.45 \times 10^{8} \mathrm{~s} / \mathrm{cm}^{3}$ \\
\hline $\begin{array}{l}\text { transport resistance } \\
\text { at } t=t_{2}\end{array}$ & $4.58 \times 10^{2} \mathrm{~s} / \mathrm{cm}^{3}$ & $3.45 \times 10^{2} \mathrm{~s} / \mathrm{cm}^{3}$ \\
\hline
\end{tabular}


TABLE 26

EXAMPLE OF INDIVIDUAL SOURCE CONTRIBUTIONS (PWR, PRESSURIZED RODS)

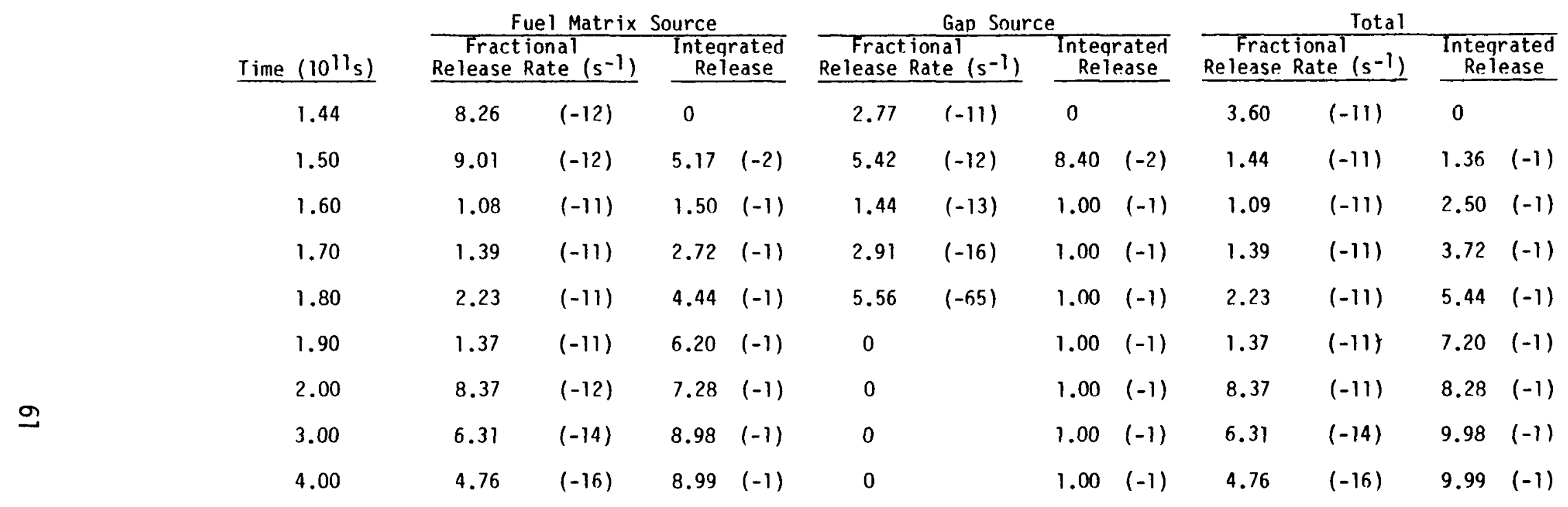


time are plotted in Figure 7 for both the PWR and the BWR cases with unvented (pressurized) rods. The peak at time of initial cladding breach is due to the rapid release of the highly mobile fission products in the qap which are quickly depleted. The following build-up and peak at time $t_{2}$ corresponds to the matrix fuel leaching and dissolution as the cladding completely fails. The exponentially decaying tail after time $t_{2}$ indicates depletion of the fission products in the fuel matrix. It should be carefully noted that the release rates are not corrected for radioactive decay since this would require more specific information than is contained in the general model.

In the case of vented and resealed fuel rods, the cladding is assumed to have an infinite transoort resistance up to time $t_{2}$ when the claddina is completely corroded. The claddina barrier characteristics after time $\mathrm{t}_{2}$ are given in Table 25. The resulting release rates are shown in Fiaure 8. Notice that very high peak release rates occur as the aap material is released over a relatively short time span.

Since, in this case, all rods in the canister are assumed to he equivalent, the fractional release rates just derived can be applied to the contents of the canister as a whole and are independent of the number of fuel rods in the package.

\section{Case 2: Intact Assembly}

An intact subassembly is placed in the center of a canister which is then filled with a stabilizer. If the stabilizer is a qas or a particulate material, it will have little barrier function, and the response of the waste form will be identical to that in Case 1. If, however, a solid stabilizer is used, it will provide some time delay before the cladding is attacked.

The subassembly was divided into seven equally spaced circular zones as shown in Figure 9. The rods in anv particular zone were assumed to he equivalent. The zones are sequentiallv attacked as the stabilizer corrodes inward. As previously mentioned, the solid stabilizer is assumed to have 


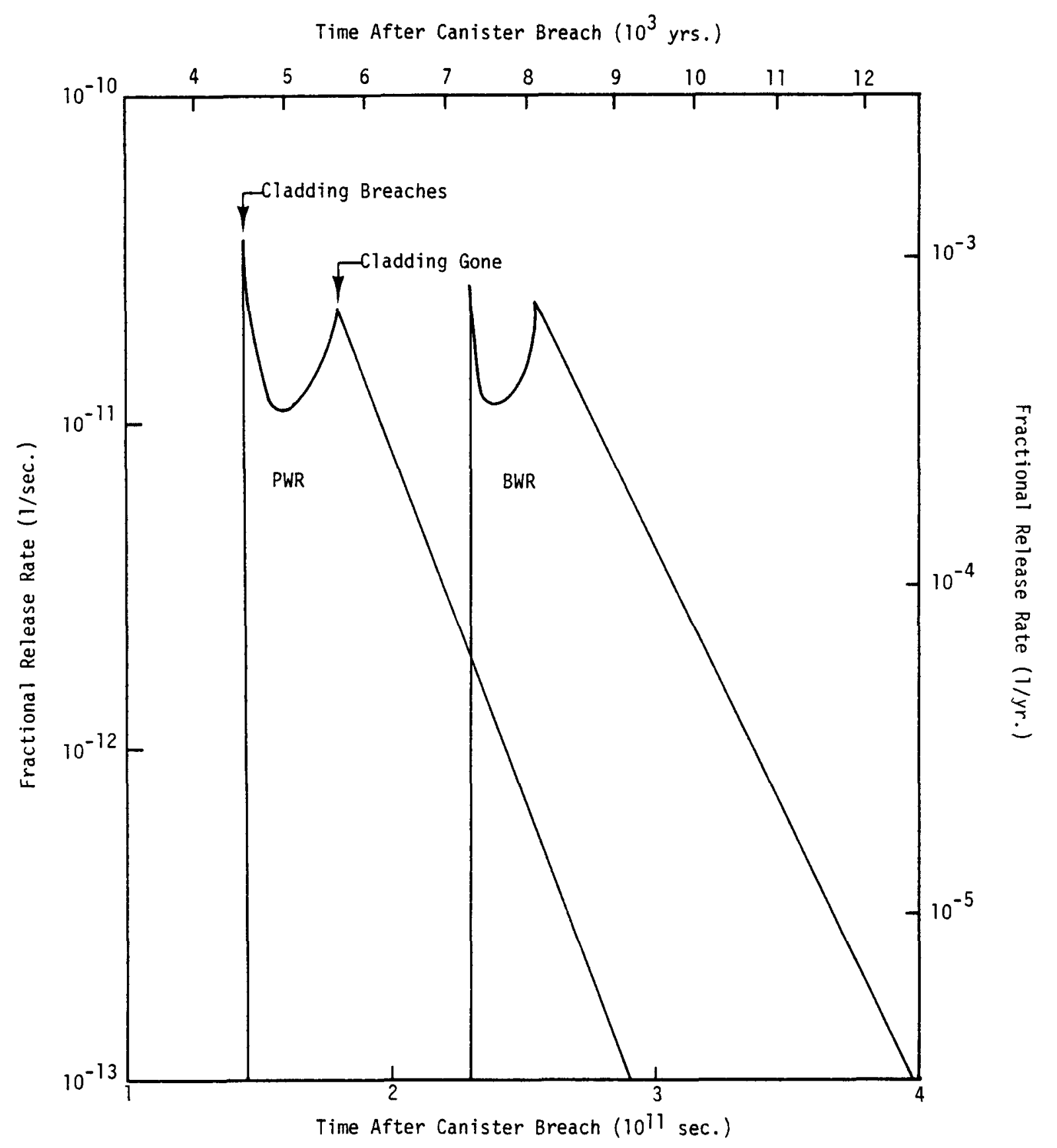

FIGURE 7. Individual Rod Fractional Release Rates for Unvented (Pressurized) Rods. 


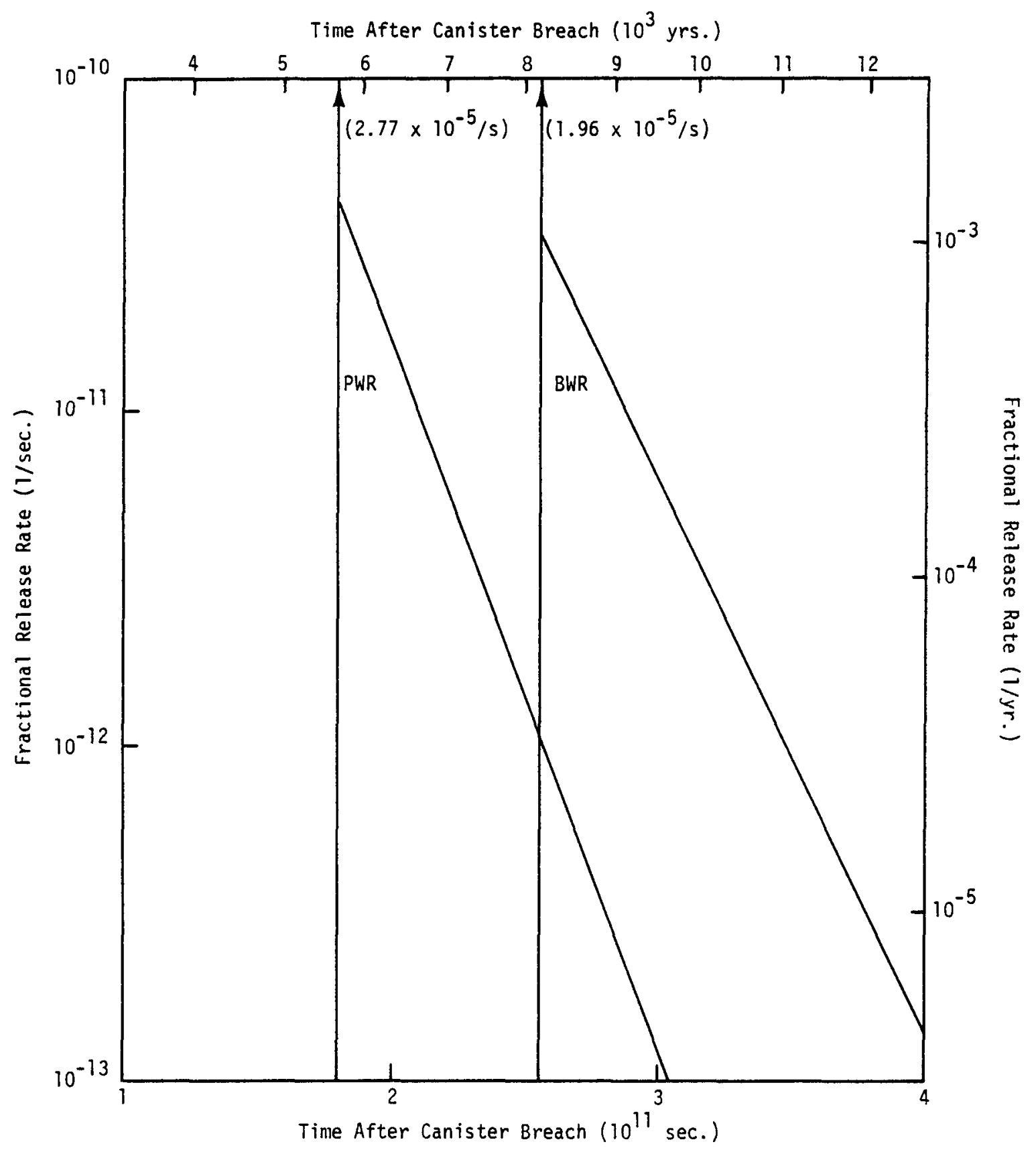

FIGURE 8. Individual Rod Fractional Release Rates for Vented and Resealed Rods. 


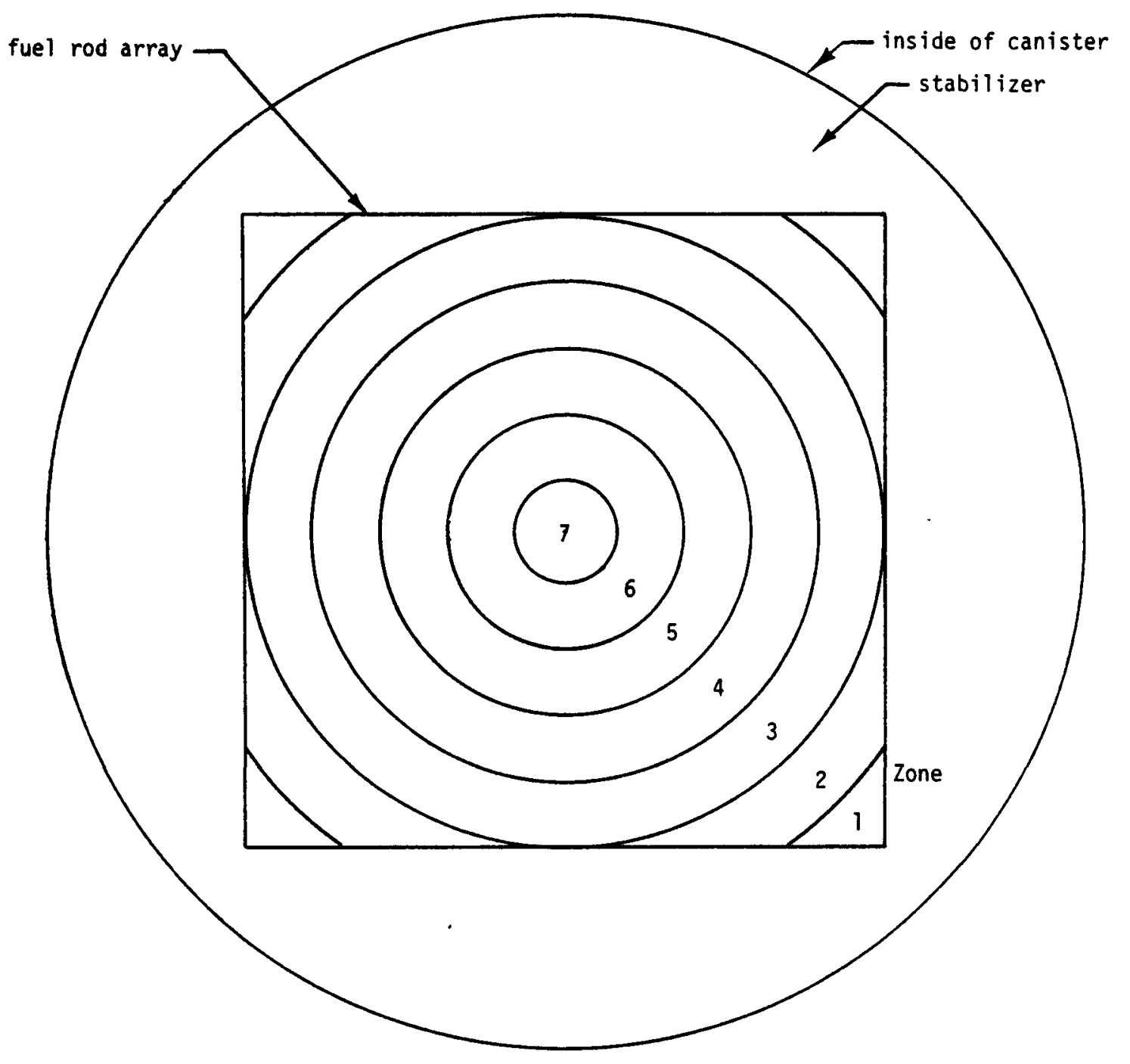

FIGURE 9. Zone Placement for Analys is of Intact Subassembly with Solid Stabilizer (PWR). 
properties similar to lead and to corrode at the rate of $5 \times 10^{-2} \mathrm{~mm} / \mathrm{v}$. Assuming the inside radius of the canister to be $17.2 \mathrm{~cm}$ (see Table 5), the time required for the ground water to reach the center of the canister is about $1.1 \times 10^{11} \mathrm{~s}(3430 \mathrm{y})$. The time to reach the outer edqe of the fue 1 rod array is about $1.4 \times 10^{10} \times \mathrm{s}(445 \mathrm{y})$ for the PWR and $5.2 \times 10^{10} \mathrm{~s}$ (1640 y) for the BWR.

Because of the larqe transport area associated with the stabilizer remains, the transport resistance due to the failed stabilizer was generally found to be small compared to the resistances due to the fuel rods themselves and was not included. As mentioned previously, however, this barrier would introduce a transport time delay which would depend on the local details including transport speed and retardation factor for the particular radionuclide of interest. The first pins at the corners of the subassembly begin to breach at about $1.6 \times 10^{11} \mathrm{~s}(5070 \mathrm{v})$ at which time the stabi1izer has long since corroded awav.

The release responses for the rods in each of the array zones were summed and the resulting curve smoothed. The resulting fractional release rate is shown in Fiqure 10. This fractional release rate is based on the total fission product inventory in the subassemblv. The correspondina release function for the case of a BWR subassembly is exnected to be much the same except for a time delay (due to the thicker cladding) similar to that shown in Figure 7.

A comparison of Figure 7 with Fiqure 10 indicates that the case of a single subassembly in a solid stabilizer offers no substantial reduction in peak release rate over that predicted for the close-packed case. The stabilizer does, however, produce a net time delay of about 2000 years for the single PWR subassembly case.

\section{Case 3: Chopped Fuel in Stabilizer}

The fuel rods are assumed to be removed from the subassemblv, chopped into short pieces, and dropped into a basket which fits into the canister. 


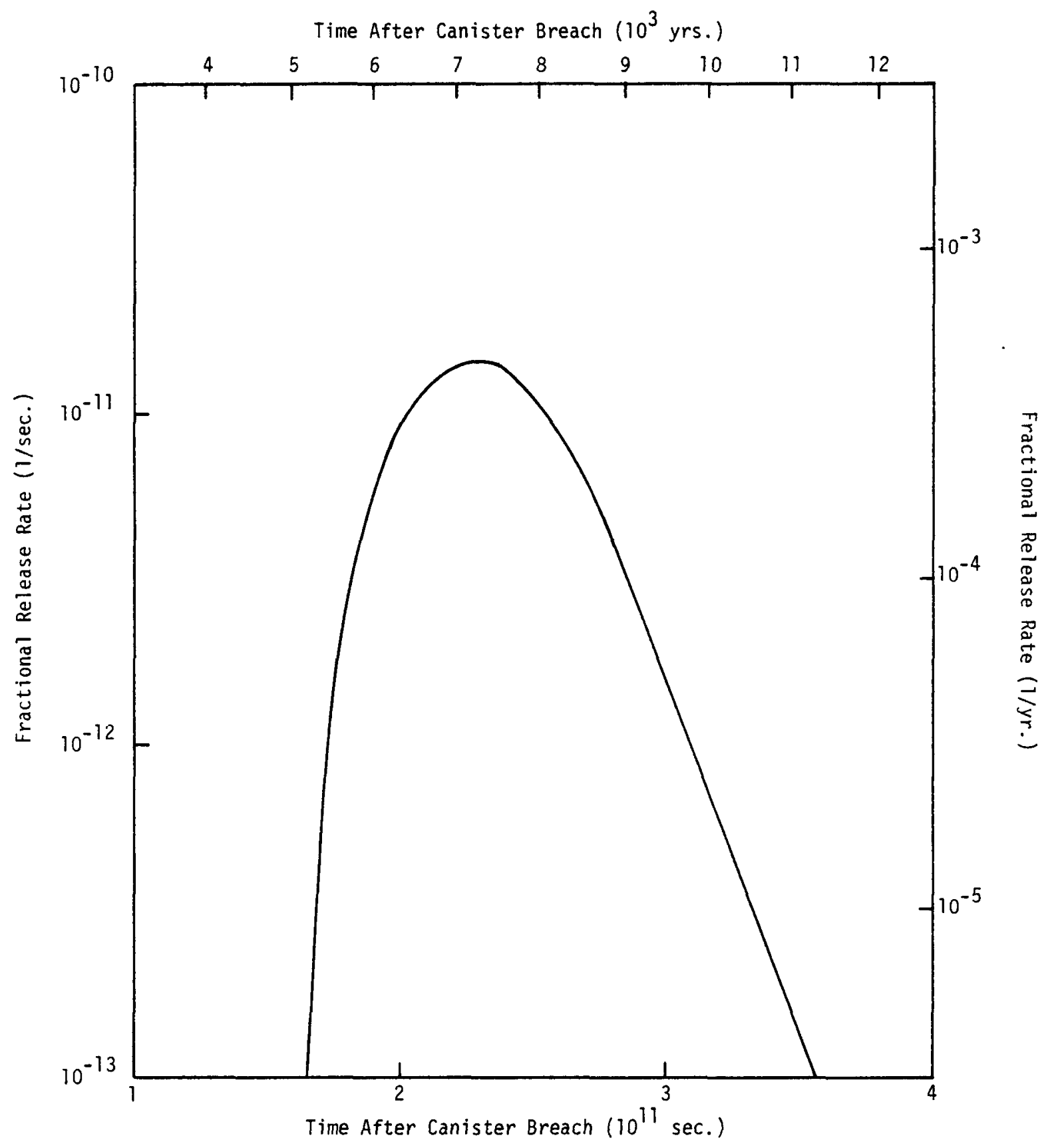

FIGURE 10. Fractional Release Rate for an Unvented PWR Assembly in a Solid Metallic Stabilizer. 
A stabilizer, assumed to be a qlass with suitable characteristics, then fills the canister. The corrosion properties of different qlasses varv considerably; however, for purposes of this analysis, a typical value of about $2 \times 10^{-12} \mathrm{~g} / \mathrm{cm}^{2} \mathrm{~s}$ was chosen, (28) leading to an equivalent volumetric removal rate of approximately $1 \times 10^{-12} \mathrm{~cm}^{3} / \mathrm{cm}^{2} \mathrm{~s}$ (as compared with $1 \times 10^{-11}$ $\mathrm{cm}^{3} / \mathrm{cm}^{2} \mathrm{~s}$ for $\left.\mathrm{UO}_{2}\right)$.

It was assumed that the chopped fuel and the stabilizer inside the hasket were homogenized into a composite material which corrodes at the same rate as $U_{2}$, i.e., $1 \times 10^{-11} \mathrm{~cm}^{3} \mathrm{~cm}^{2} \mathrm{~s}$. Furthermore, it is assumed that chopping the fue 1 reduces $25 \%$ of the $\mathrm{UO}_{2}$ and fission products to a powdered or granulated material (fines) which mixes uniformly with the stabilizer as it is pumped into the canister. The inside radius of the canister is assumed to be $21.6 \mathrm{~cm}$ (see Table 5) and the stabilizer filled space between the canister wall and the caqe is assumed to be $1 \mathrm{~cm}$ wide. Twn subcases will be considered here: (a) that the radionuclides in the fuelcladding gap remain in the qap during the stabilizer fill and cooling process and (b) that the fuel-cladding qap material exits the qap and mixes uniformly with the stabilizer material during fabrication.

The resulting source concentrations (normalized to total canister inventory) are given in Table 27. These concentrations are based on the currently proposed canister dimensions for the chopped fuel case. The resulting release rates are shown in Fiqure 11 . It should be noted that the low release rates indicated depend on the optimistic assumption that the glass stabilizer is completelv intact (i.e., uncracked).

To determine the possible effect of an extensivelv cracked stabilizer glass, subcase (a) was recalculated, assuming the stabilizer was nermeable with $1 \%$ of its cross-section available for transport. All the chopped fuel rod pieces are exposed at the time of canister breach. The resulting release rate is shown in Figure 12 . The initial spike at time $t=0$ is due to the sudden release of the material in the fuel cladding qao. If all the material from the gap were dissolved in the matrix (subcase (b)), the response would be very similar except that the initial spike would be absent. 


\section{TABLE 27}

SOURCE CONCENTRATIONS FOR THE CHOPPED FUEL CASE*

\begin{tabular}{|c|c|c|}
\hline I TEM & Subcase (a) & Subcase (b) \\
\hline $\begin{array}{l}\text { fraction of inventory } \\
\text { in stabilizer }\end{array}$ & 0.25 & 0.325 \\
\hline $\begin{array}{l}\text { concentration in } \\
\text { stabilizer }\left(/ \mathrm{cm}^{3}\right)\end{array}$ & $4.36 \quad(-7)$ & $5.67 \quad(-7)$ \\
\hline $\begin{array}{l}\text { fraction of inventory } \\
\text { in fuel chunks }\end{array}$ & 0.75 & 0.675 \\
\hline $\begin{array}{l}\text { homogenized concentration } \\
\text { in fuel chunks }\left(/ \mathrm{cm}^{3}\right)\end{array}$ & $1.44 \quad(-6)$ & $1.30 \quad(-6)$ \\
\hline $\begin{array}{l}\text { total concentration } \\
\text { inside cage }\left(/ \mathrm{cm}^{3}\right)\end{array}$ & $1.88 \quad(-6)$ & $1.87 \quad(-6)$ \\
\hline
\end{tabular}




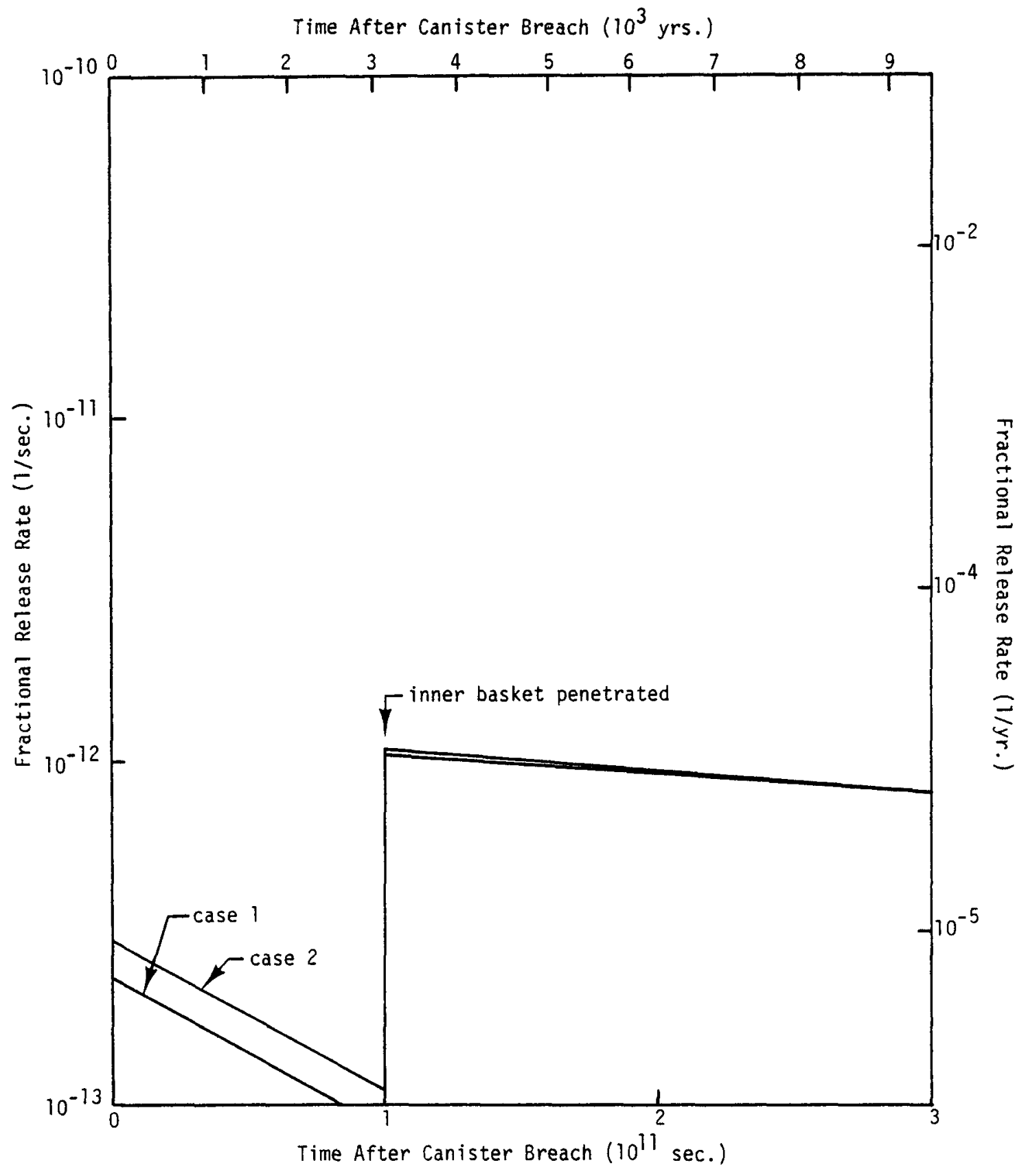

FIGURE 11. Release Rates for Chopped Fuel in Uncracked Stabilizer. 


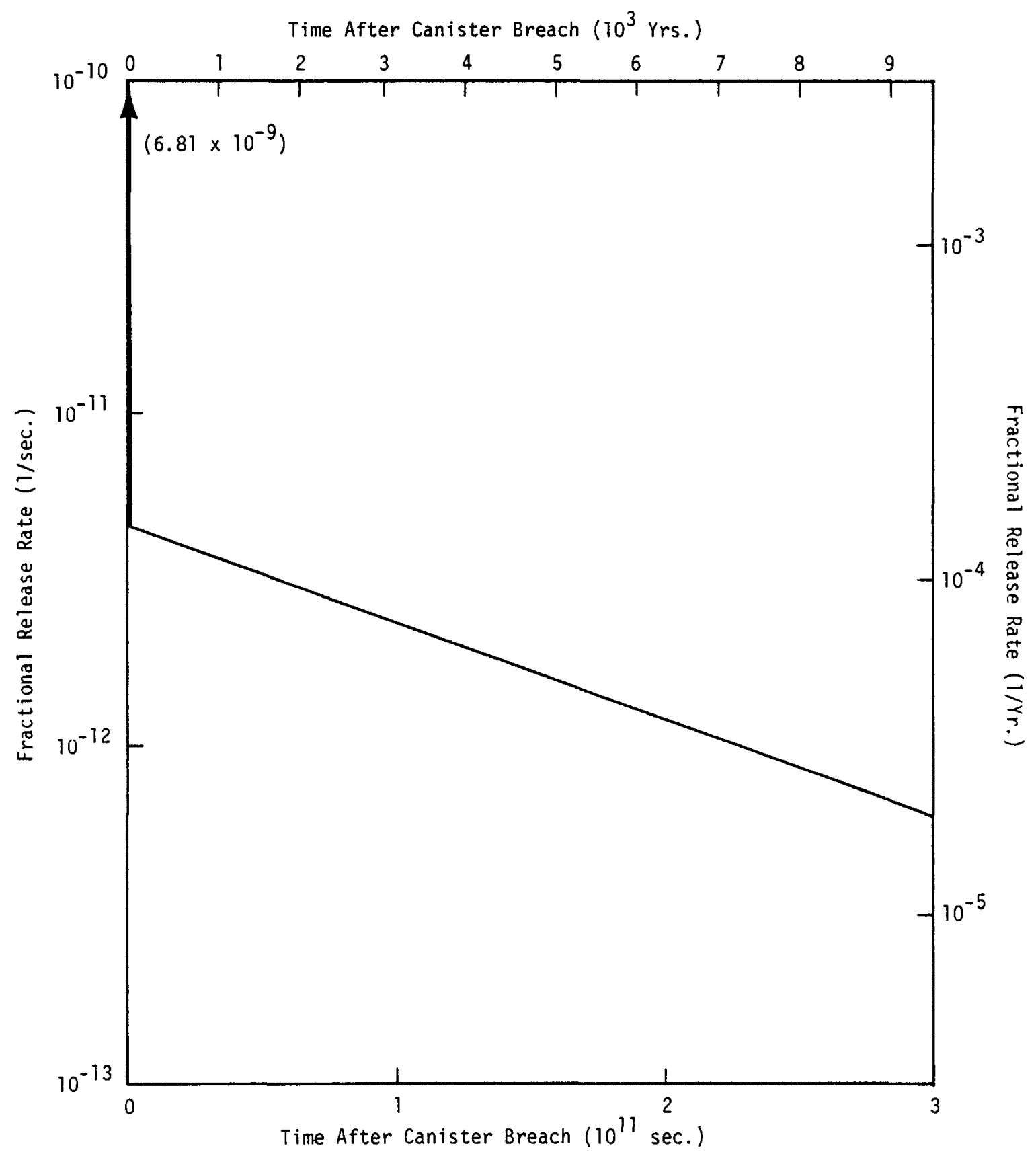

FIGURE 12. Release Rate for Chopped Fuel in Cracked Stabilizer. 


\section{Discussion of Results}

Initial release rate spikes associated with the sudten release of gap fission products were observed in the close-backed unpressurized rod cases and in the chopped fuel case with cracked stabilizer. These very high instantaneous release rates, shown in Fiqures 8 and 12, are artifacts of the model assumptions and would probably be reduced hy several orders of magnitude by probabilistic and internal transport delay mechanisms not included in this model. For example, the release rates indicated in Fiqure 8 imply that all the gap material is released within a few hours of cladding breakdown. In reality, all the fuel rods would not fail at one time, and the cladding on any given rod would not corrode uniformly. This could easily extend the release period for the qap material over several years, thereby reducing the peak release rate by about 4 orders of magnitude. In addition, the radionuclide retention in the stabilizer remains due to adsorption has not been included. This would, again, possiblv reduce the apparent release rate from the waste form. The presence of those release rate soikes should not, therefore, be used as a basis of rating the qeneral release rates of the various waste forms.

It is apparent that the release rates for all the waste forms considered are comparable with none havina any obvious superiority. The only important difference is the delay time between canister breach and onset of release. Several important points are evident:

1. The 4000 to 8000 year time delav before onset of release is due mainly to the presence of the intact cladding.

2. A metallic stabilizer in the sinale subassembly case (case 2) mav add 1000 to 2000 years to the delay time.

3. The chopped fuel in a cracked stabilizer produces zero time delay because of the absence of an intact cladding barrier.

Since the fission product activity at times after the thermal period ( 1000 years) is due to long lived isotopes, the time delavs produced hy the intact 


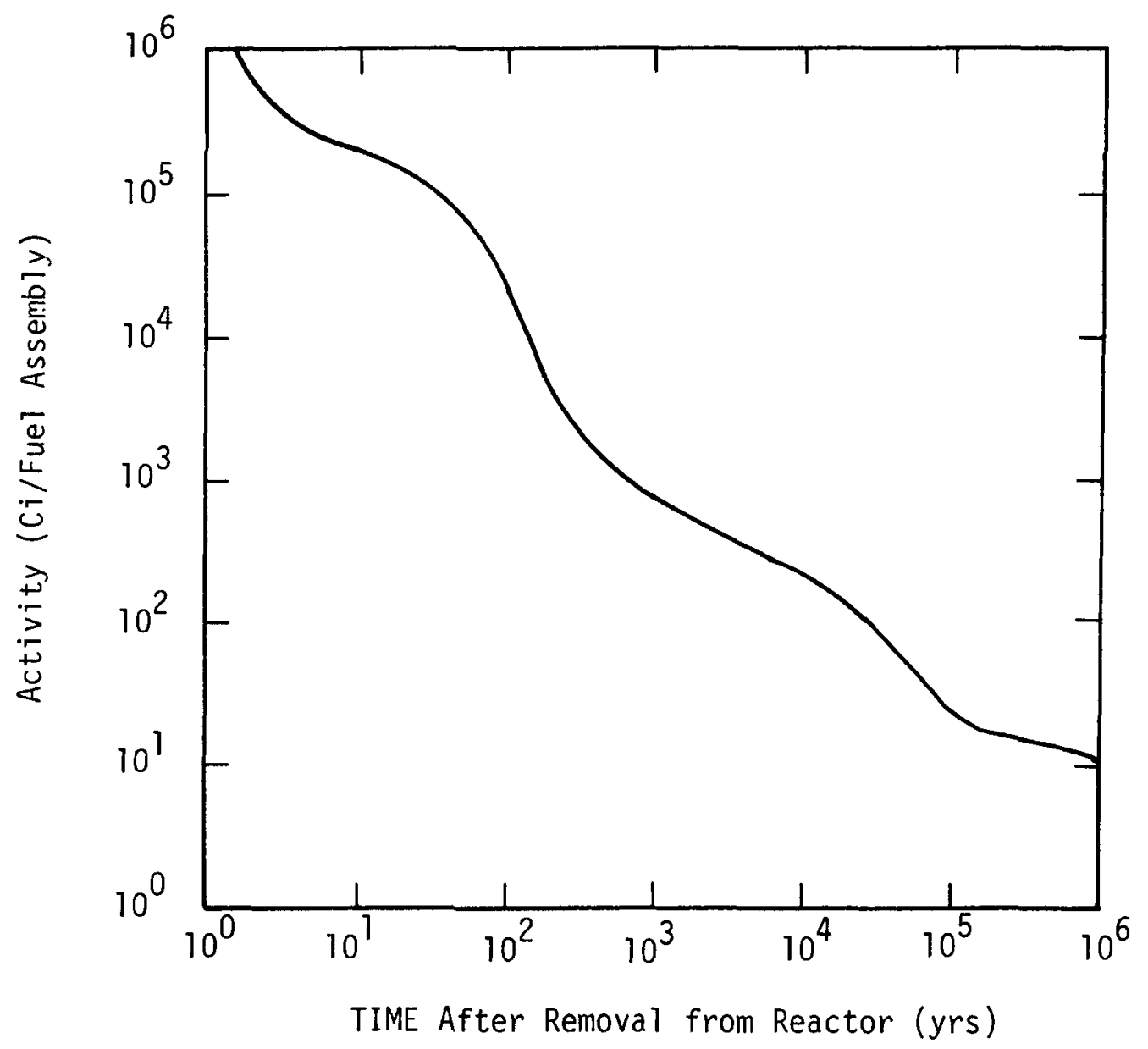

FIGURE 13. Total Radioactive Decav of PWR Spent Fuel. (27) 
cladding do not produce a larqe reduction in activity released, as shown in Figure 13. (29) If the canister were to breach prematurely during the time when short-lived radionuclides dominate, however, a built-in time delay of a few thousand years to onset of release would become a critical safetv factor.

The release characteristics of the various waste forms, once the cladding is breached, is dominated by the internal resistance of the fuel matrix source, i.e., the leaching characteristics of the fuel. Anv degradation of the fuel prior to canister breach could drasticallv affect the absolute leaching characteristics and, hence, the overa 11 performance of the waste form. It is important, therefore, to maintain cladding integrity prior to canister breach, since breach of the cladding (e.q., chopping the fuel) would lead to larqe uncertainties in the state of the fuel pellet after the waste package breaches.

The overall ratings of the waste forms based on release characteristics is shown in Table 28. The chopped rod case is down-rated because of the uncertainties in fuel state due to loss of cladding integrity and also because of lack of time delay before onset of release in the case of a premature canister breach.

\section{B. CRITICALITY}

It is necessary for water to inundate the canister in order for there to be sufficient moderation for criticalitv to occur. It is not a sufficient condition, since some highly unlikely as vet unidentified event must occur to cause the fuel to rearrange shape. One must consider the question of criticality, though, since until the burnup of LWR fuel exceeds anproximatelv 20 GWD/MTU, $(30-33)$ there is enough fissile material in a sinale assemblv to go critical if the correct ratio of fuel to moderation is allowed to occur. Steps should be taken to prevent criticalitv from occurring in the repository. If criticality occurred, the heat load of the repository would be increased at least an order of maqnitude (at shut down, decay heat produces $7 \%$ of a reactor thermal load) and the radiation field would also be 


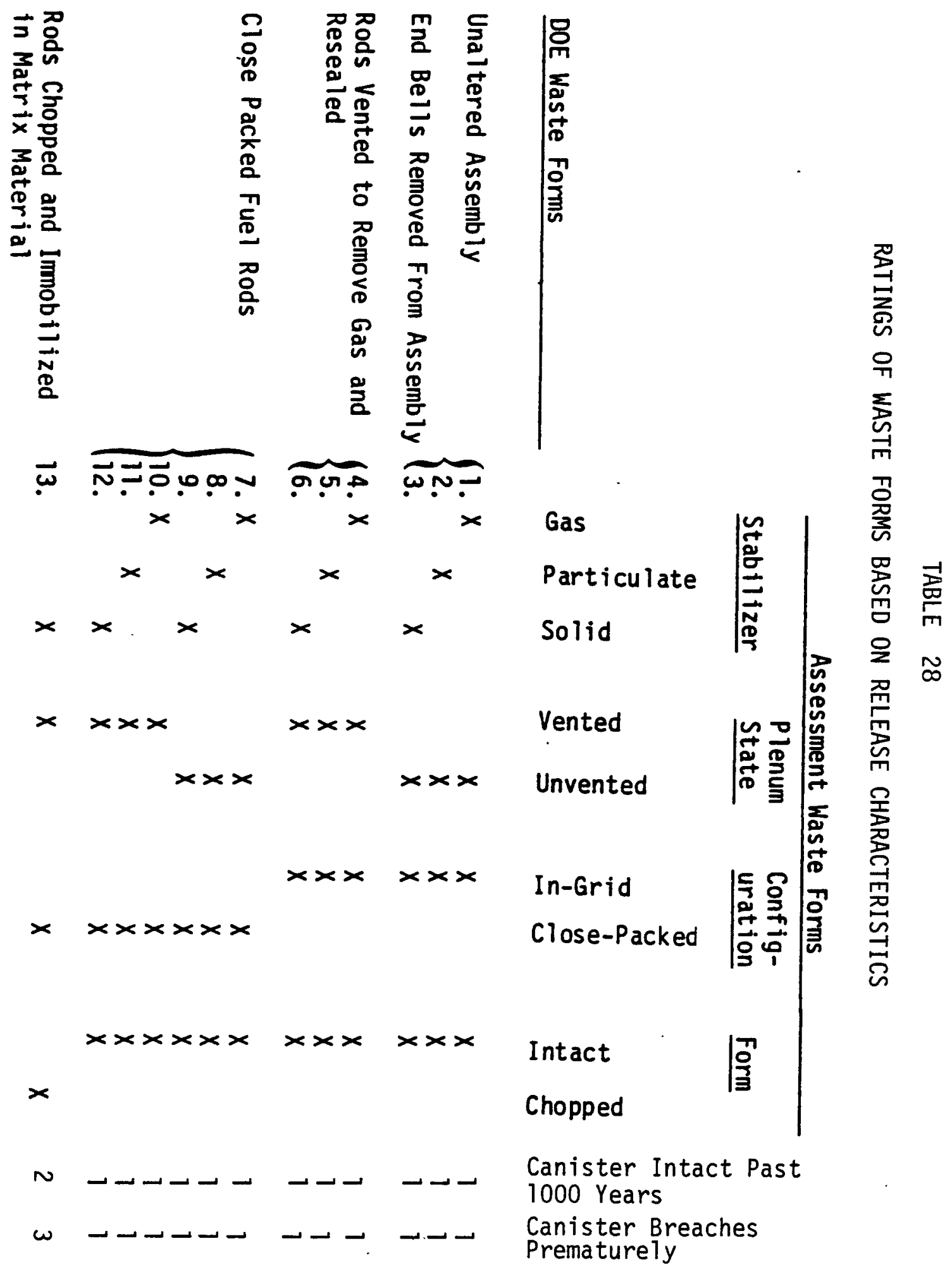


significantly larger. Besides the generation of gas due to radiolysis and radiation damage to the package components, the integrity of the package and repository must be reassessed at the higher temperature. In addition, the arguments based on eventual decay of the spent fuel to the activity levels of natural uranium are no longer valid, since new short-lived isotopes will be generated.

Battelle has studied the question and concluded that for certain configurations of fuel ${ }^{(30-33)}$ there is a possibility of criticality occurring. These results were considered further, since they represented highiy improbable and ideal situations. An independent assessment of the BNWL criticality calculations ${ }^{(30-33)}$ was made under more plausible scenarios to evaluate the criticality possibility.

The calculations were made with the KENO-IV Monte Carlo code ${ }^{(33)}$ and compared to the $B N W L$ results to provide verification of the present calculations. Although small differences are apparent, the BNWL studies are expected to be more accurate, since their detailed pin cell calculations provide better effective cross sections. General trends should remain unchanged.

\section{General Sensitivities}

The Battelle calculations and those conducted at HEDL permit a number of simplifications to be made to an otherwise complex multivariable problem. First, for a reasonably long cylinder $\left(\frac{\text { length }}{\text { diameter }}>10\right)$, the length of the cylinder is relatively unimportant, so that geometry effects can be discussed in the context of only the cylinder diameter. For the same reason, the absolute amount of fissile material is unimportant; only its homogenized density is pertinent. Secondly, hydrogen moderation is very important, so that the hydrogen-to-uranium ratio is an important variable. These considerations lead to the representation of criticality parameters shown in Figure 14.

Figure 14 displays $k_{\text {eff }}$ as a function of the volume of water to volume of $\mathrm{UO}_{2}$ ratio: 


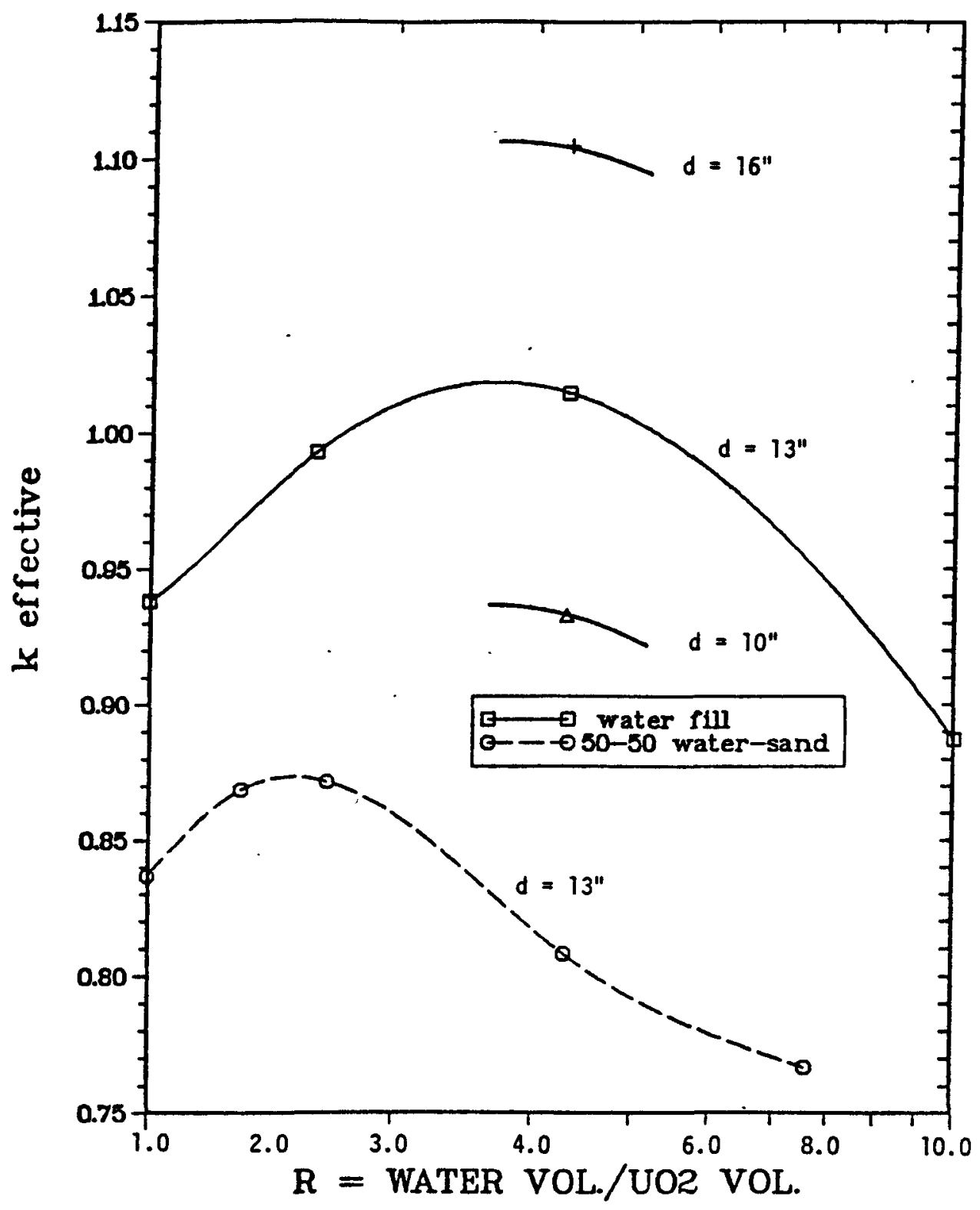

FIGURE 14. Keff as a Function of the $\mathrm{H}_{2} \mathrm{O}$ Volume to $\mathrm{UO}_{2}$ Volume Ratio and for Different Cylinder Diameters, $d$.

(Note: for each curve, both the water and uranium oxide volumes are varied to fill homogeneously the entire canister volume). 


$$
\mathrm{R}=\mathrm{V}_{\mathrm{H}_{2}} \mathrm{O} / \mathrm{V}_{\mathrm{UO}}
$$

Separate curves for $\mathrm{V}_{\mathrm{H}_{2} \mathrm{O}}+\mathrm{V}_{\mathrm{UO}}=$ constant are shown for different cylinder radii (10-in., 13-in., $\left.{ }^{2} 16-i n.\right)$ ? The base case results in Fiqure 14 were computed for the following conditions. $\mathrm{UO}_{2}$ and $\mathrm{H}_{2} \mathrm{O}$ are assumed to completely fill the cylinder and are homogenized over the entire cylinder. The outside of the canister cylinder is water reflected, and the fuel is fresh (no burnup) at $3.5 \%$ enrichment.

Battelle studies $(30-32)$ indicate that a volume ratio of water to uranium-oxide of about $R=3.3$ is optimally moderated for these conditions. The HEOL work is in aqreement with this conclusion. Battelle's ahsolute values of $k_{e f f}$ are sliahtly higher than HEDL results, but the densities are also slightly higher for the same postulated conditions.

Figure 14 shows that criticality is a definite possibility for the base case diameter of $d=13-i n$. if only fuel and water and some cladding are in the canister. For a single spent fuel assembly, the $\mathrm{H}_{2} \mathrm{O}$ and $\mathrm{UO}_{2}$ ratio is close to $R=5$ for dispersed fuel. Clearlv, a settling of fuel as the fuel pins disintegrate could drive this ratio towards the obtimum value near $R=3.3$. Moreover, if the canister disintegrated and, along with a shifting of the surrounding medium, allowed the effective homogenized radius to increase, then the system would become more reactive.

Since there is much more than a critical mass available, the surest way to avoid criticality appears to limit the amount of moderation due to water intrusion. One way is simoly to store more fuel in the canister, which leaves less room for water. But this approach, of course, increases the amount of fissile material so that if gross distortions of the geometrv at very long disposal times are considered, it becomes more difficult, to rule out criticality scenarios. A more obvious approach is to ensure the displacement of significant amounts of water hy an appropriate non-fissile filler. This is apparent in the "SAND" curve in Fiqure 14 where sand and 
water were assumed to occupy equal volumes. The value $R$ retains its meaning as the ratio $\mathrm{V}_{\mathrm{H}_{2}} \mathrm{O} / \mathrm{V}_{2}$. For a fixed volume, the sand replaces both water and $U$ for a fixed ratio $R$, thus sianificantlv lowering the reactivitv. These effects are noted for more specific cases helow.

\section{Specific Sensitivities}

Additional calculations were made to further define the effect of varving assumptions. The base case chosen was three close packed assemhlies within a 13-in. titanium shell (Fiqure 15) with sant and water fill hetween the spent fuel rods. Fiqure 14 shows this confiquration to he well subcritical as expected from the earlier discussion since the fuel and cladiing fills over half of the availahle canister volume. Also, as expected, the fuel with a burnup of 30,000 MWD/MTU further reduces the reartivity from the base case, which assumed fresh fuel. Finally, note that one assembly with water or water and sand intrusion is closer to being critical than three assemblies, as long as the geometry remains intact so that less space is available for water modification when three assemblies are included.

\section{Other Cases}

With this background, six cases noted below as possible spent fuel canister design concepts can be discussed.

\begin{tabular}{|c|c|c|c|}
\hline Case & Stabilizer & Confiquration \& Form & Number of Assemblies \\
\hline 1 & Gas & In-Grid & 1 \\
\hline 2 & Gas & Close Packed & 3 \\
\hline 3 & Particulate & In-Grid & 1 \\
\hline 4 & Particulate & Close Packed & 3 \\
\hline 5 & Sol id & In-Grid & 1 \\
\hline 6 & Solid & Close Packed \& Chopned & 2.28 \\
\hline
\end{tabular}




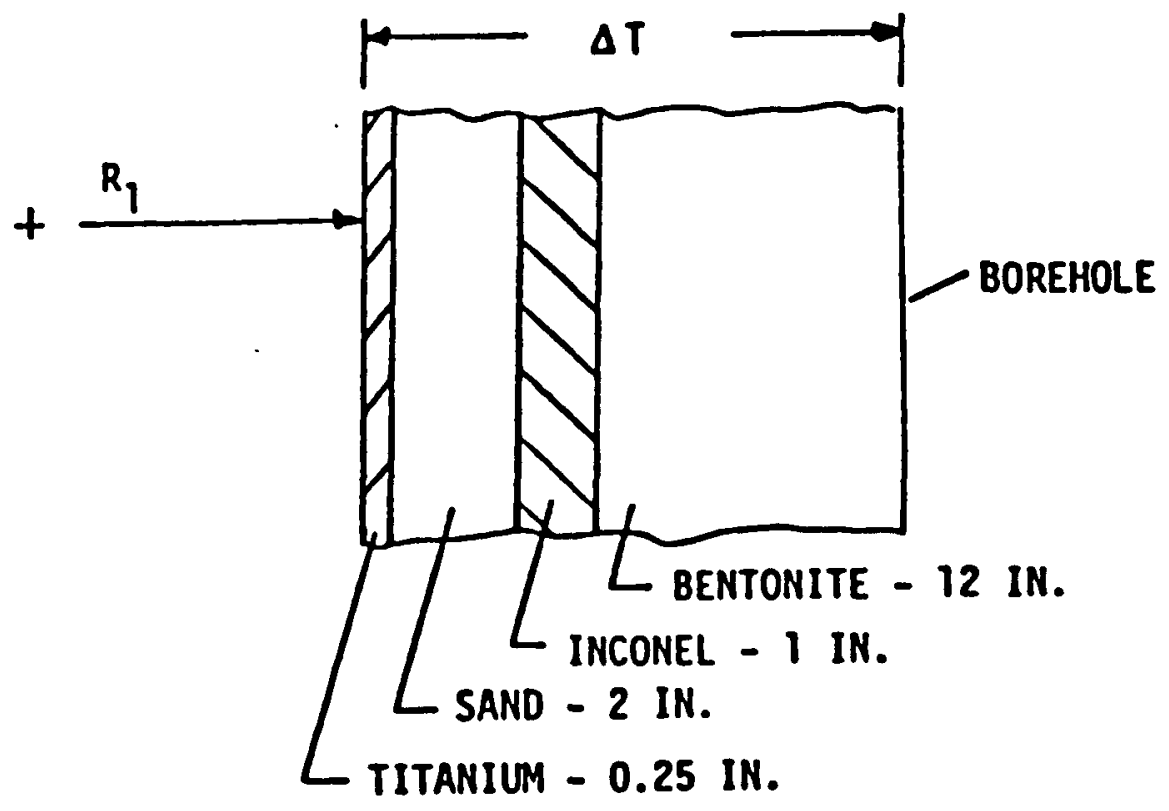

FIGURE 15. Spent Fuel Containment Configuration. 
From a criticality standpoint, the solid stabilizers are best not only because of their ability to resist water intrusion but also because they are less susceptible to configuration changes. In order to achieve criticalitv, not only does the stabilizer have to break down, but a rather unlikely separation of the stabilizer and fuel would also be required. The sand stabilizers are similar, except that configuration changes are more conceivable. For example, a slumping of three assemblies consisting of a water-sand mixture interspersed with disintegrated fuel could correspond to an expanded cylinder that would bring the curve shown for sand in Figure 14 closer to criticality. This scenario requires not only that the canister surroundings expand along with the disintegrated canister but also that additional sand and water enter the mixture to add the additional reactivity required to achieve an optimum $\mathrm{H}_{2} \mathrm{O} / \mathrm{UO}_{2}$ ratio. A sinqle assembly in sand is, in fact, initially closer to criticalitv (see Fiqure 16).

While the waste packaqe is intact and no water enters the canister, there is no criticality problem. After water enters the canister, there is the possibility of criticality occurring in the cases where there are intact assemblies with a gas stabilizer. Either a particulate or a solid stabilizer helps prevent criticality by limiting the amount of water that enters the canister. In addition, the solid stabilizer would prevent redistribution of the fissile material.

If one accounts for poisons in the burnt fuel, the criticality possibility is further reduced for all the cases, but this has not yet been allowed by the NRC. If one decreases the size of the canister which limits the water, then the possibility of criticality is also reduced.

For the purpose of ranking the thirteen waste forms with respect to possibility of criticality occurring, the differences between solid and particulate stabilizers were not great enough to be considered significant (i.e., both were very far from criticality -- see Fiqure 16). The only case which appeared to create a possible criticality problem was that of the intact assemblies with a gas stabilizer, and these ontions were down-rated. The ranking of the waste forms are given in Table 27. 


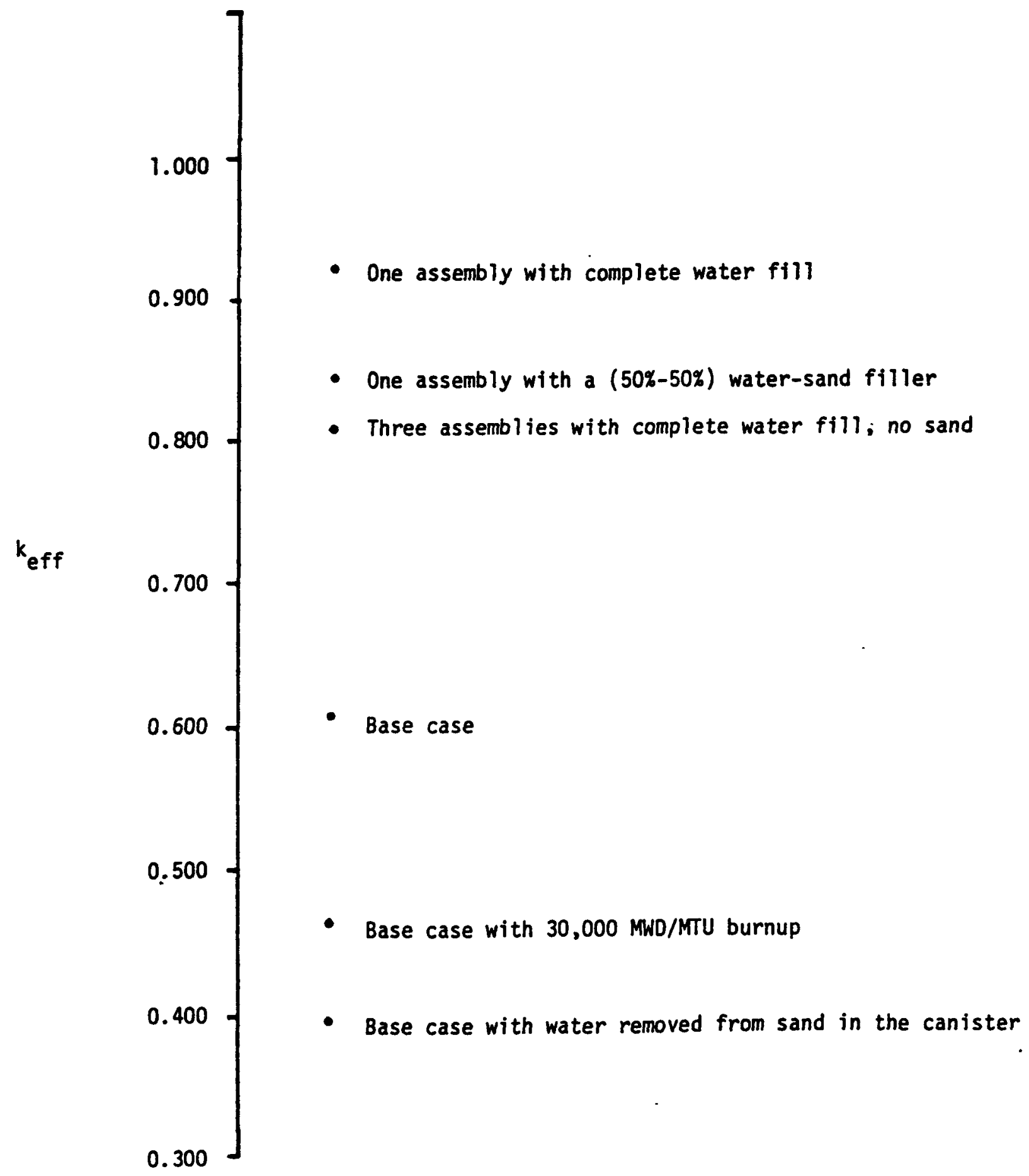

FIGURE 16. Keff Sensitivity Study Results

(Base case $=3$ assemblies with a $(50 \%-50 \%)$ sand water mixture in the voids in a 13-in. ID canister. All materials are homogenized over the canister volume. The spent fuel canister and surroundina materials remain intact. Fuel is fresh at $3.5 \%$ enrichment.) 
TABLE 29

WASTE FORM RANKING BASED ON POSSIBILITY OF CRITICALITY

Assessment Waste Forms

\begin{tabular}{|c|c|c|c|}
\hline Stabilizer & $\begin{array}{l}\text { Plenum } \\
\text { State }\end{array}$ & $\begin{array}{l}\text { Config- } \\
\text { uration }\end{array}$ & Form \\
\hline
\end{tabular}

DOE Waste Forms

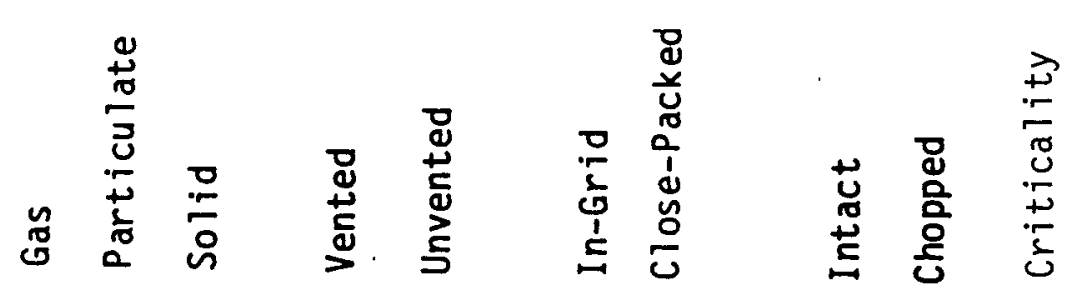

$\underset{\infty}{\infty}$

Unaltered Assembly
End Bells Removed From Assembly

Rods Vented to Remove Gas and

Resealed

Close Packed Fuel Rods in Matrix Material $\left\{\begin{array}{l}\text { 1. } x \\ 2 . x \\ 3 .\end{array}\right.$

$\begin{array}{ll}x & x \\ x & x \\ x & x\end{array}$

$\left\{\begin{array}{lll}4 . x & x \\ 5 . & x & x \\ 6 . & x\end{array}\right.$

$\begin{array}{ll}x & x \\ x & x \\ x & x\end{array}$

$x$
$x$

$x$
$x$
$x$

13.

$x \quad x$

$x$

$x$
$x$
$x$
$x$
$x$

$\begin{array}{ll}x & 2 \\ x & 1 \\ X & 1 \\ X & 2 \\ X & 1 \\ X & 1\end{array}$

$\begin{array}{ll}x & 1 \\ x & 1 \\ x & 1 \\ x & 1 \\ x & 1 \\ x & 1\end{array}$

$x$

$X$

2 
-

- 


\section{RANKING OF THE WASTE FORMS}

\section{A. TEMPERATURE LIMITS}

The Waste Form Assessment has revealed a number of "thermal period" temperature limits which affect the relative rankinas of waste forms. These are shown in Fiqure 17 and are summarized helow:

1) $425^{\circ} \mathrm{C}$-- the temperature at which there is concern about the integrity of the cladding

2) $600^{\circ} \mathrm{C}--$ the temnerature at which acceptable $(20 \%)$ qas release from the matrix occurs

3) apnroximately $660^{\circ} \mathrm{C}$-- at which appreciable qas release occurs

Rankings were done for four temperature ranges: below $425^{\circ} \mathrm{C}, 425$ tn $600^{\circ} \mathrm{C}, 600$ to $660^{\circ} \mathrm{C}$, and above $660^{\circ} \mathrm{C}$.

\section{B. RANKING OF POSSIBLE FUNCTIONS}

Rankings of the waste forms based on lithostatic pressure resistance are the same for all four temperature ranges; they are taken directly from Table 9 .

Rankings of the waste forms based on the abilitv to provide lonq-term stability for resistance to radionuclide miqration depends on the condition of the cladding. Hence, ratinas depend directly on the ability of the cladding to remain intact in anv particular temperature ranqe. Mathematicallv speaking, it is a convolution of the ratings in Table 12 and Table 14 . A ranking of "1" in Table 12 means that the claddinq will not fail, so it is convoluted with the intact column in Tahle 1?. A ranking of "2" or "4" in Table 14 means that the cladding will fail and should be convoluted with the breached column in Table 12 . 


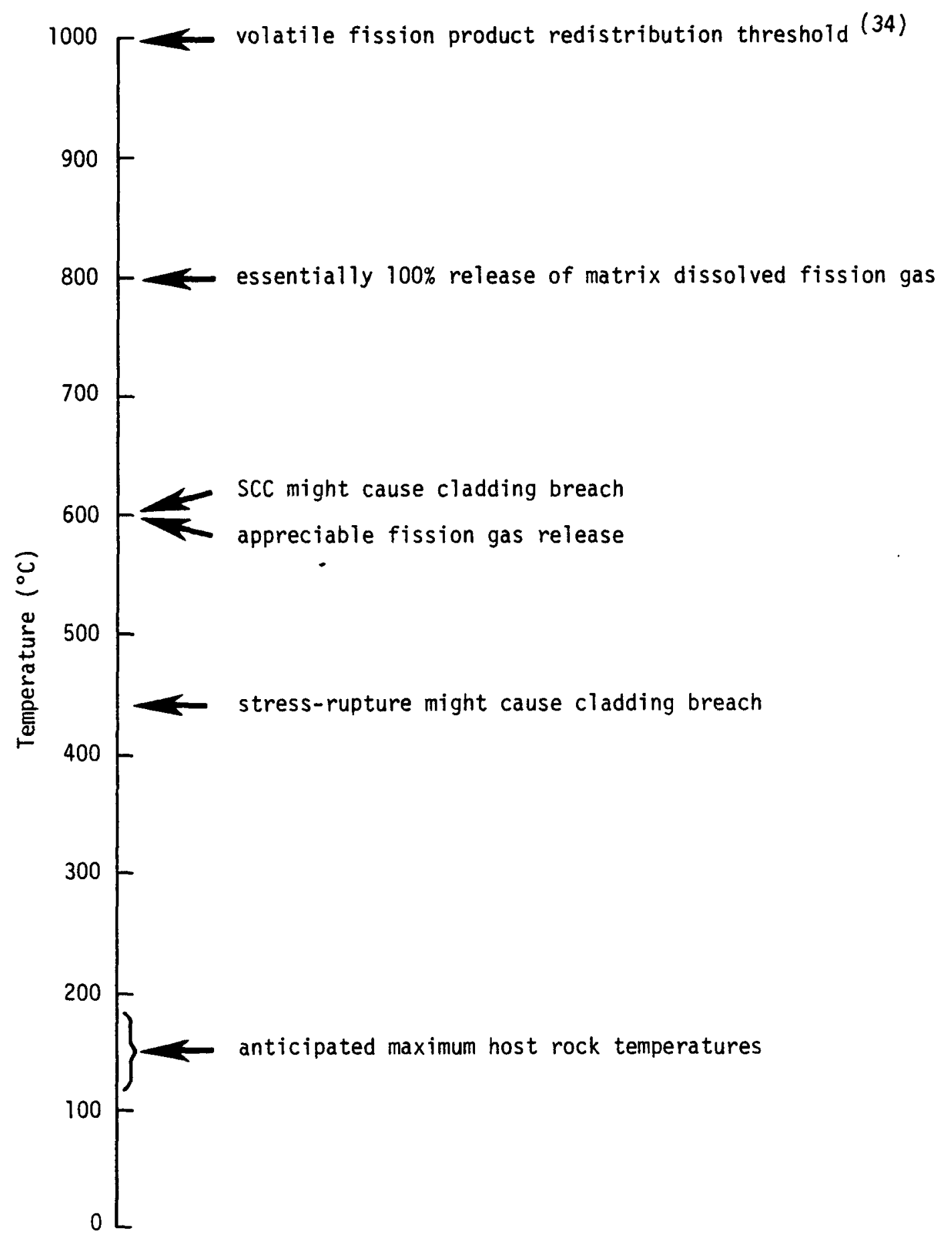

FIGURE 17. Temperature Scale for In-Repository Effects on Spent Fuel Degradation. 
Rankings of the waste forms based on the ability to maintain cladding integrity is dependent on the in-repository gas release. Since this is already taken into account in Table 14, the rankings are used directly.

The ability of the waste form not to compromise the package was evaluated from the point of view of normal and abnormal in-repository events. The correct cases referenced to Table 17 for the four temperature ranges are given in Table 30 . The numerical ranking given to each waste form is the average of the rankings in the two categories. Fractional rankings are raised or lowered according to the expected normal performance. These rankings are conservative. No credit was taken for the drop in temperature with repository residence nor for the expected time of breach for the cladding. Any ranking of " 1 " in this category should be considered satisfactory performance. Any other ranking indicates that further detailed calculations are necessary prior to actual use of that waste form.

The heat transfer rankings are based solely on the relative operating temperatures of the various waste forms. The lower the operating temperature, all other things being equivalent, the better the rating. In some temperature ranges, this may be important. The rankings are taken directly from Table 22. The exception is the temperature range greater than $660^{\circ} \mathrm{C}$, where heat transfer is no longer a concern.

The rankings given in Table 28 are based on the delay times between waste package breach and radionuclide release. As shown in Section V.A, most of the delay time can be attributed to the presence of the intact cladding. In Section IV.B, the waste forms were ranked according to their ability to prevent or delay radionuclide migration if the rods had initially intact cladding. This ranking depends on the waste form temperature at the time migration takes place and on the condition of the cladding. Assuming that the repository waste package performs as expected, radionuclide migration will not occur for thousands of years after emplacement. At that time the repository and waste package will be at ambient temperature irrespective of 
TABLE 30

USE OF TABLE 17 FOR RANKING OF THE WASTE FORM'S ABILITY NOT TO COMPROMISE THE CANISTER

$\begin{array}{ccc}\text { Temperature Range } & \frac{\text { Normal Events }}{\text { Canister }} & \frac{\text { Off-Normal Events }}{\text { Canister }} \\ 4250^{\circ} \mathrm{C} & \frac{\text { Case } 1 *}{\text { Case } 3} \\ 425 \text { to } 6000^{\circ} \mathrm{C} & \text { Case } 2 & \text { Case 3 } \\ 600 \text { to } 660^{\circ} \mathrm{C} & \text { Case 3 } & \text { Case 3 } \\ 6600^{\circ} \mathrm{C} & \text { Case 3 } & \text { Case 3 }\end{array}$

*These cases are described in Section IV.D and enable the reader to chose the correct ranking for any desired response. For example, if the reader wanted to know the waste form ranks in the temperature range below $425^{\circ} \mathrm{C}$ as it applies to off-normal events he would go to Case 3 in Table 17. 
the initial waste form temperature. Therefore the rankings of the waste form with respect to delay of migration can vary among the temperature ranges only if the cladding is compromised during the thermal period. As a result, the temperature rankings given in Tables 31 through 34 reflect the convolution of rankings given in Table 14 (rankings established for maintaining intact cladding) and Table 28 (rankings of waste forms based on release characteristics).

The rankings of radionuclide migration were based on the assumptinn that the fuel pellet was in the same condition for each intact waste form. This may not be the case if the cladding is not maintained intact during the thermal period. While relative differences in delay times may not be meaningful after the 1000-year thermal period, fuel with breached cladding mav have much higher absolute release rates and was, therefore, downaraded.

During the thermal period, when the waste package is intact, no water enters the canister, and criticality is precluded due to lack of moderation. After the thermal period, the ground temperature will be near ambient and independent of the initial starting temperature, so that in the post-thermal period, when criticality is a consideration, all the temperature ranges will have the same rankings. As a result, the rankings qiven in Section IV.B can be used without further convolution.

The ratings of the 13 waste forms in terms of the possible functional requirements and temperature ranges are qiven in Tables 31 to 34 .

\section{WEIGHTING OF FUNCTIONAL REQUIREMENTS}

Ideally, it would be appropriate to give a weight to each of the seven functional requirements and evaluate which waste form/stabilizer combination appears best. There are enough unknowns in the analys is to make this global approach somewhat meaningless. The rankings for a particular waste form/ stabilizer function is really an ordering. A " 3 " is worse than a " 2 " and a " 2 " is worse than a "1", but no indication is made that a "2" is twice as bad as 
06

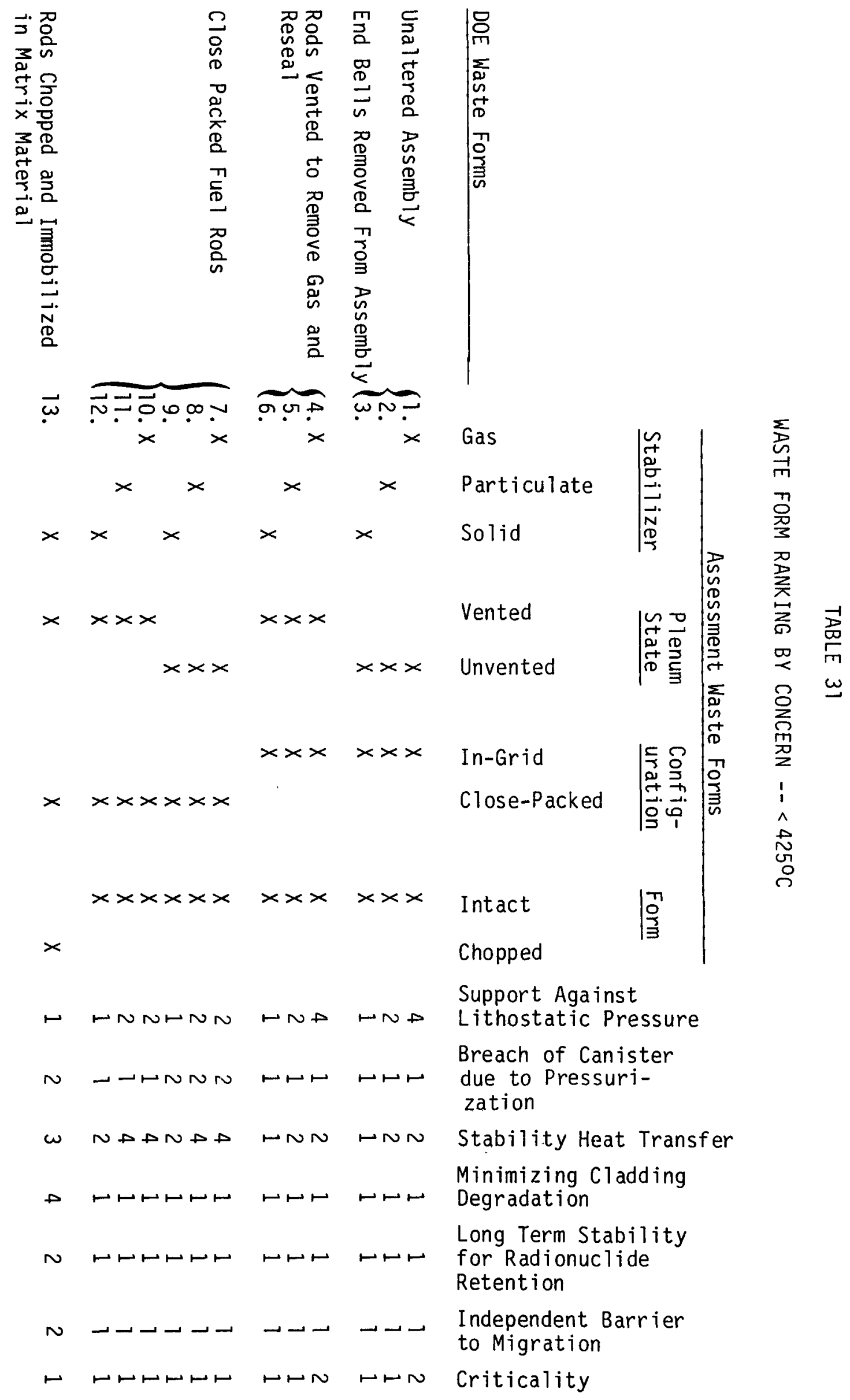




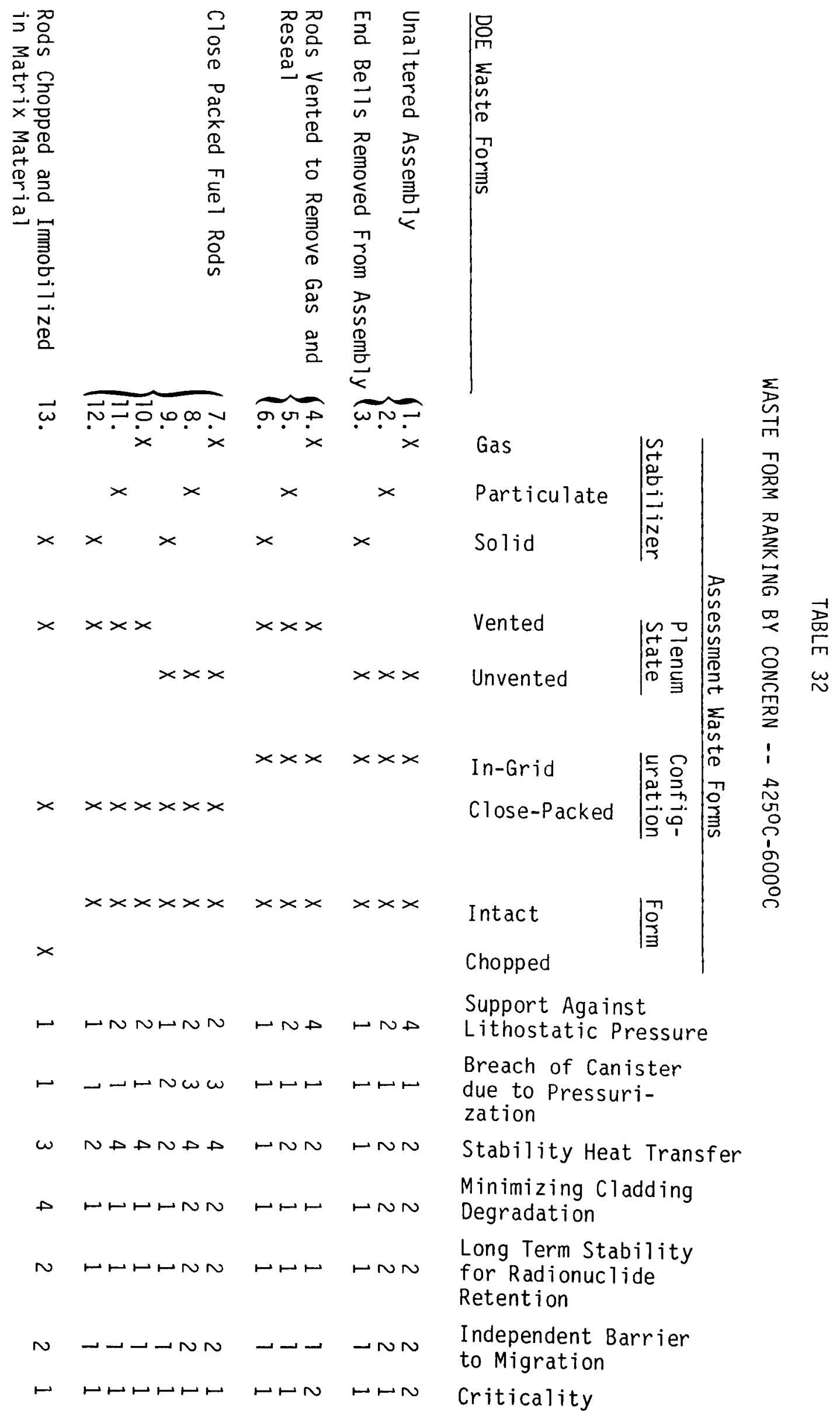




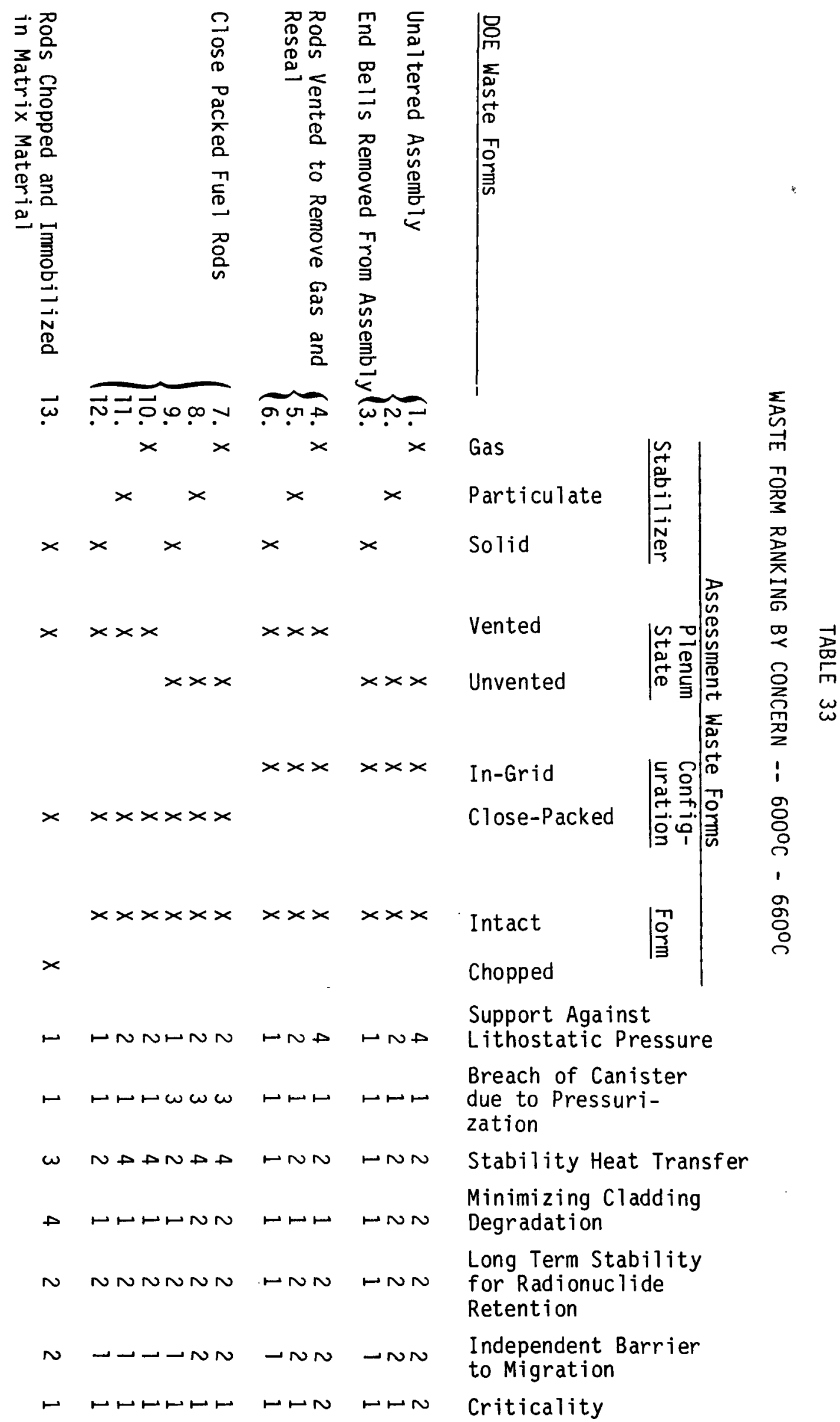




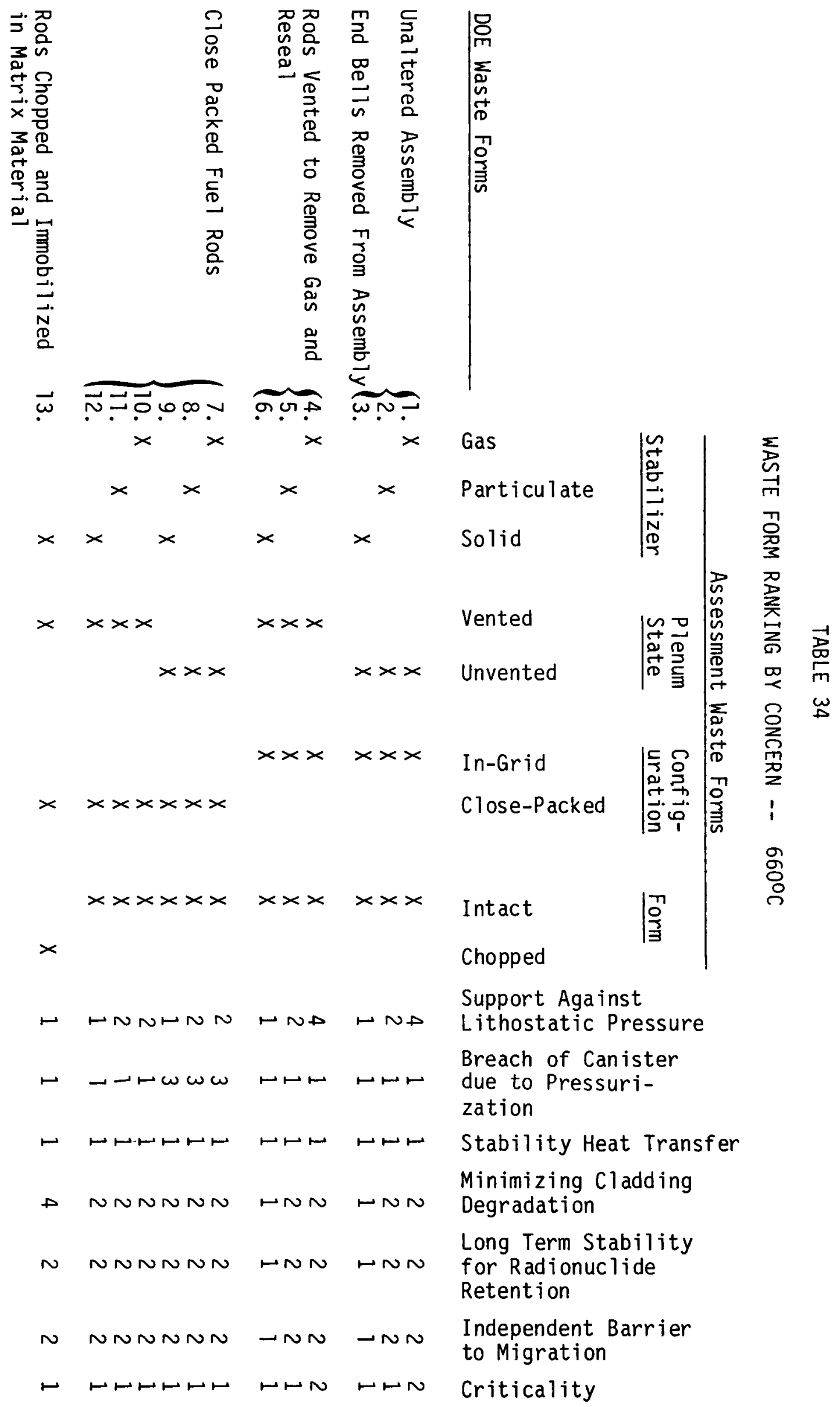


" $1 "$ or 10 times as bad as a "1", and in most cases a differential between two orderings will vary for different functions.

A second problem is that for many of the functions, the orderings are only relative. There is no absolute cut-off which makes one waste form/ stabilizer combinations acceptahle and others not acceptable with respect to a particular functional requirement. For example, the functional requirement for resistina 1 ithostatic pressure has rankings from 1 to 4 . " 1 " means that there is little or no propensity for ovality to occur, and "4" means that there is a chance that one can qet a hiqhly oval canister. But there is no way as yet to say that a critical eccentricity has been exceeded and that the associated waste form/stabilizer combination should be rejected. All of the waste forms may result in unacceptable ovalitv, or none of the waste forms may result in excessive ovality. Similar arquments may be applied to the other functional requirements.

In order to circumvent these problems, an alternative sequential procedure has been used. While the method is also subjective, it produces an overall ranking without numerically weighting each function. The seven functions are ordered from most important to least important. The wasto form/stabilizer combinations are first ordered by grouns with respect to the most important functional requirement. Then each group is ordered by the second functional requirement, and this is continued until each of the functional requirements has been used as an ordering function. An example of this method is shown in Figure 18.

Since there are 4 temperature ranges of concern, there would he over 5000 different orderings of the 7 functions in each temperature ranqe. Obviously, not all cases can be considered. To date, no firm set of functional requirements has been set on the waste form/stabilizer combination; as a result, no priority has been given to the suggested functions. Based on contacts with other beople working on OWNI programs, the functions have been ordered in the following way. 
SCHEMATIC APPROACH TO ORDERING THE WASTE FORM/STABILIZER COMBINATIONS

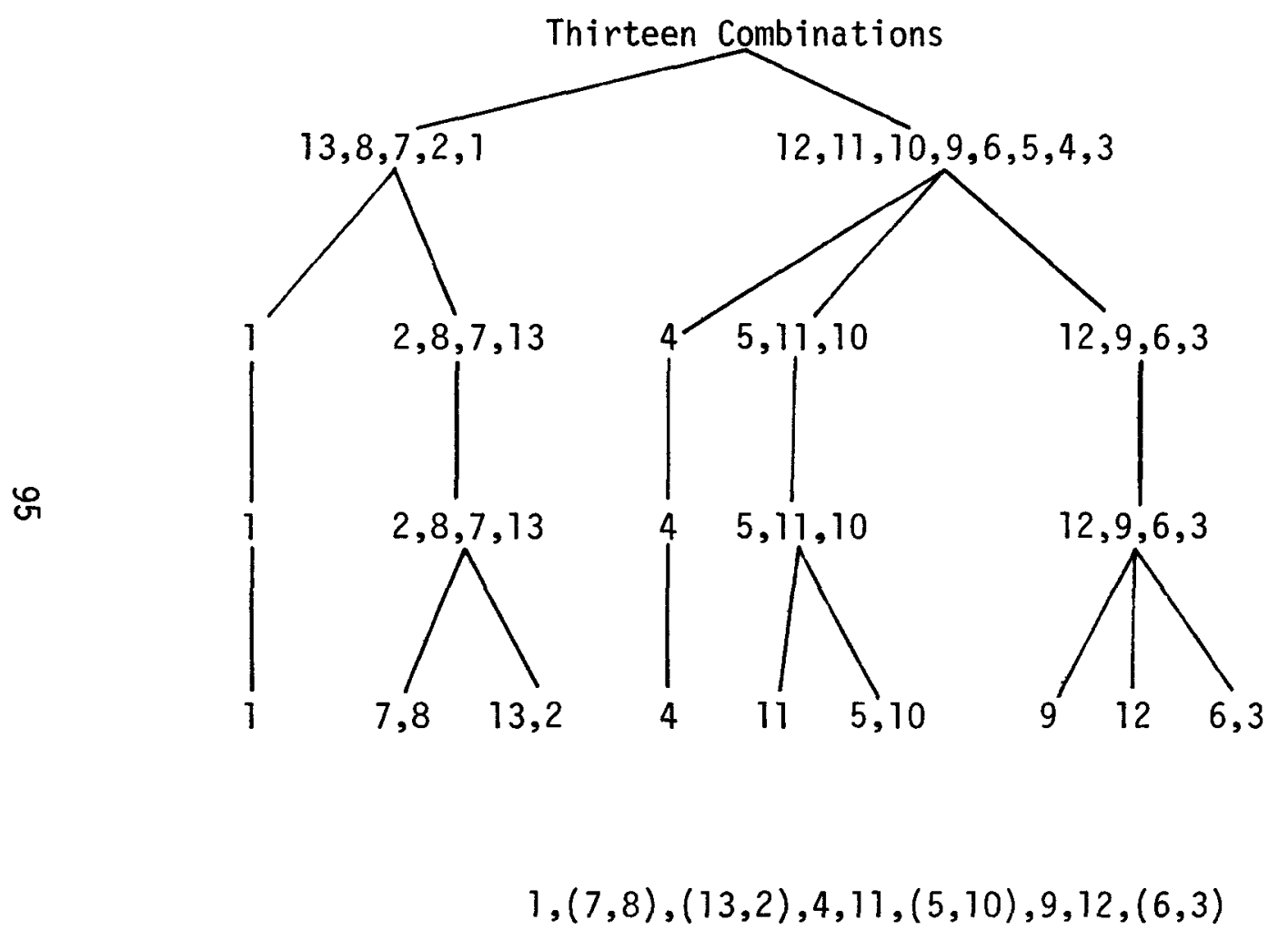

Function $A$

Function B

Function C

Function D

Worst

Best

Final Ordering

FIGURE 18. Schematic Approach to Ordering the Waste Fuel/Stabi1izer Combinations 
a) Long-term fuel stability for radionuclide retention

b) Minimize cladding degradation

c) Support the canister against lithostatic pressure

d) Prevent criticality

e) Prevent compromise of canister/reoository integrity

f) Degree of stabilizer heat transfer

Minimization of cladding degradation is placed second on $1 v$ because, in some instances, it would be needed to provide protection to the fuel to ensure long-term fuel stabilitv. The stabilizer as an indenendent barrier is not listed, since the ranking is identical to lona-term fuel stability in all cases. If a waste form is best at preserving lonq-term fuel stability, it is also the best as a barrier for radionuclide release. The importance of improving heat transfer was rated low, since all stabilizer types provide respectable heat transfer. While the analyses did show that certain waste form/stabilizer combinations could possibly compromise the canister and a repository, it was felt that the likelihood of this happening was quite smal1, and thus this function was not highly rated.

Since long-term stahility of the fuel has the highest priority and the necessity for intact cladding has not been well established, two cases have been considered in each of the four temperature ranges. The first evaluation is with intact cladding as a requirement and the second evaluation is with intact cladding not required. The analys is showed that all waste forms should be stable below $425^{\circ} \mathrm{C}$. Since this is the most likely temperature range for a spent fuel repository, a number of additional orderings were conducted by dropping the first two functional requirements (i.e., fuel stability and cladding integrity) and using some changes in the remaining functional requirements. The ratings according to this scheme are qiven in Appendix $D$. 


\section{TRENDS IN THE RANKINGS}

The rankings in Appendix $D$ have been ordered from the best to the worst waste forms in Figure 19. Equivalent waste forms are circled. Not surprisingly, the best waste form in all temperature ranges was the intact assemblv with a solid stabilizer. The rods could he vented or unvented and the end bells removed, if desired. Also no surprise, the intact assembly with a gas stabilizer was always the worst or nearly-worst waste form.

With minor exceptions, the relative "goodness" of a waste form/ stabilizer combination was independent of the temperature range. The biqgest variation occurred for chopped fuel. It ranged from "acceptable" to "worst" depending on whether consideration was given to intact rods. Because of uncertainties about possible fuel-stabilizer-canister interactions, cases where integrity of the cladding is maintained were considered the most reasonable situations. As a result, chopped fuel is to be considered as a "worst" or "nearly worst" waste form.

If preservation of the cladding and resistance to lithostatic pressure are the most important and necessary functional requirements for the waste form/stabilizer combinations, then waste forms above the line in Fiqure 19 should be given the most serious consideration. In addition to intact assemblies with a solid stabilizer, bundled close-packed rods that are either vented or unvented are also included. Intact assemblies with a particulate stabilizer and close-packed rods with either a gas or particulate stabilizer are less desirable, since they may not be able to support lithostatic pressure. Further experimental work on the compaction of particulate stabilizers and acceptable eccentricities in canisters are necessary to determine whether these lower classes of waste forms can be used.

It should be noted that, in general, if support for lithostatic pressure is offered, then the occurrence of criticality is also prevented. 


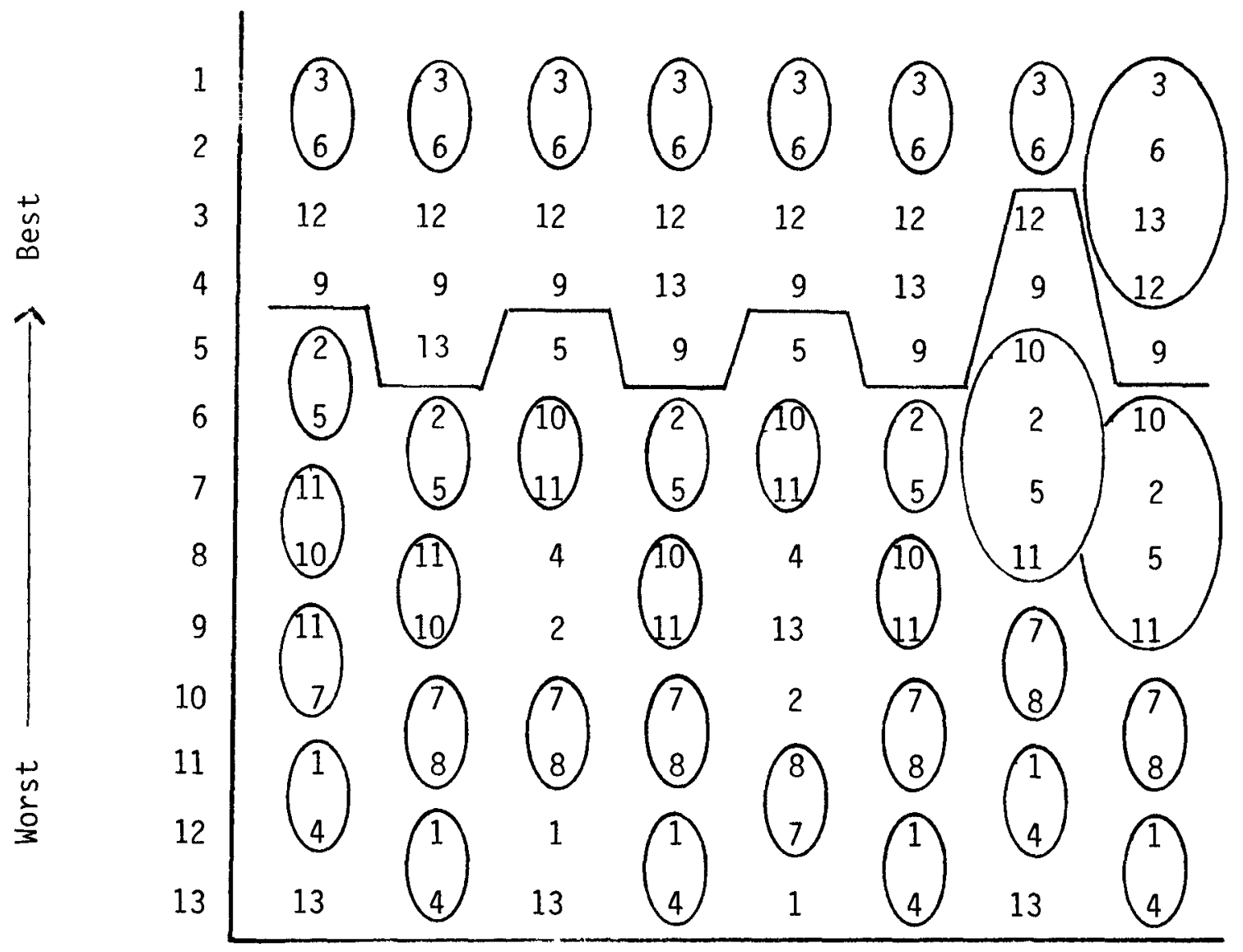

$a-I=c l a d d i n g$ remains intact during thermal period.

b - NI = cladding may be compromised during thermal period. $\longrightarrow=$ equivalent rankings.

FIGURE 19. Waste Form Ranking Order. 
For the temperature range up to $425^{\circ} \mathrm{C}$, the most probable for repository disposal, the order of the functions were varied. As seen in Appendix $D$, in general, the order of the functions did not substantially alter the rankings of the waste forms given in Table 35. 
TABLE 35

RECOMMENDED WASTE FORM/STABILIZER COMBINATIONS

Most Desirable

1. Intact Assemblies - - vented and resealed or unvented with solid stabilizer

2. Bundled Close-Packed Rods -- vented or unvented

Less Desirable

3. Intact Assemblies -- particulate stabilizers -- vented or unvented

4. Close Packed Assemblies -- not bundled-vented or unvented-qas or particulate stabilizer

Not Desirable

5. Intact Assemblies -- vented or unvented -- qas stabilizer

6. Chopped Fuel 
VII. CONCLUSIONS

The five waste forms suggested by ONWI were expanded to thirteen waste form/stabilizer combinations to assess their relative in-repositorv performance. The ultimate goal of the waste form/stabilizer combination is to prevent radionuclide release for as long a time as possible and then to limit the release rate to a low value. In order to evaluate this, a number of possible functional requirements had to be assessed. These included:

1) Stabilizer support against lithostatic pressure

2) Long-term stability for radionuclide retention

3) Minimization of cladding degradation

4) Prevention of canister/repository breach due to pressurization

5) Stabilizer heat transfer

6) The stabilizer as an independent barrier to radionuclide migration

7) Prevention of criticality

A number of relevant conclusions can be drawn from this assessment:

1) The stabilizer plays a minor role as an independent barrier unless its corrosion resistance is nearly the same or better than Zircaloy.

2) Criticality can be a concern if a sinqle assembly is placed in a canister with either a gas or a particulate stabilizer.

3) Three critical temperatures exist: $425^{\circ} \mathrm{C}$, above which the $\mathrm{claddina}$ may be compromised; $600^{\circ} \mathrm{C}$, where gas release from the fuel may become significant; and $660^{\circ} \mathrm{C}$, where significant qas release will occur over the thermal period.

4) As long as the cladding stays intact during the thermal period, all waste forms perform equally well in limiting radionuclide migration. If the cladding is compromised during the thermal period, fuel-stabilizer-canister interactions may occur which degrade the fuel significantly. This interaction must be studied if temperatures are set above $425^{\circ} \mathrm{C}$, since cladding intearity may be compromised.

5) Waste forms with particulate stabilizers may have trouble helping the canister resist lithostatic pressure. 
6) The relative rankings of the waste forms is rather independent of the repositorv temperature, although the absolute performance mav vary with temperature drastically.

7) The rankings of the waste forms is fairly independent of the relative weighting of the functional requirements.

Based on these conclusions, a number of statements can be made concerning the best spent fuel waste forms:

1) There is not enough available information to make a definitive division between acceptable and non-acceptable waste forms.

2) The best waste form/stabilizer combination is the intact assembly, with or without end bells, vented or unvented, with solid stabilizer.

3) A suitable alternative is the combination of bundled close-packed rods with a solid stabilizer around the outside of the bundle.

4) The other possible waste forms are of lower ranking. The worst waste form/stabilizer combination is the intact assemblv with a qas stabilizer or the chopped fuel.

For the purposes of integrating of the in-repository performance with the assessments conducted by the other contractors (Westinghouse Advanced Energy Systems Division, and E. R. Johnson Associates), the following waste form/ stabilizer combinations should be used.

1) Intact assemblies with a solid stabilizer

2) Shortened assemblies with a solid stabilizer

3) a) Vented (and resealed) rods in intact assemblies with solid stabilizer

b) Vented (and resealed) rods, close-packed and bundled, gas stabilizer

4) Close-packed and bundled rods with a aas stabilizer

5) Chopped fuel with a cracked monolith

This waste form/stabilizer assessment is so structured that the assessment can readily be reneated or supplemented for other waste forms, stabilizers, functions, or assessment-weighting factors. 
VIII. REFERENCES

1. Proposed Rulemaking on the Storage and Disposal of Nuclear Waste, DOE/NE-0007, US Department of Energy, Washington, DC, Apri1 15, 1980.

2. W. D. Kingery, Ed., Ceramic Fabrication Processes, John Wiley \& Sons, Inc., New York, NY, 1958.

3. W. D. Kingery, Introduction to Ceramics, John Wiley \& Sons, New York, NY, 1960.

4. "10CFR60 Disposal of High Level Wastes in Geologic Repositories", Federal Register, Vol. 46, No. 130, p.35280, Nuclear Regulatory Commission, JuTy 1981.

5. F. Garzarolli, R. Von Jan, and H. Stehle, "The Main Causes of Fuel Element Failure in Water-Cooled Power Reactors", Atomic Energy Review 171 , p. $31,1979$.

6. N. Wynhoff, S. E. Girault, R. L. Fish, Spent Fuel Stabilizer Material Characterization and Screening, HEDL-TME 87-2, Hanford Engineering Development Laboratory, Richland, WA, November 1981.

7. S. W. Heaberl ine and G. P. Selby, Effect of Fissile Isotope Burnup on Criticality Safety for Stored Disintegrated Fuel Rods , PNL-2589, Pacific Northwest Laboratory, Richland, WA, September 1978.

8. M. J. Smith, et al., Engineered Barrier Development for a Nuclear Waste Repository, RH0-BWI-ST-7, May 1980.

9. Handbook of Chemistry and Physics, 45th Ed., Chemical Rubber Company, CTeveland, Ohio, 1965.

10. D. R. 01 ander, Fundamental Aspects of Nuclear Reactor Fuel Elements, TID-26711 (1976).

11. D. M. Bosi, An Assessment of Spent Fuel Structural Integrity Under Disposal Site Conditions, HEDL-TME 80-84, Hanford Engineering Development Laboratory, Richland, WA, July 1981.

12. K. R. Merckx, "Calculational Procedure for Determining Creep Collapse of LWR Fuel Rods", Nucl. Eng. and Design 31, p.95, 1974.

13. L. D. Blackburn, D. G. Farwick, S. R. Fields, L. A. James, R. A. Moen, Maximum Allowable Temperature for Storage of Spent Nuclear Fuel, HEDL-TME 78-37, Hanford Engineering Development Laboratory, Richland, WA, May 1978.

14. R. E. Einziger, D. A. Cantley, J. C. Krogness, D. E. Stellrecht, and V. Pasupathi, "Spent Fuel Resistance to Internally Produced Cladding Degradation", Proceedings of Aiternate Waste Forms Information Workshop, Gatl inburg, Tennessee, May 1980. 


\section{REFERENCES (Cont'd)}

15. A. K. Miller and H. Ocken, "Stress Corrosion Cracking of Zircaloy: The Use of Laboratory Data to Predict In-Reactor Behavior", IAEA Specialists' Meeting on Pellet-Cladding Interaction in Water Reactors, RISO, Denmark, September 1980.

16. J. T. A. Roberts, et a1., LWR Fuel Performance Program: Progress in 1978, EPRI-NP-1024-SR, Electric Power Research Institute, Pa10 Alto, CA, February 1979.

17. R. L. Fish and R. E. Einziger, A Perspective on Fission Gas Release From Spent Fuel Rods During Geologic Disposal, HEDL-TME 31-3, Hanford Engineering Development Laboratory, Richland, WA, May 1981.

18. C. L. Mante11, Ed., Engineering Materials Handbook, McGraw-Hi11, Inc., New York, NY, 1958.

19. G. E. Raines, "Development of Reference Repository Conditions", Proceedings of the 1980 Natural Waste Termainal Storage Program Information Meeting, ONWI-212, December 1980.

20. R. E. Westerman, et a1., Preliminary Conceptual Designs for Advanced Packages for the Geologic Dispesal of Spent Fuel, PNL-2990, Pacific Northwest Laboratory, Richland, WA, Apri1 1979.

21. Y. B. Katayama and D. J. Bradley, "Long-Term Leaching of Irradiated Spent Fuel", Scientific Basis for Nuclear Waste Management, Vol. 2 C.J.M. Northrup, Jr., Ed., Plenum Press, New York, NY, 1980.

22. T. T. Vandergraaf, L. H. Johnson and D. W. P. Lau, "Leaching of Irradiated CANDU UO ${ }_{2}$ Fuel", Scientific Basis for Nuclear Waste Management, Vol. 2, ${ }^{2}$ C.J.M. Northrup, Jr., Ed., Plenum Press, New York, NY, 1980.

23. E. M. Greene, Spent Fuel Data for Waste Storage Programs, HEDL-TME 79-80, Hanford Engineering Development Laboratory, Richland, WA, September, 1980.

24. M. J. Smith, et. al., Engineered Rarrier Development for a Nuclear Waste Repository in Basalt: An Integration of Current Knowledge, RHO-BWI-ST-7, (May 1980).

25. W. E. Berry, Corrosion in Nuclear Applications, John Wiley and Sons, Inc., New York, NY, 1971.

26. M. P. Hardy and G. Hocking, Numerical Modeling of Rock Stresses with a Basaltic Nuclear Waste Repository, Phase II - Parametric Desian Studies, RH0-BWI-C-23 (July 1978). 


\section{REFERENCES (Cont'd)}

27. F. L. LaQue and H. R. Copson, ed., Corrosion Resistance of Metals and Alloys, Reinhold Publishing Corp., New York, NY, 1963.

28. Characteristics of Solidified High-Level Waste Products, IAEA Techn. Report No. 187 (1979). 29. The Disposal of Spent Nuclear Fuel Topical Report, ONWI-59 (Dec.
1979).

30. S. W. Heaberlin and G. P. Selby, Criticality Safety Comparisons of Spent Fuel Facility Concepts, PNL-2590, Pacific Northwest Laboratory, Richland, WA, September 1978.

31. S. W. Heaberlin and G. P. Selby, Effect of Fissile Isotope Burnup on Criticality Safety for Stored Disintegrated Fuel Rods, PNL-2589, Pacific Northwest Laboratory, September 1978.

32. B. F. Gore, G. W. McNair, and S. W. Heaberlin, Criticality Safety Considerations in the Geologic Disposal of Spent Nuclear Fuel Assemblies, PNL-3268, Pacific Northwest Lahoratorv, Richland, WA, Mav 1980.

33. L. M. Petrie and N. F. Cross, KENO IV - An Imbroved Monte Carlo Criticality Program, Oak Ridqe National Laboratory, Oak Ridqe, TN, November 1975.

34. D. Cubicciotti, State-of-the-Art Model for Release of Volatile Fission Products from U02 Fuel, SRI-EPRI RP 355-11, December 1978. 
APPENDIX A

EVALUATION OF FUEL PELLET DEGRADATION MECHANISMS 


\section{CONTENTS}

Page

I. Chemical Changes in the Fuel A-5

II. Volatile Fission Product Migration A-7

III. Gas Diffusion A-10

IV. Radiation Damage A-14

V. Thermal and Mechanical Fragmentation A-16 


\section{FIGURES}

Figure

Page

A.1 Schematic Representation of Redistribution and Release

A-8 Behavior of Volatile Fission Products Predicted by the Model of Reference A.9.

A.2 Approximate Vapor Pressure for Important Volatile Fission Products $\left(\mathrm{C}_{\mathrm{s}} \mathrm{I}, \mathrm{RbI}, \mathrm{C}_{\mathrm{s}} \mathrm{Br}, \mathrm{Cs}_{2} \mathrm{Te}\right.$, and $\left.\mathrm{Cs}_{2} \mathrm{Se}\right)$.

A.3 Diffusion Coefficient of $\mathrm{Xe}$ in Sintered $\mathrm{UO}_{2}$. A-12

A.4 Low-Temperature Thermal Diffusion Coefficients for Xe in $\mathrm{UO}_{2}$ (Extrapolated From the Data of Reference A-20).

A.5 Estimated Fission Gas Release from the Fuel in 1000 Years as a Function of Grain Size and Temperature.

A.6 Fuel Pellet Radial Temperature Drop as a Function of Fuel Temperature and Age. 


\section{TABLES}

Table

Page

A.1 Decay Power for PWR Fuel (3.3\% Enriched, 37.3

A-17

MW/MTU, $33 \mathrm{MWD} / \mathrm{kgU}$ )

A.2 Thermal Conductivity of $\mathrm{UO}_{2}$ at $92 \%$ T.D.

A-18 


\section{CHEMICAL CHANGES IN THE FUEL}

Previous studies (A.1,A.2) of possible mechanisms of fuel degradation have not been able to identify any chemical mechanisms which could cause significant degradation of the fuel material as long as the cladding remains intact. It is expected that chemical compounds formed during irradiation will remain essentially unchanged at the much lower temperatures in pool storage or repository.

The only cause which would be expected to alter the chemical state significantly over a period of time is the decay of fission products into other chemical species. It is evident from the rapid decrease in decay heat during the first few years ${ }^{\text {(A.3) }}$ that much of the degradation from this cause would occur during the initial cooling period due to relatively shortlived radionuclides. Metallographic examinations of intact spent fuel after up to 11 years of pool storage have disclosed no noticable degradation of the fuel. (A.4,A.5) Damage in a repository (after pool storage) would have to be due to the daughters of long-lived radionuclides. The quantities of such fission products are generally small, and they tend to decay into chemically similar elements. (A.6) Most fission products, being neutron rich, decay by $\beta$ emission and thus increase their atomic number by one. Accordingly, for the most part,

a) Oxide formers decay into oxide formers

b) Noble metals decay into other noble metals 
c) Reactive metals decay into other reactive metals Exceptions to this are decays $(A-6)$ involving the inert gases:

$$
{ }^{85} \mathrm{Kr} \underset{10.76 \text { y }}{\stackrel{B}{10}}{ }^{\mathrm{Rb}}
$$

and

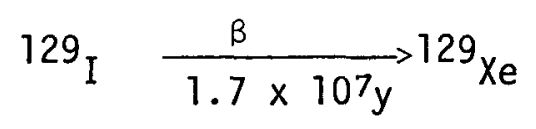

Because of half-life considerations, only the decay of ${ }^{85} \mathrm{Kr}$ is of any concern.

Probably the most important exception to the above argument is ${ }^{137} \mathrm{Cs}$, which decays to stable ${ }^{137}$ Ba with a half-life of 30 years. The fact that Cesium is monovalent while barium is divalent indicates that this process will have a chemical effect,since there is a high in-reactor yield of the highly mobile CS nuclide ${ }^{(A .7)}$. For example, if Cs is present as CSI, the expected change will be $2 \mathrm{CSI} \rightarrow \mathrm{BaI}_{2}+\mathrm{Ba}$. The free $\mathrm{Ba}$ will remain as a metal or act as a getter for oxygen or any other available atom. In ten-year-old fuel, ${ }^{137} \mathrm{Cs}$ is present at a concentration of about 0.15 atom $\%$ of heavy metal in PWR fuel irradiated to 30,000 MWD/MTU and about 0.10 atom $\%$ in BWR fuel irradiated to 25,000 MWD/MTU. (A. 8 ) This may increase near the pellet's outer surface, (A.9) since cesium tends to migrate down the temperature gradient. Essentially all of the ${ }^{137}$ Cs initially present will decay to barium during the 1000-year thermal period, and the magnitude of the effect as a fuel degradation mechanism is unclear. It should be noted, however, that about $21 \%$ of the ${ }^{137}$ Cs initially present decays during the first 10 years of pool storage, and, as previously mentioned, examinations have disclosed no evidence of change. 
The effect, therefore, is probably minor. These metallographic examinations, however, were directed mainly at investigation of cladding degradation. More detailed experimental studies of spent fuel are needed in order to reliably assess chemical changes, if any, occurring in spent fuel.

\section{VOLATILE FISSION PRODUCT MIGRATION}

Significant migration of volatile fission products within the fuel could cause a decrease in the fuel's resistance to attack by a leachant if the volatiles accumulate near the outer edge of the fuel. Migration of volatile fission products as a function of temperature was extensively investigated by Cubicciotti $(A .9, A .10)$ who found that migration rates were extremely sensitive to temperature. He deduced the existence of a threshold for migration of volatile solids at a fuel center temperature of $1000^{\circ} \mathrm{C}$; he reported a threshold for release from the fuel at a centerline temperature of approximately $1400^{\circ} \mathrm{C}$. Behavior of the volatile fission products as a function of burnup and fuel center temperature is shown schematically in Figure A.I(from reference A.9). The reason for the sensitivity of migration rate to temperature can be appreciated by examining Figure A.2, which shows approximate vapor pressure as a function of temperature for the important group of volatile solid fission products, including CsI, RbI, CsBr, $R b B r$, $\mathrm{Cs}_{2} \mathrm{Te}$, and $\mathrm{Cs}_{2} \mathrm{Se}$. As can be seen, the vapor pressure rapidly becomes vanishingly small at temperatures much below $1000^{\circ} \mathrm{C}$. The vapor pressure at $400^{\circ} \mathrm{C}$ is about $6-1 / 2$ orders of magnitude below that at the redistribution threshold which, along with the relatively insignificant temperature gradient 


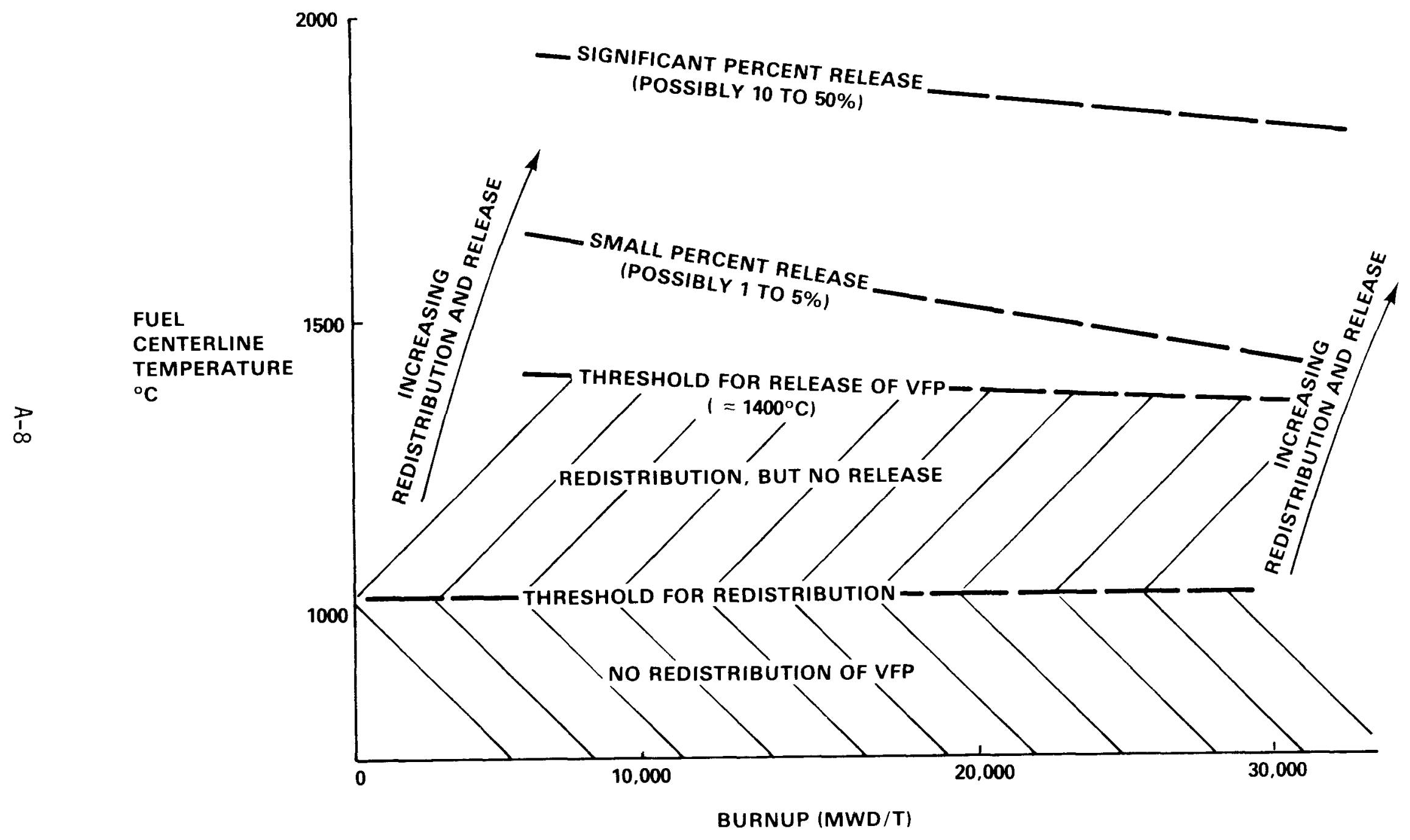

FISLRE A.1. Scheratic Representation of Redistribution and Release Behavior of Volatile Fission Prociucts Predictec by the iociel of Reference A.9. 


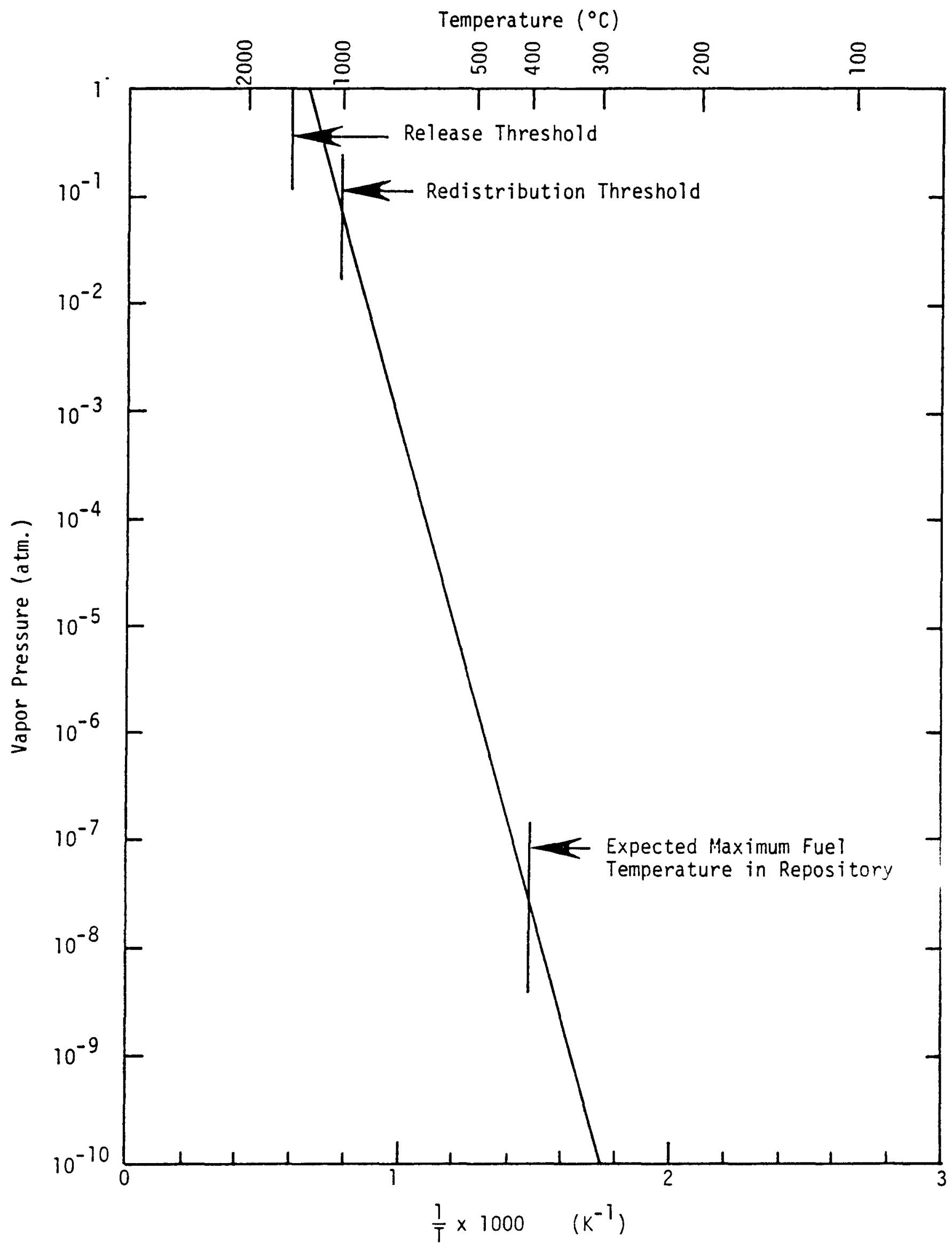

FIGURE A.2. Approximate Vapor Pressure for Important Volatile Fission Products $\left(\mathrm{C}_{\mathrm{s}} \mathrm{I}, \mathrm{RbI}, \mathrm{C}_{\mathrm{s}} \mathrm{Br}, \mathrm{Cs}_{2} \mathrm{Te}\right.$, and $\left.\mathrm{Cs}_{2} \mathrm{Se}\right) .(\mathrm{A} .9, \mathrm{~A} .11)$ 
across the fuel in repository (see Section E), renders vapor transport of these violatile fission products virtually inoperative.

\section{GAS DIFFUSION}

The principal fission gases produced in LWR fuel are $\mathrm{Kr}$ and $\mathrm{Xe}$; Xe predominates, producing about 90 atom $\%$ of gas. (A.8) These gases are produced in the fuel matrix during in-core irradiation, and at temperatures above about half the absolute melting temperature, they begin to form gaseous precipitates. (A.12) These precipitates contain a few to several hundred vacancies per gas atom. They tend to grow into bubbles by collecting additional gas atoms and vacancies, but they can also be destroyed by a thermal spike from a nearby fission event. An equilibrium condition is established

between gas in bubbles and in solution within the fuel grain. (A.13, A.14, A.15) Baker $(A .16)$ calculated the fraction of total gas generated and residing in the intragranular bubbles by measuring bubble diameters and densities in fuel between $950^{\circ} \mathrm{C}$ and $1800^{\circ} \mathrm{C}$. Results indicated that the fraction of gas in intragranular bubbles is about $20 \%$ up to $1400^{\circ} \mathrm{C}$ and increases to about $40 \%$ above $1600^{\circ} \mathrm{C}$. The gas in solution diffuses to form bubbles at the grain boundaries, which gradually increase in size and density until interconnection occurs and gas begins venting to the free volume of the rod. This interconnection of intergranular porosity by means of grain-edge tunnels is usually well developed at less than 1 atom \% burnup. (A.9, A.17, A.18, A.19)

Although gas diffusion will be a slow process at the relatively low temperatures expected in a repository, it is expected that some gas will 
diffuse out of the grains over a long period of time and could conceivably accumulate at any unvented intergranular porosity. This diffusion and accumulation could possibly lead to weakening of the grain boundaries.

Diffusion of xenon out of sintered $\mathrm{UO}_{2}$ at low temperatures has been experimentally studied by Taketani and Ikawa between $400^{\circ} \mathrm{C}$ and $800^{\circ} \mathrm{C}$. (A.20) They found that the effective diffusion coefficient undergoes a transition at about $600^{\circ} \mathrm{C}$, as shown in Figure A.3. Below the transition temperature, effective diffusion coefficient can be represented by:

$$
D\left(\frac{m^{2}}{s}\right)=2.54 \times 10^{-22} \exp \left[-\frac{4.003 \times 10^{3}}{T\left({ }^{\circ} \mathrm{K}\right)}\right]
$$

This diffusion coefficient has been used in our assessment, since it is a conservative upper bond on the data extrapolated from higher temperature measurements C9 (see Figure A.3). Extrapolating to repository temperatures produces very low estimates for the diffusion coefficient, as shown in Figure A.4.

Total gas release fractions have been estimated for an equivalent silierical grain after 1000 years at various constant temperatures. The calculations were based on simple diffusion of the gas in solution in the grain and took no account of the presence of intragranular bubbles as trapping centers. A fundamental mode concentration profile within the grain was assumed at the beginning of the repository period, and the grain 


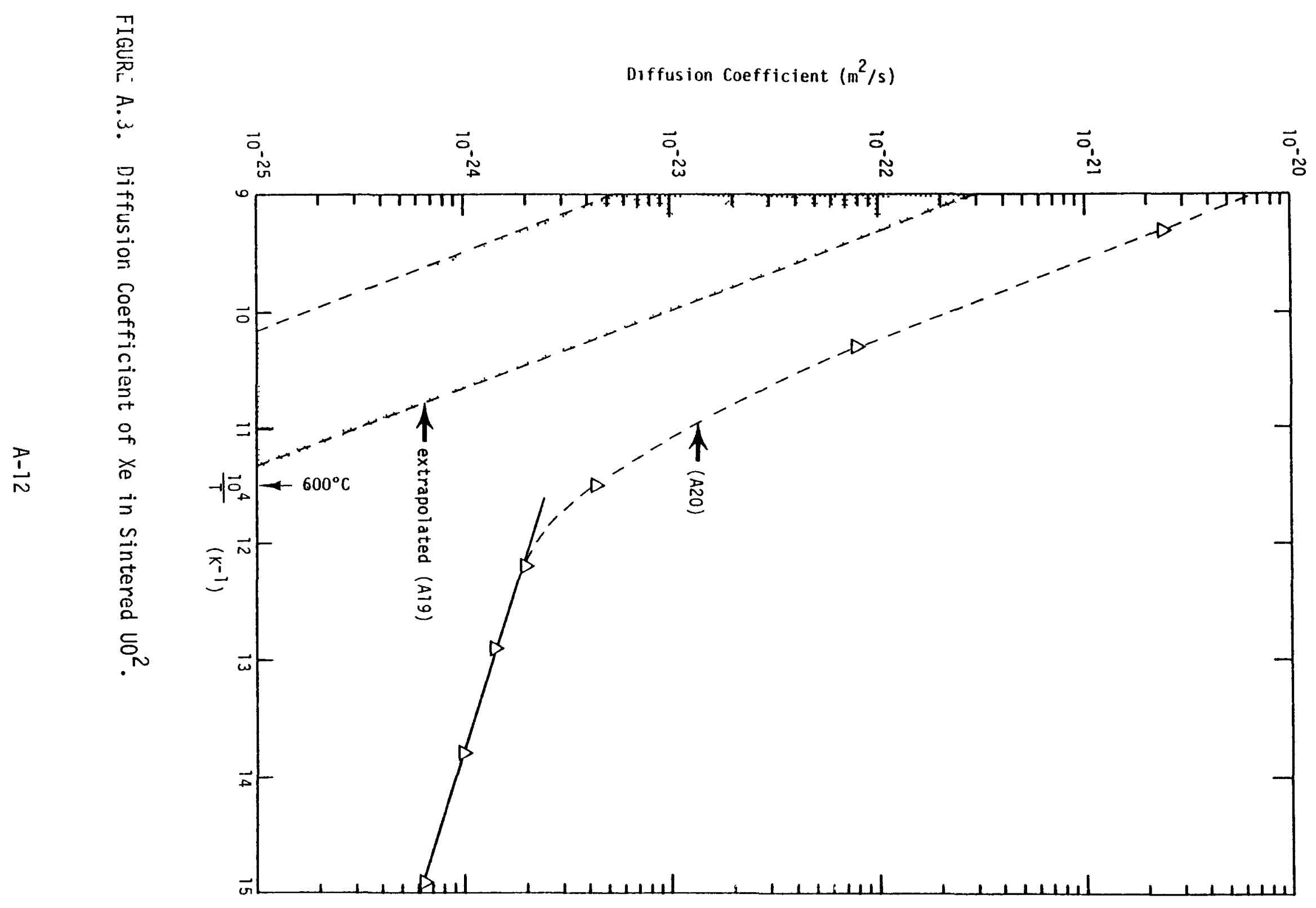




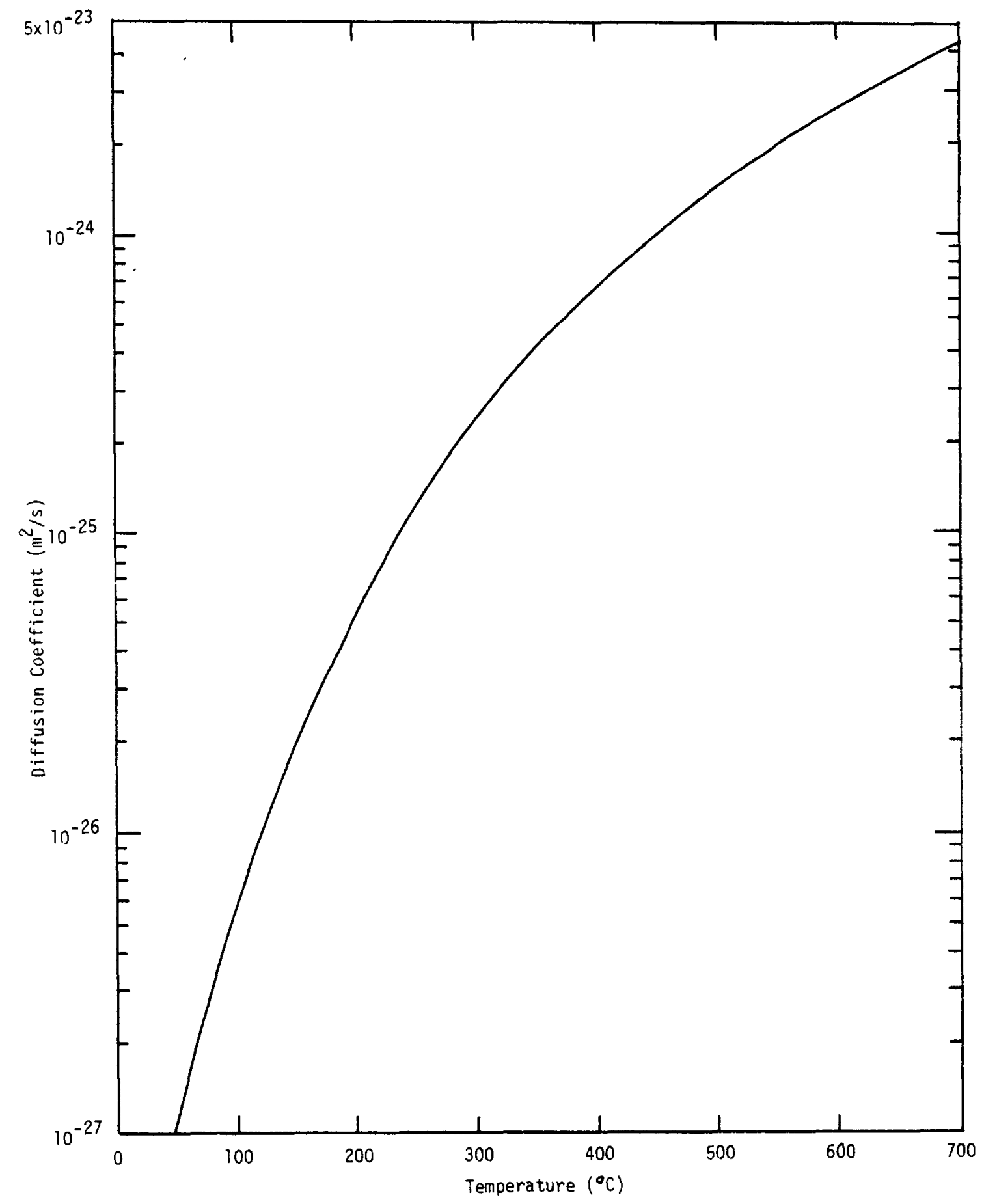

FIGURE A.4. Low Temperature Thermal Diffusion Coefficient for Xe in $\mathrm{UO}_{2}$ (Extrapolated From the Data of Reference A.2U). 
surface was conservatively assumed to be a perfect sink. The resulting release fraction estimates are shown in Figure A.5 for the typical range of grain sizes in LWR Fuel. (A.13) As would be expected, the release fraction increases very rapidly above $500^{\circ} \mathrm{C}$, and after 1000 years at $800^{\circ} \mathrm{C}$, nearly all the gas has either left solution or reached equilibrium with the internal pressure of the rod. It should be noted that the temperatures shown in Figure A.5 are assumed to be constant over the thermal period (first 1000 years).

\section{RADIATION DAMAGE}

The effects of radiation damage in single crystal $\mathrm{UO}_{2}$ (analngous to individual grains) at low temperatures (less than $400^{\circ} \mathrm{C}$ ) and relatively high exposures were investigated by Bates, et al. (A.21) They found $\mathrm{UO}_{2}$ to be extremely resistant to radiation damage; a total exposure of $1.44 \times 10^{20} \mathrm{f} / \mathrm{cm}^{3}$ produced a lattice strain of about $0.024 \%$ and only "subtle and minute" changes in microstructure along with some hardening. This exposure is equivalent to a total energy deposition of about $4.6 \times 10^{9}$ $\mathrm{J} / \mathrm{cm}^{3}$, compared to a conservatively estimated deposition rate of about $3.2 \times 10^{6} \mathrm{~J} / \mathrm{cm}^{3}$ per year for typical PWR fuel only 1 year old. (A.3) According to lower exposure data reviewed by Lustman, (A.22) the lattice strain appears to pass through a maximum of about $0.16 \%$ at an exposure of about $5 \times 10^{16}$ $\mathrm{f} / \mathrm{cm}^{3}$, and the damage anneals out above this exposure. (A.21, A.22) The maximum lattice strain of $0.16 \%$ is comparable to the effect of a solution of about $7 \% \mathrm{ThO}_{2}$; this comparability indicates that the changes in observed 


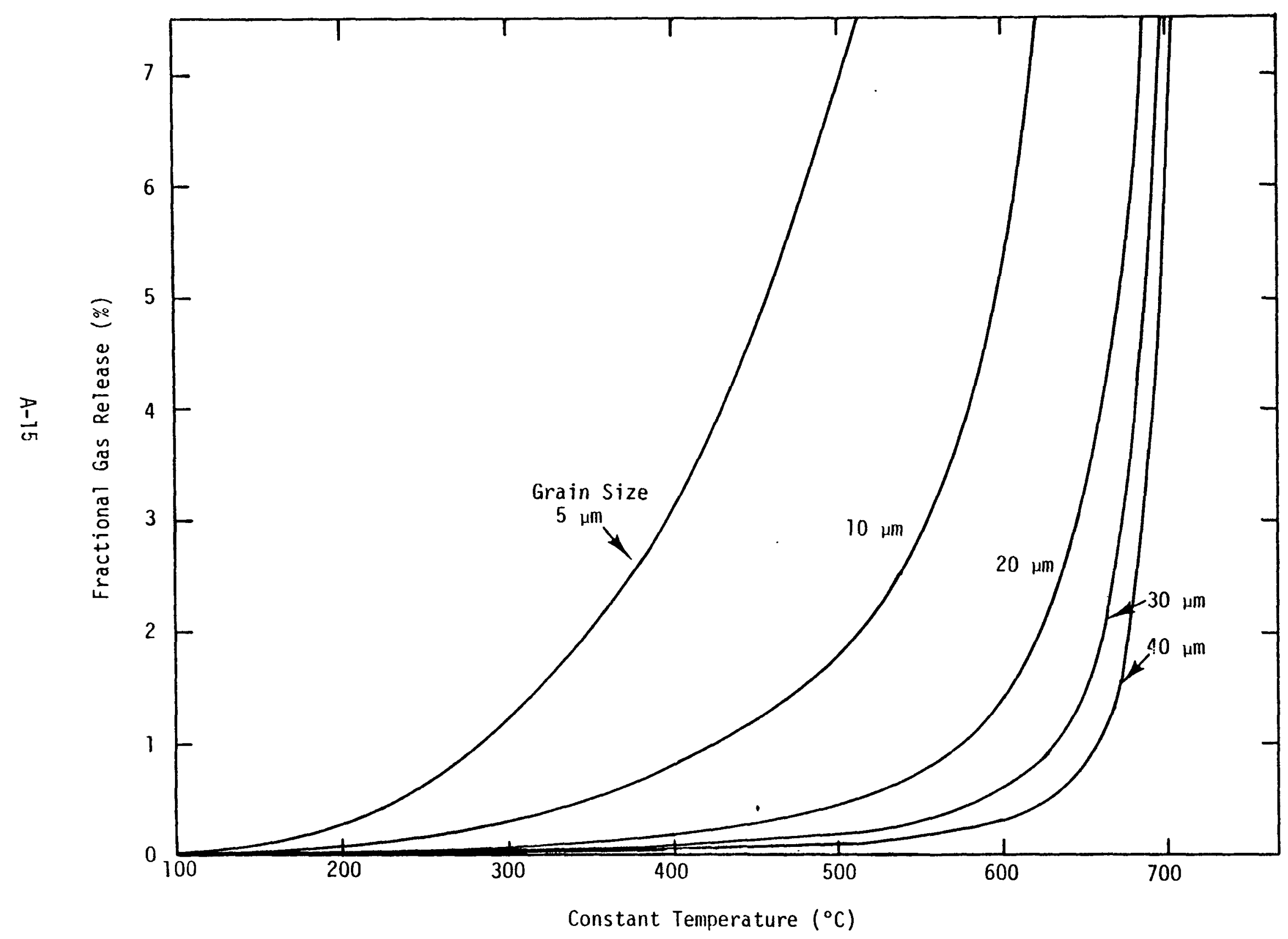

FIGURE A.5. Estimated Fission Gas Release From the Fuel in 1000 Years as a Function of Grain Size and Temperature 
properties would be expected to be minor and would appear to anneal rapidly at temperatures above $200^{\circ} \mathrm{C}$. (A.22, A.23) These data are based on irradiation of $\mathrm{UO}_{2}$ in a reactor at low temperatures. Most of the damage is due to fission fragments, which are much more disruptive than, for example, atom recoil or alpha emission processes. Damage associated with in-reactor, low-temperature irradiation can therefore be considered an upper limit on the damage due to the less disruptive processes associated with radioactive decay. The $\mathrm{UO}_{2}$ structure is therefore not expected to change significantly because of selfradiation while in repository.

\section{THERMAL AND MECHANICAL FRAGMENTATION}

Fragmentation of the fuel after end of irradiation would have the effects of increasing the surface area available to a leachant and providing access to previously isolated fission product phases within the fuel.

The total fuel pellet centerline-to-surface temperature drop was calculated for typical LWR fuel as a function of fuel age and temperature. Power levels and fuel thermal conductivities shown in Tables A.1 and A.2 were used, and a pellet radius of $0.5 \mathrm{~cm}(A .24)$ was assumed. The resulting temperature drops are very small even for freshly irradiated fuel, as shown in Figure A.6. A thermal stress analysis by Bosi (A.26) indicates that the minimum temperature drop to fracture an intact pellet (worst case) is approximately $66^{\circ} \mathrm{C}$. The thermal stresses due to shocks and gradients are 
TABLE A1

DECAY POWER FOR PWR FUEL $(3,3 \%$ ENRICHED, $37.3 \mathrm{MW} / \mathrm{MTU}$,
$33 \mathrm{MWD} / \mathrm{kgU})(A 3)$

FUEL AGE

DECAY POWER (KW/MTU) HEAT SOURCE O $92 \%$ TD $\left(\mathrm{w} / \mathrm{cm}^{3}\right)$

10d

87

0.88

180d

19

0.19

$1 y$

11

0.11

$5 y$

2

0.02

$10 y$

1

0.01 


\section{TABLE A2}

THERMAL CONDUCTIVITY OF $\mathrm{UO}_{2}$ AT $92 \%$ T.D. (A25)

TEMPERATURE $\left({ }^{\circ} \mathrm{C}\right)$

50

100

200

300

400

500

600

700

800

900

1000 $k\left(w / \mathrm{cm}^{\circ} \mathrm{C}\right)$

0.070

0.064

0.055

0.048

0.043

0.039

0.035

0.032

0.030

0.028

0.026 


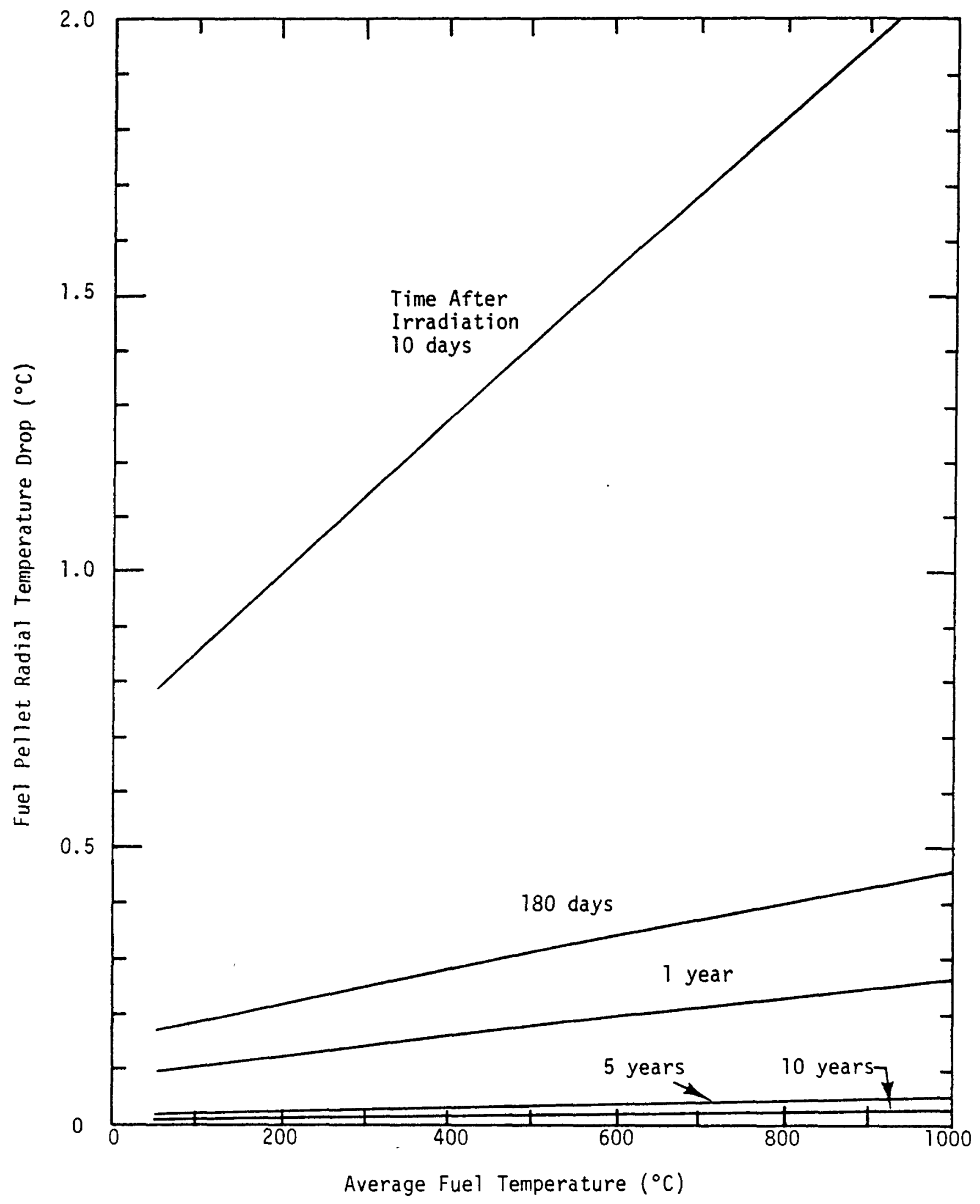

FIGURE A.6. Fuel Pellet Radial Temperature Drop as a Function of Fuel Temperature and Age 
far more severe during reactor transients and shutdown (when the fuel actually fragments) than during time in pool storage or repository. The fuel is therefore not expected to suffer any additional fragmentation due to thermal effects during geologic disposal.

The possibility of fuel degradation due to mechanical shock during handling and geologic disposal was assessed by Bosi. (A.26) He considered a peak transportation shock loading, consisting of a half-sine wave pulse with a duration of $0.059 \mathrm{msec}$ peaking at $2.9 \mathrm{~g}$ acceleration. (A.27) Applying this loading to intact pellets (worst case) in cladding produced contact stresses of approximately 1317 psi and 1390 psi for PWR and BWR fuel, respectively; these stresses are well below the fracture strength of approximately $11.5 \mathrm{ksi}$ at $0^{\circ} \mathrm{C}$. Since for closely fitting nested cylinders the contact stress varies with the applied force to the $1 / 2$ power, (A.28) it would require about 68 times the postulated maximum loading to fracture a pellet.

In order to determine the seismic loading force, Bosi $(A .26)$ surveyed the data on seismicity in deep geologic formations and adopted a peak acceleration of $0.25 \mathrm{~g}$ with a frequency of $3 \mathrm{~Hz}$ based on a Mercalli intensity of 7.5 and a mean distance from the causitive fault of 15 miles. Since expected seismic shock loadings are far less than those caused by handling and transportation (barring physical disruption of the rod), further fracturing of the fuel due to seismic effects is not expected. 
A.1 M. Y. Almassy and R. E. Woodley, Possible Effects of $\mathrm{UO}_{2}$ Deterioration on Light Water Reactor Spent Fuel Performance in Geologic Disposal, HEDL-TC1502, Rev. 1, Westinghouse Hanford Company, Richland, WA, October 1981.

A.2 G. E. Zima, An Evaluation of Potential Chemical/Mechanical Degradation Processes Affecting Fuel and Structural Materials Under Long-Term Water Storage, NUREG/CR-0668 (PNL-2379), May 1979.

A.3 A. S. Benjamin, D. J. McCloskey, D. A. Powers and S. A. Dupree, Spent Fuel Heatup Following Loss of Water During Storage, NUREG/CR-0469 (SAND77-1371), March 1979.

A.4 A. B. Johnson, Jr., Behavior of Spent Nuclear Fuel in Water Pool Storage, BNWL-2256, September 1977 .

A.5 A. B. Johnson, Jr., "Spent Fuel Storage Experience", Nuc1. Tech., 43, p. 165,1979 .

A.6 C. M. Lederer, J. M. Hollander, and I. Perlman, Table of Isotopes, Sixth Edition, John Wiley \& Sons, Inc., New York, NY, 1967.

A.7 F. T. Ewart, et al., "The Chemical Effect of Composition Changes in Irradiated Oxide Fuel Material II -- Fission Product Segregation and Chemical Equilibrium", J. Nucl. Mat., 61, p. 254, 1967.

A.8 R. L. Fish and R. E. Einziger, A Perspective on Fission Gas Release From Spent Fuel Rods During Geologic Disposal, HEDL-TME 81-3, Westinghouse Hanford Company, Richland, WA, May 1981.

A.9 D. Cubicciotti, State-of-the-Art Model for Release of Volatile Fission Products from $\mathrm{UO}_{2}$ Fuel, SRI-EPRI RP 355-17, December 1978.

A.10 D. Cubicciotti, A Quantitative Model for Fission Product Release from $\mathrm{UO}_{2}$ Fuel, SRI-EPRI RP 355-11-1, June 1979.

A.11 D. Cubicciotti and J. E. Sanecki, "Characterization of Deposits on Inside Surfaces of LWR Cladding", J. Nucl. Mat., 44, p. 136, 1972.

A.12 W. Chubb, V. W. Storhok, and D. L. Keller, "Observations Relating to the Mechanisms of Swelling and Gas Release in Uranium Dioxide at High Temperatures", J. Nucl. Mat., 44, p. 136, 1972.

A.13 M. H. Wood and J. R. Matthews, "A Simple Operational Gas Release and Swelling Mode1, I. Intragranular Gas", J. Nucl. Mat., 91, p. 35, 1980.

A.14 R. M. Cornel1, M. V. Speight and B. C. Masters, "The Role of Bubbles in Fission Gas Release from Uranium Dioxide", J. Nucl. Mat., 30, p. 170, 1969.

A.15 D. R. 0lander, Fundamental Aspects of Nuclear Reactor Fuel Elements, TID$26711-P 1,1976$. 
A.16 C. Baker, "The Fission Gas Bubble Distribution in Uranium Dioxide From High Temperature Irradiated SGHWR Fuel Pins", J. Nucl. Mat., 66, p. 283, 1977.

A.17 M. 0. Tucker and J. A. Turnbu11, "The Morphology of Interlinked Porosity In Nuclear Fuels", Proc. R. Soc. Lond. A., 343, p. 299, 1975.

A.18 J. R. Matthews and M. H. Wood, "A Sample Operational Gas Release and Swelling Model, II. Grain Boundary Gas", J. Nucl. Mat., 91, p. 241, 1980.

A. 19 W. L. Badewicz, The State-of-the-Art of Fission Gas Release From LWR Fuels, UCLA-ENG-7740, May 1977.

A.20 K. Taketani and K. Ikawa, "Release of Xenon From Sintered $\mathrm{UO}_{2}$ at Low Temperatures", J. Nucl. Sci. and Tech., 4, p. 589, 1967.

A.21 J. L. Bates, J. A. Christensen and J. L. Daniel, Irradiation Effects in Uranium Dioxide Single Crystal, HW-73959, September 1962.

A.22 B. Lustman, "Irradiation Effects in Uranium Dioxide", Uranium Dioxide: Properties and Nuclear Applications, J. Belle, ed. USAEC, Washington, $\overline{D C}, 1960$.

A.23 B. G. Childs and J. McGurn, "The Differential Calorimetry of Irradiated $\mathrm{UO}_{2}$ and $\mathrm{U}_{4} \mathrm{O}_{9} "$, CR-Met-893, December 1959.

A.24 E. M. Greene, Spent Fuel Data for Waste Storage Programs, HEDL-TME 79-20, Westinghouse Hanford Company, Richland, WA, September 1980.

A.25 R. Brandt and G. Neuer, "Thermal Conductivity and Thermal Radiation Properties of $\mathrm{UO}_{2} "$, N. Non-Equilib. Thermodyn., 1, p. 3, 1976.

A.26 D. M. Bosi, An Assessment of Spent Fuel Structural Integrity Under Disposal Cycle Conditions, HEDL-TME 80-84, Westinghouse Hanford Company, JuTy 1981.

A.27 C. F. Magnuson, Shock and Vibration for a Large Shipping Container During Truck Transport (Part II), NUREG/CR-01.

A.28 R. J. Roark, Formulas for Stress and Strain, 4th ed., McGraw-Hill, Inc., New York, NY, 1965. 
APPENDIX B

SUPPORT AGAINST LIGHOSTATIC PRESSURE BY

PARTICULATE STABILIZERS OR "CLOSE-PACKED" WASTE FORMS 


\section{TABLES}

B.1. Effect of Total Compaction of Stabilizer $\quad$ B-7

B.2. Compressive Strengths of Particulates B-8 


\section{PARTICULATE STABILIZER}

Lithostatic pressure might have two effects on the compact particulate:

1) Rearrangement of the particulate to a higher packing density

2) Fracturing of the particulate, followed by rearrangement to a higher packing density.

Because of rod bow, the inter-rod spacing in a close-packed waste form is not uniform. One cannot tailor-size a particulate which would just fit into the inter-rod gaps and act as a framework which holds the rods in place. Therefore, the best particulate stabilizer would have to have a particulate size distribution which minimized stabilizer compaction under lithostatic pressure.

In practice for a single particle size, $60 \%$ dense packing is the maximum achievable density without pressure compaction. (B.1, B.2) Theoretically, close packing should achieve $76 \%$ density. If one uses a binary particulate distribution sequentially packed with a 10 to 1 coarse to fine ratio, $70 \%$ being coarse material, an $84 \%$ packing density can be achieved. (B.1, B.2) The coarse fraction fills $60 \%$ of the volume, and the fine fraction fills $60 \%$ of the remaining $40 \%$ voidage for a $24 \% \mathrm{fi} 11$.

Because of the lack of complete close packing, particulates in the stabilizer can move under lithostatic pressure until a close-packed density is achieved. If the total volume available to particulate was $V$, then this total volume would originally be filled with $60 \%$ coarse material and 
and $24 \%$ fine material. Upon completion, the coarse material would fill $0.79 \mathrm{~V}$, since it changes density from 0.7 to 0.76 (i.e., $0.6 / 0.76=0.79$ ). If this happened, then only $0.19 \mathrm{~V}$ would be available for the fine fraction $(0.79 \mathrm{~V}-0.6 \mathrm{~V})$, but a compaction of the fine material $0.24 \mathrm{~V}$ to $76 \%$ density would require a volume of $0.32 \mathrm{~V}$. Some of this volume is already available in the coarse material voidage $(0.19 \mathrm{~V})$, and the remainder $(0.13 \mathrm{~V})$ would be made up by letting the coarse fraction compact incompletely to only $0.92 \mathrm{~V}$. After compaction, a body would be left which had $92 \%$ of its original volume, consisting of a $65 \%$ dense coarse fraction and $76 \%$ dense fine fraction. In other words, a compacted mixture of rods and stabilizer would have $8 \%$ less void volume than the original stabilizer/rod mixture.

If all of this volume reduction is caused by compression of the canister in one direction, an elliptical cylinder is formed. Since lithostatic deformation occurs in the transverse cross-section of the canister, the three dimensional problem can be reduced to two dimensions in the crosssectional plane of the canister. The initial area occupied by fuel and stabilizer is:

$$
A_{\text {int }}=A_{\text {fuel }}+A_{\text {stab }}
$$

The final area occupied by fuel and stabilizer is:

$$
A_{\text {final }}=A_{\text {fuet }}+f A_{\text {stab }}
$$

where $f$ is the reduced percentage of the stabilizer area due to compaction. $A_{\text {final }}$ would be the area of the deformed elliptical canister, which has semimajor and semi-minor axis $a$ and $b$, so that:

$$
\pi a b=\left(A_{\text {fuel }}+f A_{\text {stab }}\right)=A_{\text {final }}
$$


The initially circular canister had a circumference:

$$
C=2 \pi\left(\frac{A_{\text {fuel }}+A_{\text {stab }}}{\pi}\right) 1 / 2
$$

which must be conserved during the deformation process, so that:

$$
\frac{a^{2}+b^{2}}{2}=\frac{A_{\text {fuel }}+A_{\text {stab }}}{\pi}
$$

Here $a$ and $b$ are given by the two roots of the solution of the system of equations (3) and (4).

$$
a, b=\left[\frac{A_{\text {fuel }}+A_{\text {stab }} \pm\left[\left(A_{\text {fuel }}+A_{\text {stab }}\right)^{2}-\left(A_{\text {fuel }}+f A_{\text {stab }}\right)^{2}\right]^{1 / 2}}{\pi}\right]^{1 / 2}
$$

Since the deformation forces are perpendicular to the axis of the canister, the area in the plane of deformation will only be reduced to 0.946 of its original value or $f=0.946$ (i.e., 0.92 raised to the $2 / 3$ power). With this value of $f$, the axis of the ellipse which can be calculated from:

$$
a, b=\left[\frac{A_{\text {fuel }}+A_{\text {stab }} \pm \sqrt{0.108 A_{\text {fuel }} A_{\text {stab }}+0.105 A_{\text {stab }}^{2}}}{\pi}\right]^{1 / 2}
$$

as shown in Table B1. The eccentricity $(\epsilon)$ of the resulting deformed canister is given by:

$$
\epsilon=\left(1-\left(\frac{b}{a}\right)^{2}\right)^{1 / 2}
$$

These are the maximum eccentricities that could occur from unfractured compaction if the lithostatic pressure is great enough to cause undirectional deformation of the canister. 
In addition, fracturing of the particulate could occur, which would change both the particulate size and shape distribution and hence the packing density. The probability of this happening depends on the compacting pressure and the compressive strength of the particulate material. Typical compressive strengths for particulates under consideration are given in Table B.2. If the compressive strength of the particulate is below the lithostatic pressures, which would be the case for graphite and granite, for instance, then crushing of the particulate would occur. Even if the compressive strength is above the lithostatic pressures, there could be considerable fracturing of the particulate. This has been demonstrated for quartz, where compacting pressures of $2.2 \times 10^{3}$ psi (1/3 of the compressive strength) resulted in a significant change in the particulate size distribution. (B.3)

Unfortunately, the relative ratio at which the compaction and fracturing take place is unknown. Compaction studies, although conducted as low as 7000 psi, are usually conducted on loosely packed powder, i.e., $70 \%$ void fraction. On the other hand, fracture studies are usually done at 22,000 psi, which is much higher than lithostatic pressures. (B.2, B.4)

An accurate assessment of a particulate as a stabilizer which resists lithostatic pressure on the canister is difficult to make. First, while there is the possibility of compaction, it is not known if the lithostatic pressure is high enough to cause this compaction. Curves of final density vs density of the particulate at lithostatic pressures are needed to answer this question. Second, while uniform compaction has been assumed in this 
In Grid Assembly Disassembled

Canister I.D. (in)

No. of Assemblies PWR

BWR

Total Internal Canister Cross Section $\left(\mathrm{in}^{2}\right)$

143

123

Total Rod Cross Section PWR 264 rods/assy 29

87

BWR 55 rods/assy

19.4

67.7

Cross Section Area for Stabilizer $\left(i^{2}\right)$

$\begin{array}{lll}\text { PWR } & 114 & 35 \\ \text { BWR } & 123 & 54.3\end{array}$

Deformed Ellipse Major semiaxis a and semiaxis b

$\begin{array}{lll}\text { PWR } & 7.66 / 5.68 & 6.78 / 5.69 \\ \text { BWR } & 7.69 / 5.64 & 6.90 / 5.54\end{array}$

Eccentricity

$\begin{array}{lll}\text { PWR } & .67 & .54 \\ \text { BWR } & .68 & .60\end{array}$


TABLE B.2

COMPRESSIVE STRENGTHS OF PARTICULATES

Material

Alumina
Basalt
Silica (amophous/quartz)
Granite
Graphite
UO 2 (irradiated)

Strength (psi)

$1.4-4 \times 10^{5(B 5)}$

$2.8-5 \times 10^{4(B 5)}$

$6.4 \times 10^{4}$ (240. $\mathrm{C}^{(\mathrm{B} 2)}$

$2.9 \times 10^{3(B 5)} \rightarrow 1.9 \times 10^{4}$ @ $240^{\circ} \mathrm{C}^{(\mathrm{B} 2)}$

$1.8 \times 10^{3(B 5)}$

$1.2 \times 10^{5(B 6)}$ 
analysis, a density gradient is established in pressed powders. (B.3) Third, it is not known whether the canister can withstand the eccentricity at maximum compression. Based on eccentricities in Table B.1, it is concluded that the particulate stabilizer is slightly more effective in the close-packed form than the in-grid waste form.

\section{II. "CLOSE-PACKED" WASTE FORM}

For the close-packed case, the rods themselves may help resist the 1ithostatic pressure. The theoretical triangular close-packed density for rods is approximately $91 \%$. Studies on unirradiated unbound rods at $A 11$ ied General Nuclear Services, indicate that the rods would pack to approximately $79 \%$. Actually, the density would probably be less because of bowing of the rods. If packing was $79 \%$ and 1 ithostatic pressure was applied to the canister unaxially to rearrange the rods to the close-packed configuration $(91 \%)$, the bundle would have $86 \%$ of its original volume i.e., $14 \%$ of the canister volume would be available for deformation. In this case, the full $14 \%$ compaction would occur in the plane of the lithostatic pressure. The reduced canister area and conservation of circumference can be used to obtain the axis of the ellipse in the same way in which it was obtained in the case of the particulate stabilizer.

$$
a, b=(38.83 \pm 10.51)^{1 / 2}
$$

This means that the ellipse has an eccentricity of 0.65 . 


\section{REFERENCES}

B.1 W. D. Kingery, ED., Ceramic Fabrication Processes, John Wiley \& Sons, Inc., New York, NY, 1958.

B.2 W. D. Kingery, Introduction to Ceramics, 1960, John Wiley \& Sons, New York, NY.

B.3 E. Turban, "The Behavior of Powders Compacted in a Die", Proceedings of the British Ceramic Society 3, p. 101, September 1965.

B.4 A. L. Struijts and G. J. Ondemans, "Ceramic Forming Methods", Proceedings of the British Ceramic Society 3, p. 81, September 1965.

B.5 N. Wynhoff, S. E. Girault, R. L. Fish, Spent Fuel Stabilizer Material Characterization and Screening, HEDL-TME 81-2, Hanford Engineering Development Laboratory, Richland, WA, November 1981.

B.6 D. R. 01 ander, Fundamental Aspects of Nuclear Reactor Fuel Elements, TID-26711-P2 (1976)

B.7 G. A. Townes, Spent Fuel Disassembly and Canning Programs at the Barnwell Nuclear Fuel Plant (BNFP), October 1980, AGNS-35900-1.2-104 


\section{APPENDIX C}

A SIMPLIFIED BARRIER BREAKDOWN AND FISSION PRODUCT RELEASE MODEL

$c-1 \cdot c-2$ 
- 
APPENDIX C

A SIMPLIFIED BARRIER BREAKDOWN AND FISSION PRODUCT RELEASE MODEL

Each fuel pin in the waste form is assumed to contain two sources of fission products :

1. leaching/dissolution from the fuel matrix.

2. dissolution of fission products residing in the fuel/cladding gap.

In addition, the chopped fuel option is expected to produce a quantity of powdered fuel suspended in the stabilizer used to immobilize the chopped rod pieces. As the breakdown of the stabilizer (if used), the cladding, and fuel proceeds under attack by flowing groundwater, each source is assumed to be characterized by:

1. an initial fission product inventory.

2. a "capacity" relating time-dependent inventory and the driving potential for transport.

3. an internal resistance to migration out of the source.

Once free of the source, the transporting material must pass through a series of resistances formed by the remains of any barriers between the sources and the inside of the canister remains. These terms will now be explicitly defined by an internally consistent set of relations.

For each source, the potential driving migration is assumed to be the source concentration, $c$, and the capacity is defined as the source volume, $V$, so that, for the $j \frac{\text { th }}{\text { source: }}$

$$
M_{j}=V_{j} c_{j}
$$

where $M_{j}$ is the total mass inventory of fission products in the $j$ th source. The total transport resistance for the $j$ th source, $R_{j}$, is the sum of the internal resistance of the source, $R_{0 j}$, and the barrier resistances: 


$$
R_{j}=R_{o j}+R_{c}+R_{s}
$$

where $R_{c}$ and $R_{s}$ are the transport resistances due to the cladding and the stabilizer, respectively. These resistances are defined such that:

$$
f_{j} \equiv \frac{c_{j}}{R_{j}}
$$

where $f_{j}$ is the mass transport rate of fission products out of the waste form from the $j \frac{\text { th }}{\text { source. }}$

A source resistance is defined by:

$$
R_{0 j} \equiv \frac{1}{A_{j} \nu_{j}}
$$

where $v_{j}$ is the effective source volume release rate per unit area exposed to attack (derived from leaching or corrosion data), and $A_{j}$ is the source area exposed to attack consistent with the derivation of $v_{j}$. Since the changes in $A_{j}$ with time are not in general known, $A_{j}$ is assumed to be a constant for purposes of this mode1. A transport barrier resistance is defined by:

$$
R \equiv \frac{X}{A v}
$$

where $A$ is the barrier area, $v$ is the transport speed (as determined by rate of groundwater movement), and $x$ is an assumed geometric resistance factor defined by:

$$
x=\frac{\text { total area of barrier }}{\text { area of barrier penetrations }}
$$

Note that a completely intact barrier implies $x=\infty$, while a completely permeable barrier implies $x=1$.

For the $j$ th source, the system is described by: 


$$
\begin{aligned}
& v_{j} \frac{d c_{j}}{d t}=-f_{j} \\
& \text { or } \quad \frac{d c_{j}}{d t}=-\frac{c_{j}}{v_{j} R_{j}}
\end{aligned}
$$

with the initial condition that:

$$
c_{j}=c_{j 0} \text { at } t=t_{0}
$$

where $c_{j 0}$ is the source concentration at time $t_{0}$. A straightforward integration incorporating the initial condition leads easily to:

$$
c_{j}=c_{j 0} \exp \left(-\frac{\psi_{j}}{v_{j}}\right)
$$

where $\psi_{j}=\int_{t_{0}}^{t} \frac{1}{R_{j}} d t^{\prime}$

Combining [3] and [10] yields the instantaneous release rate from the $j$ th source:

$$
f_{j}=\frac{c_{j 0}}{R_{j}} \exp \left(-\frac{\psi_{j}}{V_{j}}\right)
$$

The instantaneous and integrated release rates will, in general, be evaluated over a series of time intervals with different prevailing conditions so that $c_{j o}$ is the initial concentration at time $t_{0}$ which marks the beginning of the time interval under consideration. The arbitrary zero time $(t=0)$ is defined to be the moment that the canister is assumed to fail exposing the waste form to ground water. The forms of the total transport resistance to be considered in this preliminary analysis are: (a) constant, and (b) linear with time. For the case of constant transport resistance, Eq. [11] reduces to:

$$
\psi_{j}=\frac{t-t_{0}}{R_{j}}
$$


and, substituting into [12], the release rate becomes:

$$
f_{j}=\frac{c_{j 0}}{R_{j}} \exp \left(-\frac{t-t o}{R_{j} V_{j}}\right)
$$

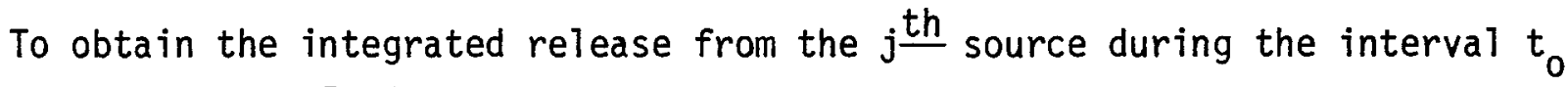
to $t$, integrate Eq. [14]:

$$
\int_{t_{0}}^{t} f_{j} d t^{\prime}=\frac{c_{j o}}{R_{j}} \int_{t_{0}}^{t} \exp \left(-\frac{t^{\prime}-t_{0}}{R_{j} V_{j}}\right) d t^{\prime}
$$

which yields:

$$
\int_{t_{0}}^{t} f_{j} d t^{\prime}=c_{j 0} V_{j}\left[1-\exp \left(-\frac{t-t_{0}}{R_{j} V_{j}}\right)\right]
$$

The total integrated release between time $t=0$ and $t$ can be found by summing Eq. [16] with the integrated releases during the previous intervals, i.e.,

$$
\int_{0}^{t} f_{j} d t^{\prime}=\int_{0}^{t} f_{j} d t^{\prime}+\int_{t_{0}}^{t} f_{j} d t^{\prime}
$$

Note that if, for the $j$ th source, $c_{j j}$ is the concentration at $t=0$, then the source concentration, $c_{j o}$, at the beginning of the current inteval is given by:

$$
c_{j 0}=c_{j i} \frac{\int_{0}^{t}{ }^{o_{f} d t^{\prime}}}{v_{j}}
$$

For the case of a transport resistance which is linear with time, let the total (positive) resistance $R$, be given by:

$$
R_{j}=a-b t \text { for } t_{0} \leq t
$$


The integrated conductance defined by Eq. [11] then becomes:

$$
\psi_{j}=\int_{t_{0}}^{t} \frac{1}{a-b t^{\prime}} d t^{\prime}
$$

or $\quad \psi_{j}=\frac{1}{b} \ln \left(\frac{a-b t_{0}}{a-b t}\right)$

Substituting into Eq. [12] produces the $j$ th source release rate:

$$
f_{j}=\frac{c_{j 0}}{R_{j}} \exp \left[-\frac{1}{b V_{j}} \ln \left(\frac{a-b t_{0}}{a-b t}\right)\right]
$$

or $\quad f_{j}=\frac{c_{j 0}}{R_{j}}\left(\frac{a-b t}{a-b t_{0}}\right) \frac{1}{b V_{j}}$

and making use of Eq. [19]

$$
f_{j}=c_{j 0} \frac{(a-b t)^{\frac{1}{b V_{j}}-1}}{\left(a-b t_{0}\right)^{\frac{1}{b V_{j}}}}
$$

Finally, integration yields:

$$
\int_{t o}^{t} f_{j} d t^{T}=c_{j 0} V_{j}\left[1-\left(\frac{a-b t}{a-b t_{0}}\right)^{\frac{1}{b V_{j}}}\right]
$$

for $t_{0} \leq t$ and $b \neq 0$.

As before, the total integrated release from $t=0$ to $t$ can be found using Eq. [17]. 
Once the release rates and integrated releases from the various sources have been determined at a given time $t$, the totals from all sources in each of the fuel rods can be obtained by summing the individual contributions. The totals for the canister can then be found by summing over the rods in the canister and including releases from fuel dissolved in the matrix (for the chopped fuel case). 
APPENDIX D

RANKING FOR THE WASTE FORM/STABILIZER COMBINATIONS

$D-1-D-2$ 
-

1

- 
TABLE D. 1

RANKING OF THE WASTE FORM/STABILIZER COMBINATIONS IN THE TEMPERATURE RANGE $<425^{\circ} \mathrm{C}$ Worst Best

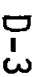
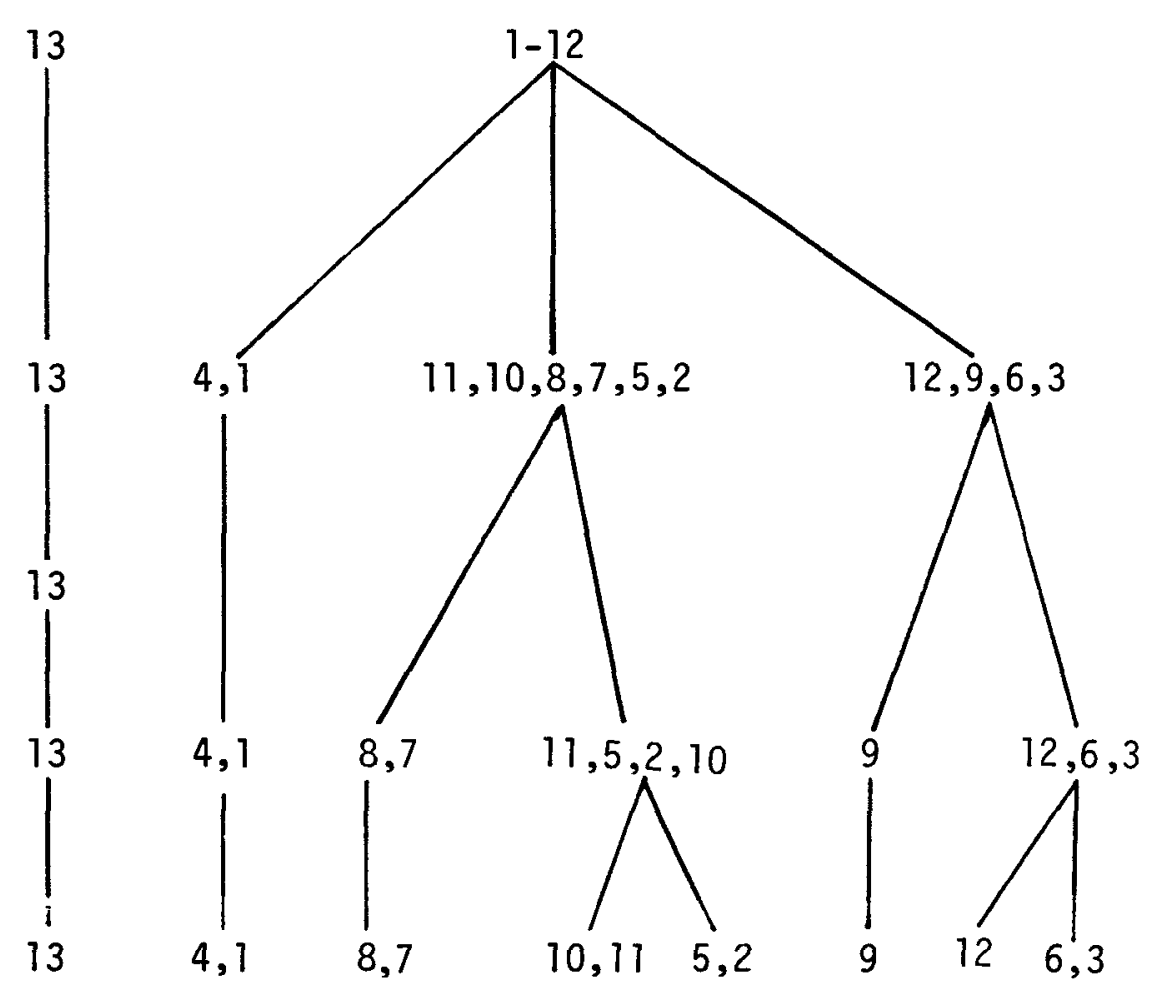

(intact cladding needed)

Maintain Fuel Stability

Minimize Cladding Degradation

Support Against Lithostatic

Pressure

Prevent Criticality

Prevent Compromise of Canister Integrity

Stabilizer Heat Transfer 
TABLE D.1 (Cont'd)

RANKING OF THE WASTE FORM/STABILIZER COMBINATIONS IN THE TEMPERATURE RANGE $\angle 425^{\circ} \mathrm{C}$ Worst $\longrightarrow$ Best

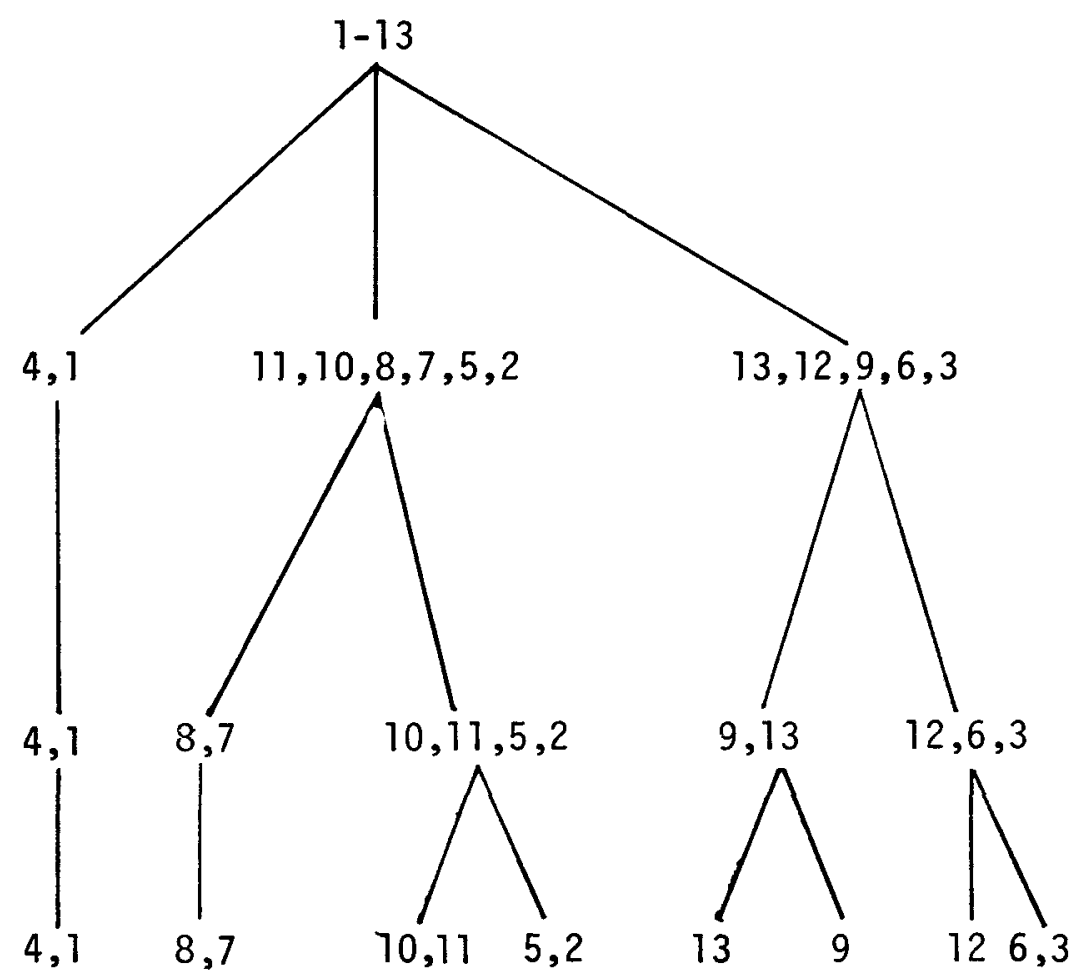

(intact cladding not needed) Maintain Fuel Stability

Minimize Cladding Degradation

Support Against Lithostatic Pressure

Prevent Criticality

Prevent Compromise of Canister Integrity

Stabilizer Heat Transfer 
TÁBLE D.2

RANKING OF THE WASTE FORM/STABILIZER COMBINATIONS IN THE TEMPERATURE RANGE $425-600^{\circ} \mathrm{C}$ Worst Best

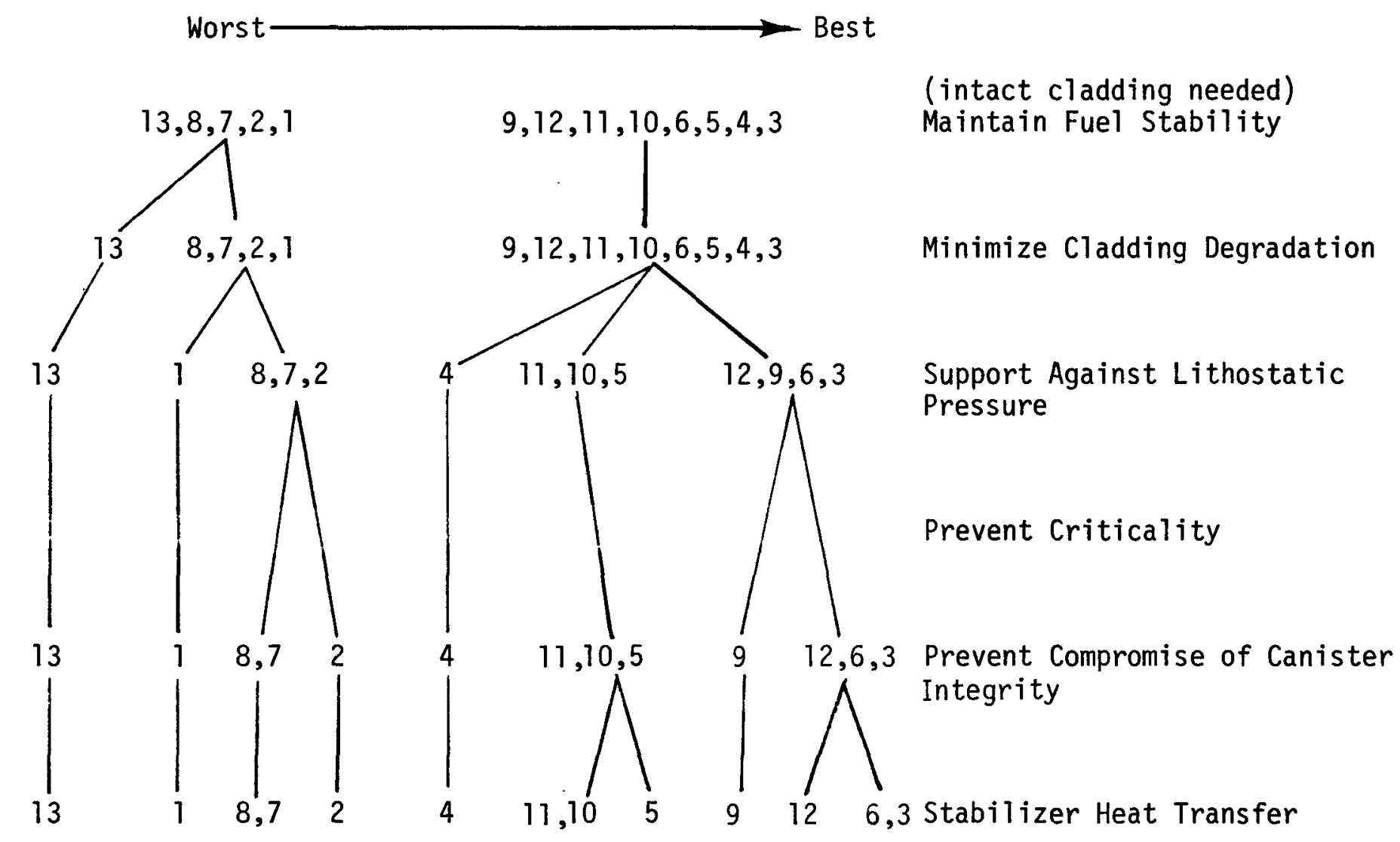


TABLE D.2 (Cont'd)

RANKING OF THE WASTE FORM/STABILIZER COMBINATIONS IN THE TEMPERATURE RANGE $425-600^{\circ} \mathrm{C}$

Worst

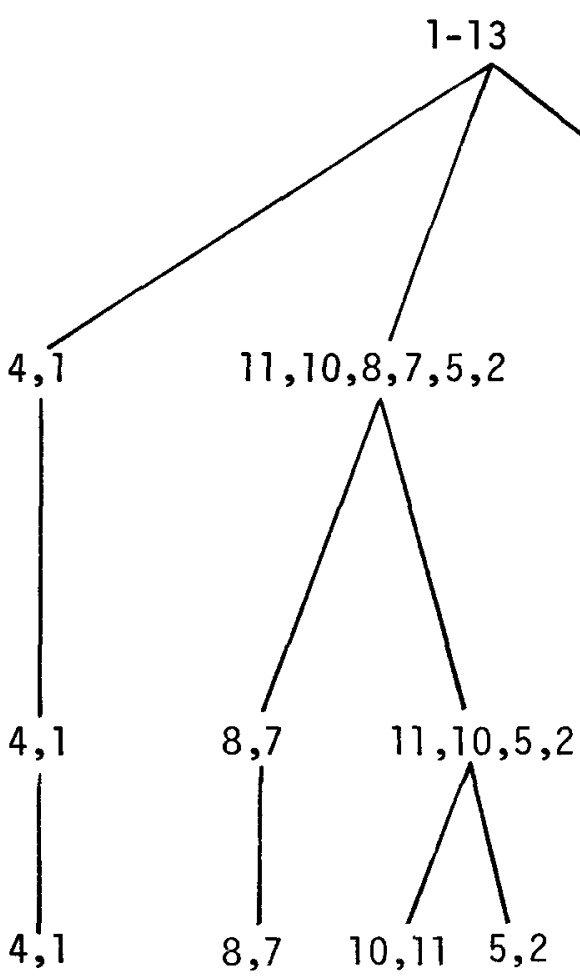

(intact cladding not needed) Maintain Fuel Stability

Minimize Cladding Degradation

Support Against Lithostatic Pressure

\section{Prevent Criticality}

Prevent Compromise of Canister Integrity

Stabilizer Heat Transfer 
TABLE D. 3

RANKING OF THE WASTE FORM/STABILIZER COMBINATIONS IN THE TEMPERATURE RANGE $600-660^{\circ} \mathrm{C}$ Worst $\longrightarrow$ Best

(intact cladding needed) Maintain Fuel Stability
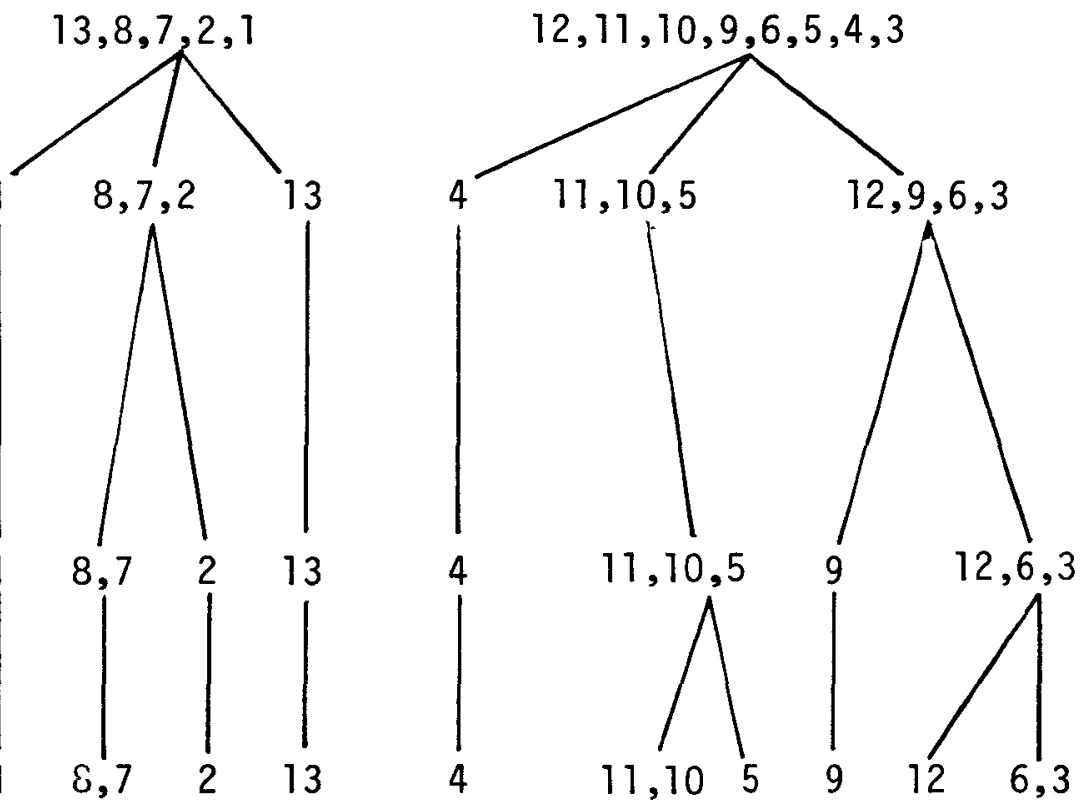

Minimize Cladding Degradation

Support Against Lithostatic Pressure

Prevent Criticality

Prevent Compromise of Canister Integrity

Stabilizer Heat Transfer 
TABLE D.3 (Cont'd)

RANKING OF THE WASTE FORM/STABILIZER COMBINATIONS IN THE TEMPERATURE RANGE $600-660^{\circ} \mathrm{C}$ Worst $\longrightarrow$ Best

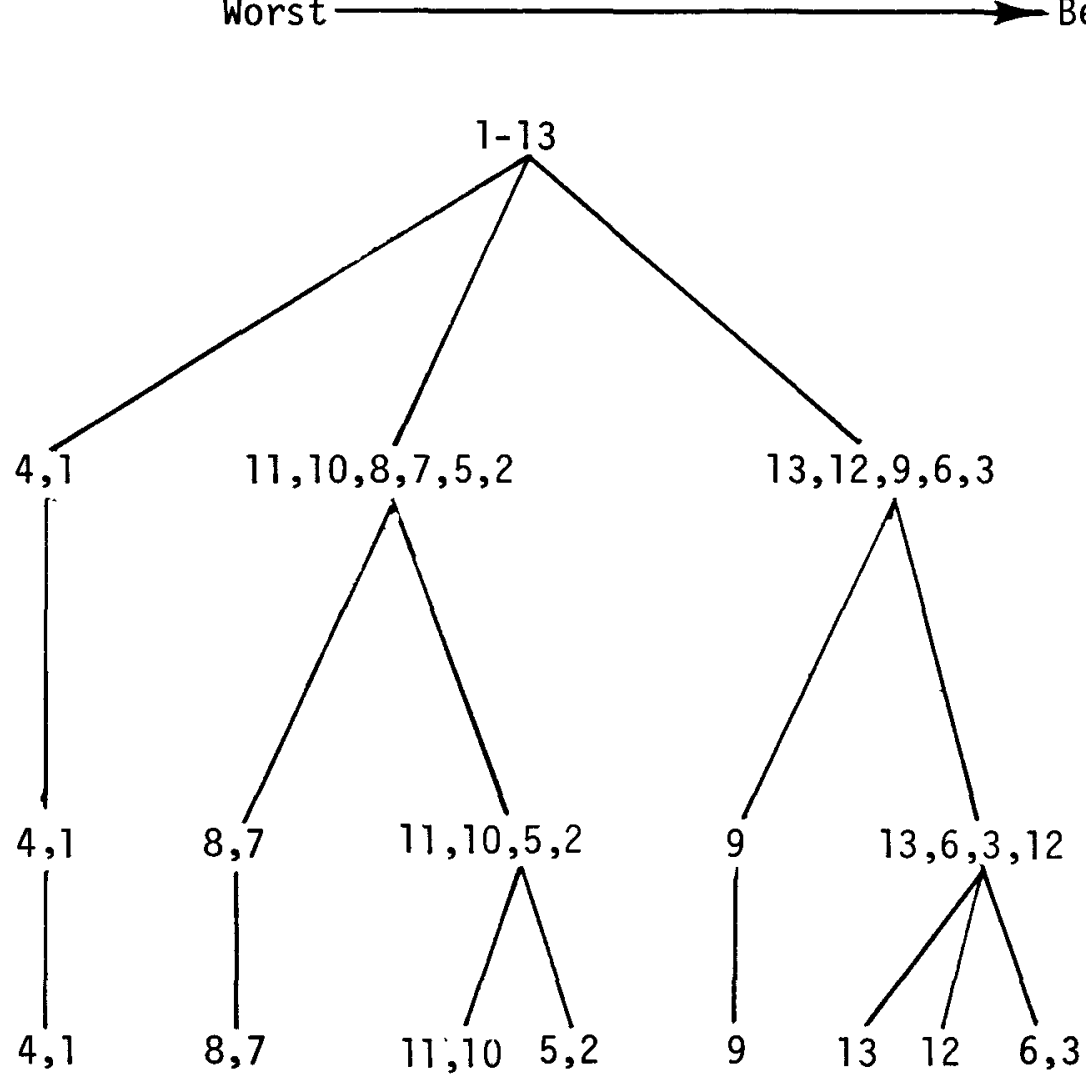

(intact cladding not needed)

Maintain Fuel Stability

Minimize Cladding Degradation

Support Against Lithostatic

Pressure

Prevent Criticality

Prevent Compromise of Canister Integrity

Stabilizer Heat Transfer 
TABLE D.4

RANKING OF THE WASTE FORM/STABILIZER COMBINATIONS IN THE TEMPERATURE RANGE $>660^{\circ} \mathrm{C}$
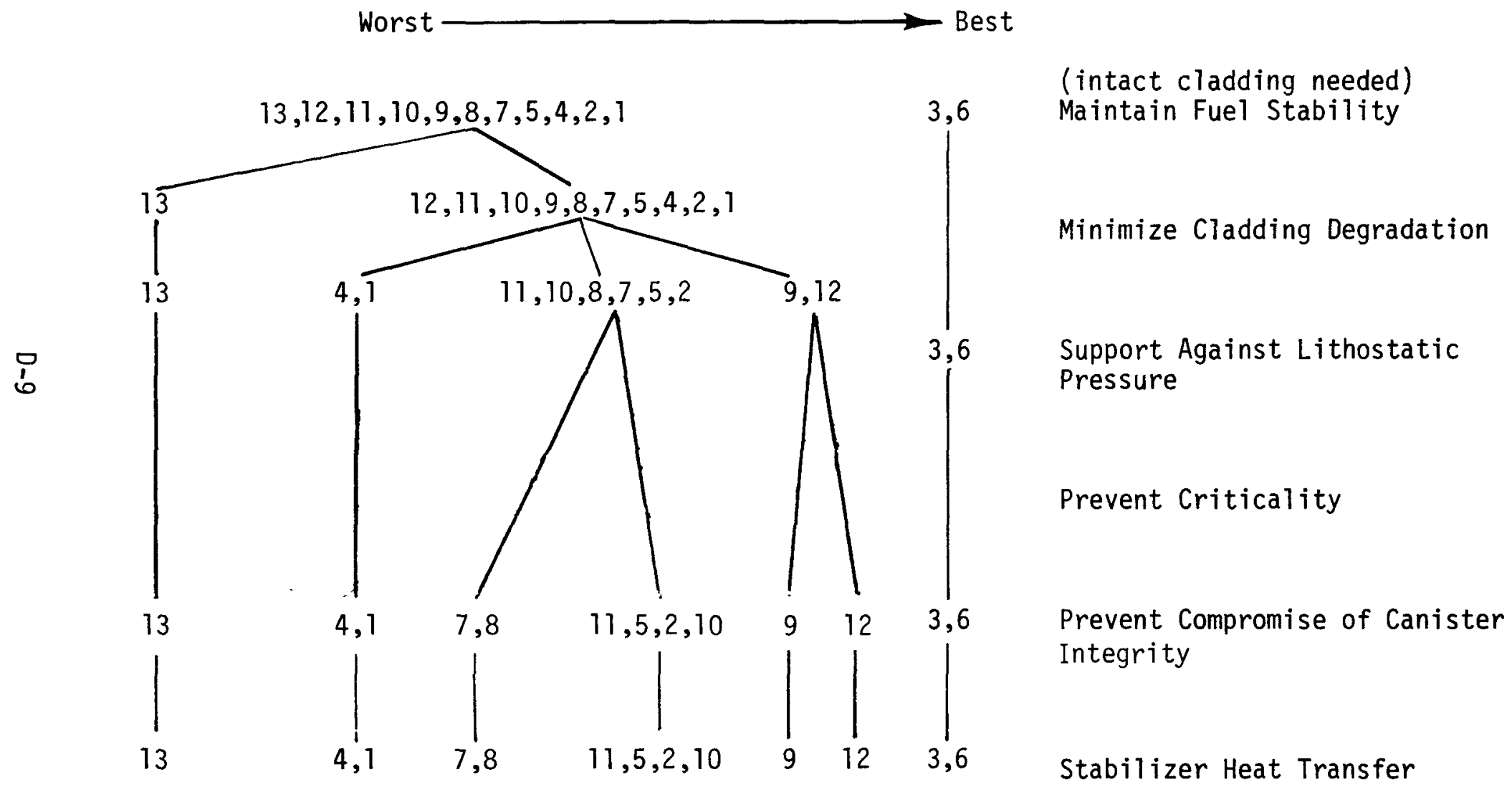
TABLE D.4 (Cont'd)

RANKING OF THE WASTE FORM/STABILIZER COMBINATIONS IN THE TEMPERATURE RANGE $>660^{\circ} \mathrm{C}$ Worst Best

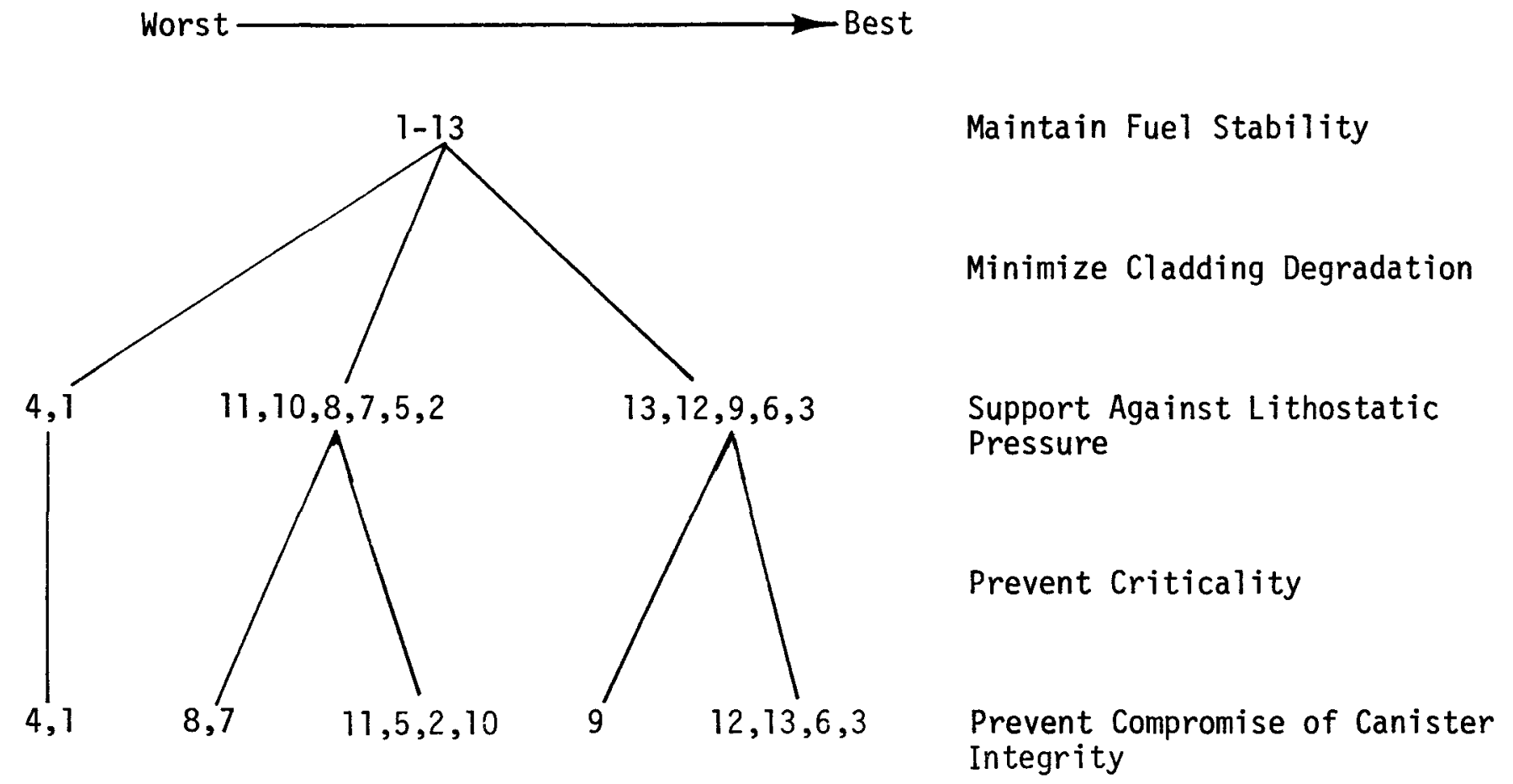

Stabilizer Heat Transfer 
TABLE D. 5

RANKING OF THE WASTE FORM/STABILIZER COMBINATIONS IN THE TEMPERATURE RANGE $<425^{\circ} \mathrm{C}$
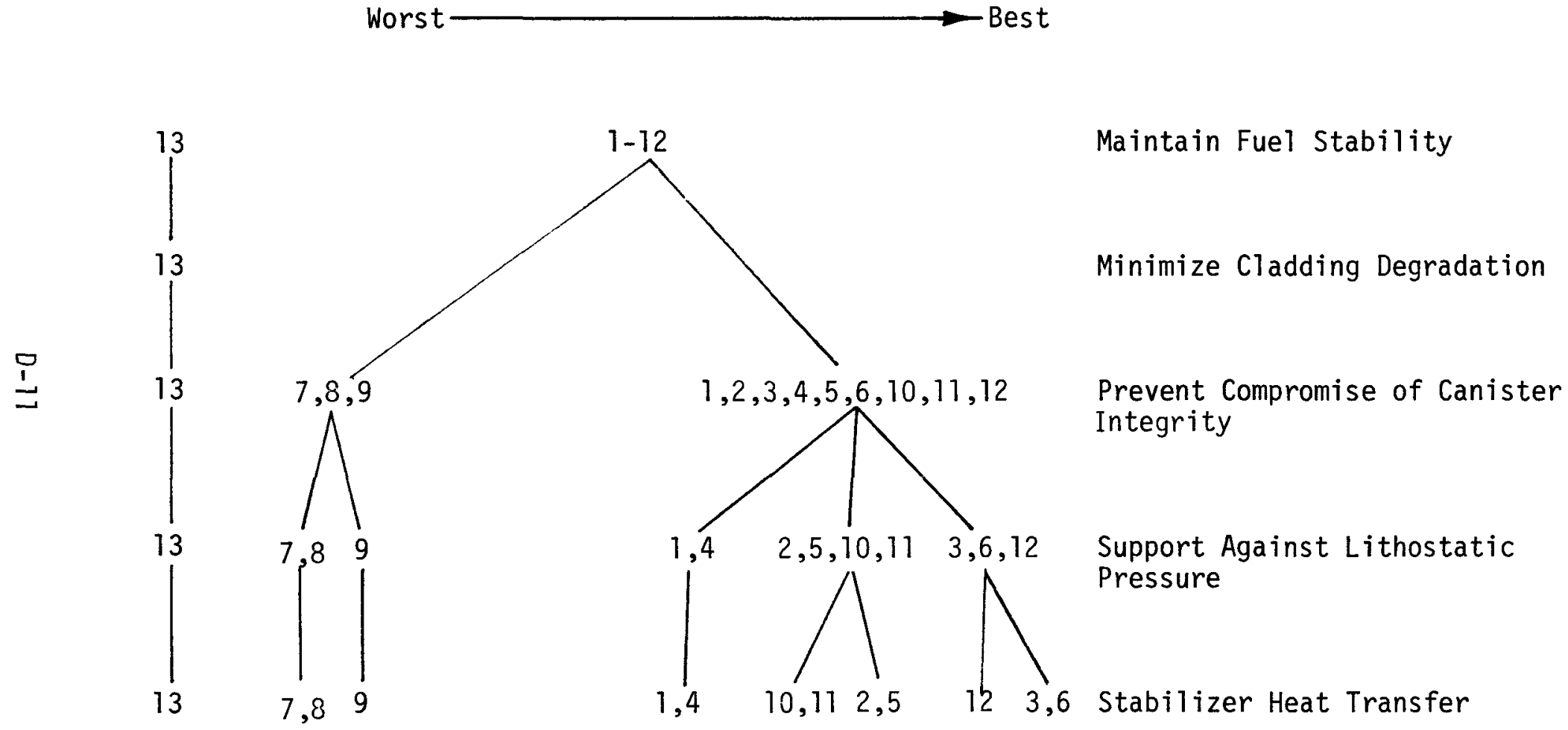

Prevent Criticality 
TABLE D.5 (Cont'd)

RANKING OF THE WASTE FORM/STABILIZER COMBINATIONS IN THE TEMPERATURE RANGE $<425^{\circ} \mathrm{C}$ Worst $\longrightarrow$ Best

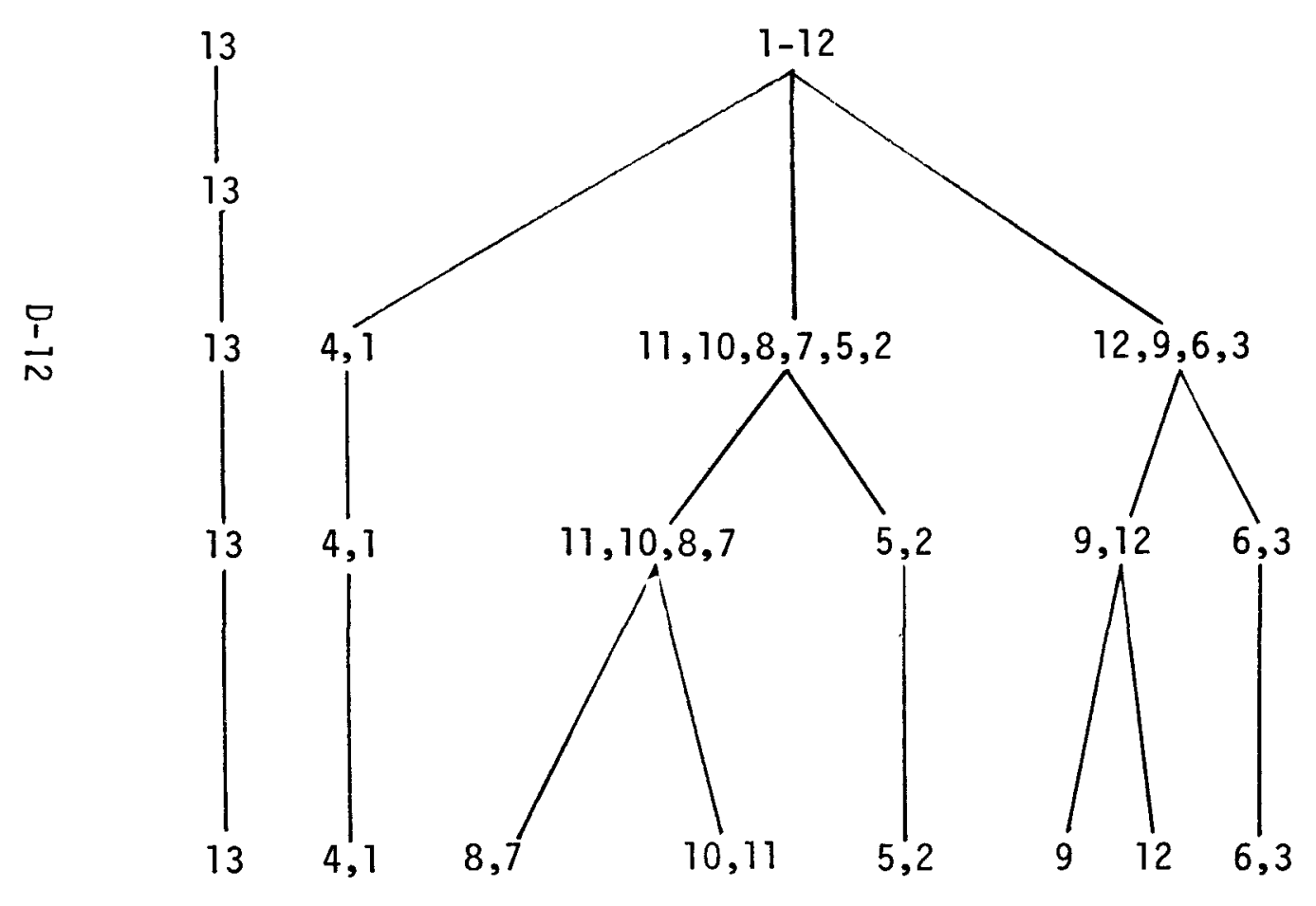

Maintain Fuel Stability

Minimize Cladding Degradation

Support Against Lithostatic

Pressure

Temperature Limit

Prevent Criticality

Prevent Compromise of Canister Integrity 
TABLE D.5 ( Cont $\left.{ }^{1} d\right)$

RANKING OF THE WASTE FORM/STABILIZER COMBINATIONS IN THE TEMPERATURE RANGE $<425^{\circ} \mathrm{C}$ Worst $\longrightarrow$ Best

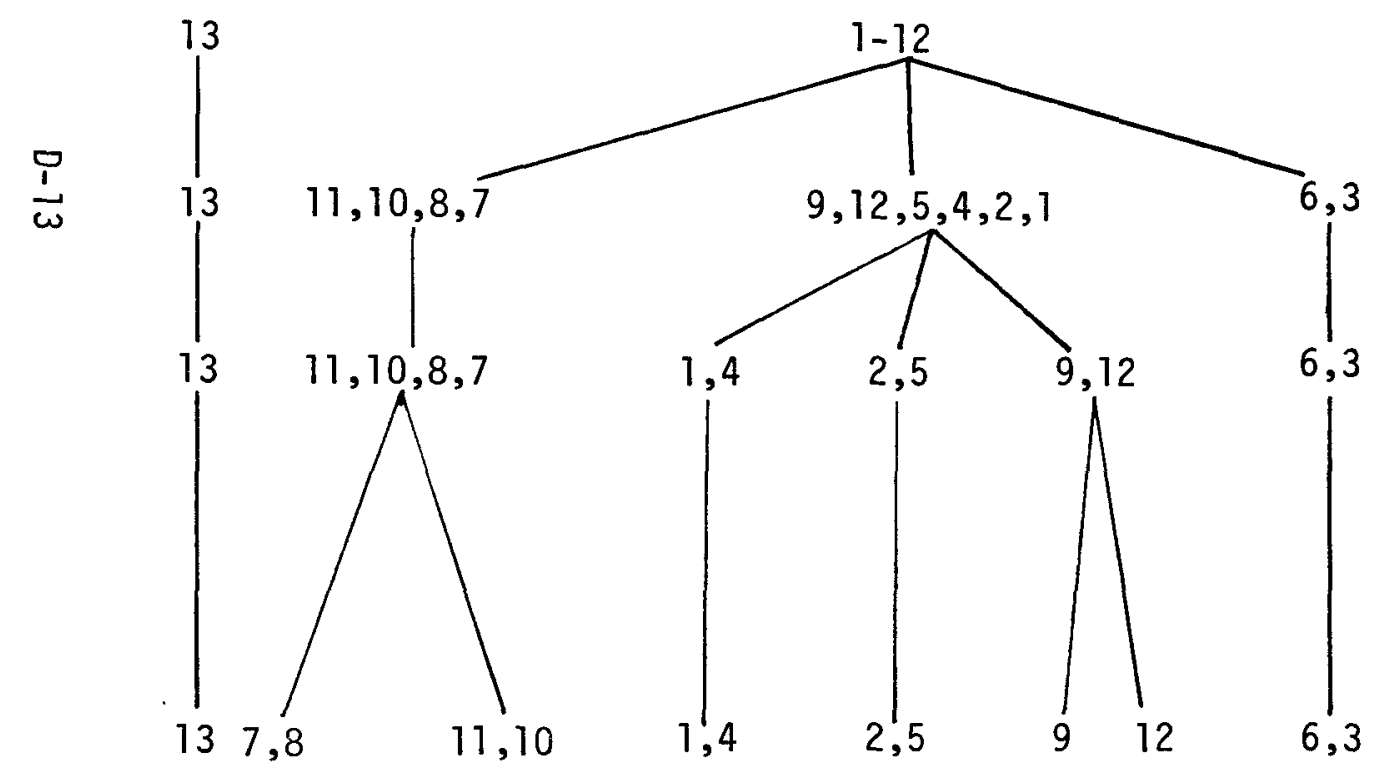

Maintain Fuel Stability

Minimize Cladding Degradation

Temperature Limit

Support Against Lithostatic

Pressure

Prevent Criticality

Prevent Compromise of Canister Integrity 
○

- 


\section{APPENDIX E}

THERMAL STRESSES IN A SOLID CYLINDER WITH AXISYMMETRIC TEMPERATURE GRADIENT

$$
E-1-E-2
$$


- 


\section{APPENDIX E}

THERMAL STRESSES IN A SOLID CYLINDER

WITH AXISYMMETRIC TEMPERATURE GRADIENT

\section{M. Bosi}

For a solid cylinder with a uniformly distributed heat source, the temperature profile is symmetric about the cylinder axis. It is conservatively assumed that all heat is conducted radially (i.e., no end effects). The radial temperature profile in such a case is easily shown to be given by

$$
T-T_{0}=\frac{\dot{q} r_{0}^{2}}{4 k}\left(1-\frac{r^{2}}{r_{0}^{2}}\right)
$$

where $\dot{q}=$ volumetric heat source,

$$
\begin{aligned}
& r_{0}=\text { outer radius of cylinder, } \\
& T_{0}=\text { temperature at } r_{0}, \text { and } \\
& k=\text { thermal conductivity. }
\end{aligned}
$$

Due to the nonuniform temperature, thermal stresses are set up in the cylinder.

From Hooke's Law, the strains $(\varepsilon)$ in terms of the stresses $(\sigma)$ are

$$
\begin{aligned}
& \varepsilon_{z}=\frac{1}{E}\left[\sigma_{z}-v\left(\sigma_{r}+\sigma_{\theta}\right)\right]+\alpha \Delta T, \\
& \varepsilon_{r}=\frac{1}{E}\left[\sigma_{r}-v\left(\sigma_{z}+\sigma_{\theta}\right)\right]+\alpha \Delta T, \quad \text { and } \\
& \varepsilon_{\theta}=\frac{1}{E}\left[\sigma_{\theta}-v\left(\sigma_{z}+\sigma_{r}\right)\right]+\alpha \Delta T
\end{aligned}
$$

where $E$ = Young's Modulus,

$\nu=$ Poisson's Ratio,

$\alpha=$ thermal expansion coefficient, 
$\Delta T=$ temperature increase above a uniform initial temperature, and $z, r$, and $\theta=$ axial, radial, and azimuthal directions, respectively.

Material properties are assumed constant with temperature.

Thermal deformation of the cylinder progresses in a plane strain stress state, i.e., deformation along the axis of the cylinder must be uniform and constant. This is imposed by the symmetry of the cylinder geometry preventing any bending deformation along the longitudinal axis when an axisymmetric temperature distribution is present. Thus the strains in terms of the axial and radial displacements are

$$
\begin{aligned}
& \varepsilon_{z}=\frac{d w}{d z}=\text { constant, } \\
& \varepsilon_{r}=\frac{d u}{d r}, \text { and } \\
& \varepsilon_{\theta}=\frac{u}{r}
\end{aligned}
$$

where $w=$ axial displacement, and

$u=$ radial displacement.

Using Eqn. [2], the strain increase in volume after thermal deformation is

$$
\Delta=\varepsilon_{z}+\varepsilon_{r}+\varepsilon_{\theta}=\frac{1-2 v}{E}\left(\sigma_{z}+\sigma_{r}+\sigma_{\theta}\right)+3 \alpha \Delta T
$$

Solving for the stresses in Eqn. [2] and using Eqn. [4] to give the stressstrain equilibrium in terms of the strain deformation only gives

$$
\begin{aligned}
& \sigma_{z}=\frac{E}{1+\nu}\left(\varepsilon_{z}+\frac{\nu}{1-2 \nu} \Delta\right)-\frac{\alpha \Delta T E}{1-2 \nu}, \\
& \sigma_{r}=\frac{E}{1+\nu}\left(\varepsilon_{r}+\frac{\nu}{1-2 \nu} \Delta\right)-\frac{\alpha \Delta T E}{1-2 \nu}, \text { and } \\
& \sigma_{\theta}=\frac{E}{1+\nu}\left(\varepsilon_{\theta}+\frac{\nu}{1-2 \nu} \Delta\right)-\frac{\alpha \Delta T E}{1-2 \nu} .
\end{aligned}
$$


Equilibrium of forces on a radial element of the cylinder of angular width $\phi$ requires

$$
\left(\sigma_{r}+\frac{d \sigma_{r}}{d r} d r\right)(r+d r)_{\phi}=2 \sigma_{\theta} d r \sin \left(\frac{\theta}{2}\right)+\sigma_{r} r \phi .
$$

For small $\phi, \sin \left(\frac{\phi}{2}\right) \approx \frac{\phi}{2}$ and the stress equilibrium for the element reduces to

$$
\frac{d \sigma_{r}}{d r}+\frac{\sigma_{r}-\sigma_{\theta}}{r}=0 \text {. }
$$

Substituting the stress-strain equilibrium-Eqn. [5] and the strain displacement Eqn. [3] into the element equilibrium Eqn. [6] leads to the element displacement compatibility relation in terms of $u$ :

$$
\frac{d}{d r}\left[\frac{1}{r} \frac{d}{d r}(r u)\right]=\frac{1+v}{1-v} \propto \frac{d \Delta T}{d r} .
$$

Integration yields the solution

$$
u=\frac{1}{r} \frac{1+\nu}{1-v} \int_{0}^{r} \alpha \Delta T r d r+C_{1} r+\frac{C_{2}}{r} \text {. }
$$

The integration constants $C_{1}$ and $C_{2}$ are determined from boundary and displacement conditions:

$$
\begin{aligned}
u & =0 \text { at } r=0 \\
\sigma_{r} & =0 \text { at } r=r_{0} \text { (no external force at the surface) }
\end{aligned}
$$

Applying boundary condition [9] to Eqn. [8] immediately produces

$$
c_{2}=0 \text {. }
$$

To evaluate $C_{1}$, combine Eqns. [3] and [5] to yield

$$
\sigma_{r}=\frac{E}{1+\nu}\left[\frac{d u}{d r}+\frac{v}{1-2 v}\left(\frac{d u}{d r}+\frac{u}{r}+\varepsilon_{z}\right)\right]-\frac{\alpha \Delta T E}{1-2 v} .
$$

But, from [8] and [11],

$$
\frac{u}{r}=\frac{1}{r^{2}} \frac{1+v}{1-\nu} \int_{0}^{r} \alpha \Delta T r d r+C_{1} \text {, and }
$$




$$
\frac{d u}{d r}=-\frac{1}{r^{2}} \frac{1+\nu}{1-\nu} \int_{0}^{r} \alpha \Delta T r d r+\frac{1+\nu}{1-\nu} \alpha \Delta T+C_{1}
$$

Substituting [13] and [14] into [12] yields

$$
\sigma_{r}=\frac{E}{1+\nu}\left[-\frac{1}{r} \frac{1+\nu}{1-\nu} \int_{0}^{r} \alpha \Delta T r d r+\frac{C_{1}}{1-2 \nu}+\frac{\nu}{1-2 \nu} \varepsilon_{z}\right]
$$

Finally, applying boundary condition [10] to Eqn. [15] gives

$$
C_{1}=\frac{1}{r_{0}^{2}} \frac{1-2 \nu}{1-\nu}(1+\nu) \int_{0}^{r_{0}} \alpha \Delta T r d r-\nu \varepsilon_{z} \text {, }
$$

and substituting back into [15] produces

$$
\sigma_{r}=\frac{E}{1+v}\left[-\frac{1}{r^{2}} \frac{1+v}{1-v} \int_{0}^{r} \alpha \Delta T r d r+\frac{1}{r_{0}^{2}} \frac{1+v}{1-v} \int_{0}^{r_{0}} \alpha \Delta T r d r\right] .
$$

Now from [6]

$$
\sigma_{\theta}=\sigma_{r}+r \frac{d \sigma_{r}}{d r}
$$

and from [16]

$$
\frac{d \sigma_{r}}{d r}=\frac{E}{1-\nu}\left[\frac{2}{r^{3}} \int_{0}^{r} \alpha \Delta T r d r-\frac{\alpha \Delta T}{r}\right]
$$

Therefore,

$$
\sigma_{\theta}=\frac{E}{T-\nu}\left[\frac{1}{r^{2}} \int_{0}^{r} \alpha \Delta T r d r+\frac{1}{r_{0}^{2}} \int_{0}^{r_{0}} \alpha \Delta T r d r-\alpha \Delta T\right] \text {. }
$$

From Eqn. [1], the center temperature, $T_{c}$ at $r=0$ is given by:

$$
T_{C}-T_{0}=\frac{\dot{q} r_{0}^{2}}{4 k} \text {. }
$$

The outer surface temperature, $T_{0}$, may be arbitrarily assumed equal to zero. Use of Eqn. [1] then gives

$$
T=T_{c}\left(1-\frac{r^{2}}{r_{0}^{2}}\right)
$$


Using [18] in [16] and [17] then gives

$$
\begin{aligned}
& \sigma_{r}=\frac{E \alpha T_{c}}{1-v}\left[\frac{r^{2}-r_{0}^{2}}{4 r_{0}{ }^{2}}\right] \text { and } \\
& \sigma_{\theta}=\frac{E \alpha T_{c}}{1-v}\left[\frac{3 r^{2}-r_{0}{ }^{2}}{4 r_{0}{ }^{2}}\right] .
\end{aligned}
$$

To determine $\sigma_{z}$, notice that the sum of axial forces must be zero, that is

$$
\int_{0}^{r_{0}} \sigma_{z} d A=0 \text {. }
$$

From [2]

$$
\sigma_{z}=E \varepsilon_{z}+v\left(\sigma_{r}+\sigma_{\theta}\right)-\alpha E T_{C}
$$

Using [19], [20], and [22] to evaluate the integral in [21] leads to

$$
\pi E\left(\varepsilon_{z} r_{0}^{2}-\alpha T_{c} r_{0}^{2}\right)=0
$$

or

$$
\varepsilon_{z}=\alpha T_{c} .
$$

Combining [23] with [2] and making use of [19] and [20] yields

$$
\sigma_{z}=\frac{E \alpha T_{c}}{1-v}\left[\frac{2 r^{2}+r_{0}^{2}}{2 r_{0}^{2}}\right]
$$

A plot of the stresses $\sigma_{\theta}, \sigma_{r}$, and $\sigma_{z}$ normalized by a factor $E \alpha T_{c} /(1-\nu)$ as shown in Figure $A 1$ reveals a peak biaxial tensile stress state at the pellel outside surface. By Coulomb-Mohr theory, fracture occurs when

$$
\frac{\sigma_{1}}{\sigma_{F}}-\frac{\sigma_{3}}{\sigma_{F}}-1 \geq 0
$$




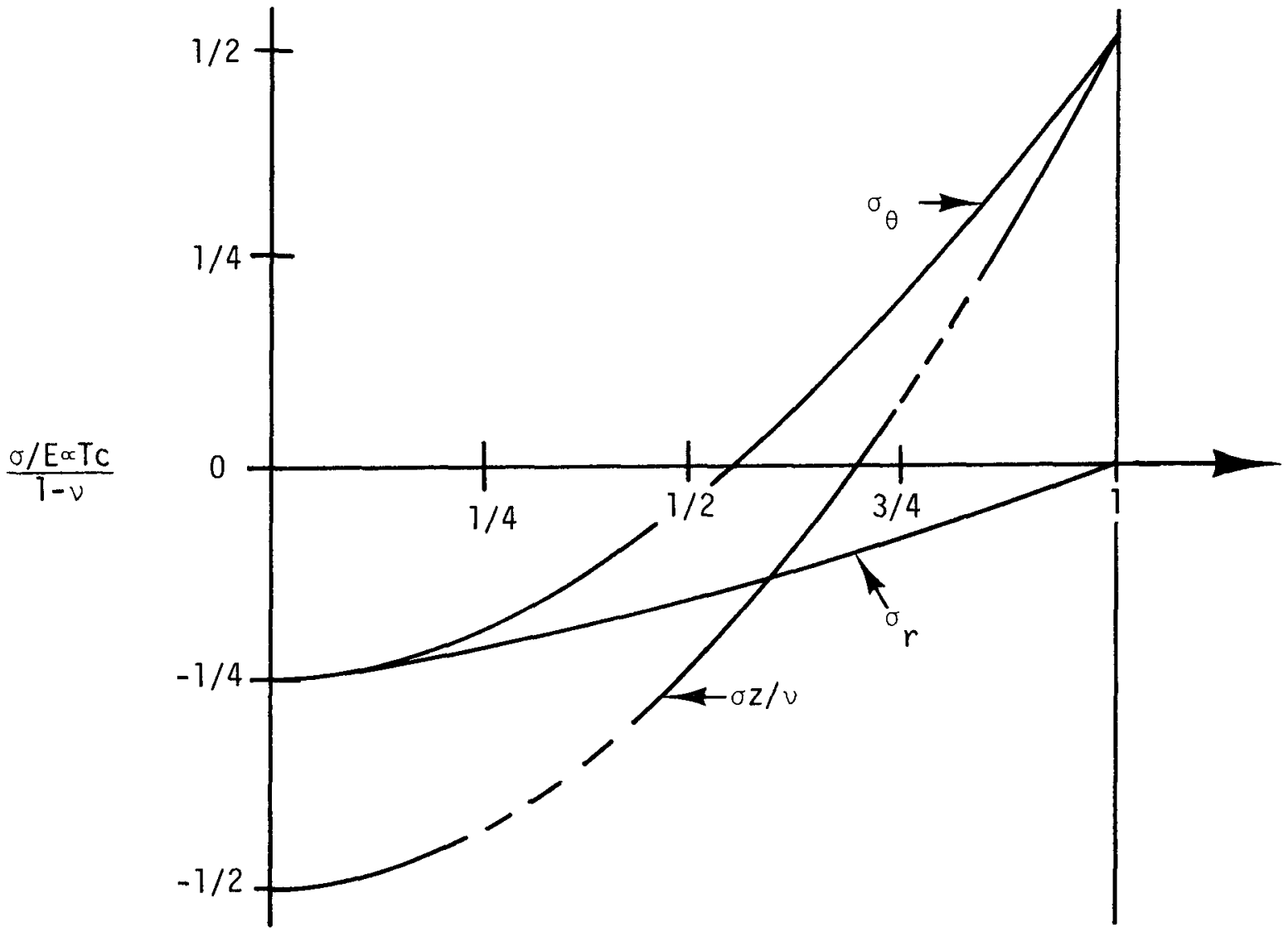

FIGURE E.1. Normalized Stresses in a Solid Cylinder with a Uniform Volumetric Heat Source. 
where

$$
\begin{aligned}
& \sigma_{1}=\left.\sigma_{\theta}\right|_{r=r_{0}} \\
& \sigma_{3}=\left.\nu \sigma_{\theta}\right|_{r=r_{0}} \\
& \sigma_{F}=\text { tensile fracture strength, and } \\
& \sigma_{F_{C}} \approx(8.0) \sigma_{F} .
\end{aligned}
$$

Eqn. [25] therefore becomes

$$
\frac{\sigma_{\theta}}{\sigma_{F}}-\frac{v \sigma_{\theta}}{8 \sigma_{F}}-1 \geq 0 .
$$

Conservatively ignoring the second term leads to fracturing occurring when

$$
\sigma_{\theta} \geq \sigma_{F}
$$

Combining Eqns. [20] and [26] at $r=r_{0}$ then produces the condition on $T_{C}$ for fracture:

$$
T_{c}=\frac{2 \sigma_{F}(1-v)}{E \alpha} \text {. }
$$

From MATPRO (Ver. 11),

$$
\begin{aligned}
E & \approx 2.6 \times 10^{7} \mathrm{psi}, \\
\alpha & =9.3 \times 10^{-6} \mathrm{~K}^{-1}(0-1000 \mathrm{~K}), \\
\nu & =0.31 \text { (constant with temperature), and } \\
\sigma_{\mathrm{F}} & =11,500 \mathrm{psi} \text { at } 0^{\circ} \mathrm{C} .
\end{aligned}
$$

Note that fracture stress of $\mathrm{UO}_{2}$ is a strong function of temperature. A conservatively low value at $0^{\circ} \mathrm{C}$ is therefore used in this calculation.

Evaluating Eqn. [27] gives

$$
T_{c}=\Delta T=65.6 \mathrm{~K}
$$


E.1 D. L. Hagrman and G. A. Reymann, MATPRO-Version II, A Handbook of Materials Properties for Use in the Analys is of Light Water Reactor Fuel Rod Behavior, NUREG/CR-0497 (TREE-1280) (Feb. 1979). 


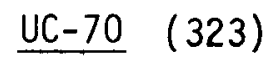

DOE-HQ/Deputy Asst Secretary for Nuclear Waste Management and Fuel Cycle Programs (3) NE-330

Washington, DC 20545

$$
\begin{aligned}
& \text { CR Cooley } \\
& \text { OP Gormley } \\
& \text { B Ramsey }
\end{aligned}
$$

DOE-RL/Office

JR Patterson II, Director, FFTF Operations Division

RJ Myjak, Operations Officer

JJ Schreiber

MW Shupe

RB Coranson

DOE/Columbus Program Office

505 King Avenue

Columbus, $\mathrm{OH} \quad 43201$

J0 Neff (3)

Chief Patent Attorney (2)

E. R. Johnson Associates, Inc.

11702 Bowman Green Drive

Reston, Virginia 22090
J. McBride
ER Johnson
M. Pellettieri

HEDL

RE Einziger (2)
RL Fish
DA Himes (2)
RL Knecht
RD Leggett
WE Roake
WF Sheely
ET Weber
JW Weber
HH Yoshikawa
Central Files (5)
Publ Services (2)

$W / E-9$

$W / E-1$

\section{DISTRIBUTION}

Office of Nuclear Waste Isolation

505 King Avenue

Columbus, $\mathrm{OH} \quad 43201$

JA Carr

(5)

All ied General Nuclear Services

P. 0. Box 847

(4)

Barnwe11, SC 29812
B. Anderson
P. McCreery
P. Heiberger
G. Townes

Electric Power Research Institute

3412 Hillview

Palo Alto, CA 94304

R. Williams

H. Ocken

JTA Roberts

Westinghouse Advanced Energy Systems Division (3) Box 10864

Pittsburgh, PA 15236

D. Newby

CR Bolmgren

W. Lundberg

Pacific Northwest Laboratory

Richland WA 99352

TD Chika1la RO/1222

Rockwell Hanford Operations

P0 Box 800

Richland, WA 99352

(3)

\section{(5)}

DA Deju

DIR-BWIP

W/A-53

W/A-53

W/A-53

W/A-40

W/E-5

$W / C-16$

$W / A-62$

$W / C-44$

$W / C-110$

$w / C-115$ 